Portland State University

PDXScholar

Civil and Environmental Engineering Master's

Project Reports

$3-2015$

\title{
Impacts of Replacing a Tight Diamond Interchange with a SPUI - A Wilsonville Interchange Study
}

Sina Vadaei

Portland State University

Follow this and additional works at: https://pdxscholar.library.pdx.edu/cengin_gradprojects

Part of the Transportation Engineering Commons

Let us know how access to this document benefits you.

\section{Recommended Citation}

Vadaei, Sina, "Impacts of Replacing a Tight Diamond Interchange with a SPUI - A Wilsonville Interchange Study" (2015). Civil and Environmental Engineering Master's Project Reports. 12.

https://doi.org/10.15760/CEEMP.23

This Project is brought to you for free and open access. It has been accepted for inclusion in Civil and Environmental Engineering Master's Project Reports by an authorized administrator of PDXScholar. Please contact us if we can make this document more accessible: pdxscholar@pdx.edu. 
Impacts of Replacing a Tight Diamond Interchange with a SPUI - A Wilsonville Interchange Study

BY

\title{
SINA VADAEI
}

A research project report submitted in partial fulfillment of the requirement for the degree of M.S in Civil \& Environmental Engineering

\author{
MASTER OF SCIENCE \\ IN \\ CIVIL AND ENVIRONMENTAL ENGINEERING
}

Project Advisor:

Dr. Christopher Monsere

Portland State University

(C)2015 


\section{ACKNOWLEDGMENTS}

I would like to express the deepest appreciation to my advisor, Dr. Christopher Monsere, who has been aiding and assisting me throughout the school year both as a professor and an advisor. Without his guidance in my academics this research project would not have been possible.

I would like to thank Dr. Robert Bertini for introducing me to the PTV VISSIM software and inspiring me to start this research project. His introduction to traffic operations and the simulation software has made the analysis portion of my research possible.

In addition, I would also like to thank Miranda Wells from HDR Engineering and Pamela O’Brien from DKS Associates for helping me out with the PTV VISSIM software and providing the vehicle turning movements for the study area. 


\begin{abstract}
Tight diamond interchanges (TDI) and single point urban interchanges (SPUIs) are generally types of interchanges that can be used interchangeably in areas where right-of-way is constrained. There are limited amount of research conducted regarding the operational analysis and comparison of these two interchanges. The research that has been done regarding this topic are outdated and generally conclude that SPUIs perform better or about the same. Without knowing the true performances of the two interchange designs, it would make it difficult for engineers and planners to choose between the two interchanges.
\end{abstract}

This research study will use the current updated version of the micro-simulation software, PTV VISSIM to analyze and compare the performance of the SPUI and the tight diamond interchange. The research will look at reconstructing a current tight diamond interchange into a SPUI in Wilsonville, Oregon to see how it will perform. The analysis was conducted for 7 varying volume levels for both the interchanges including the existing volume conditions. The volume conditions include multiplying the ramp volumes by $0.75,1.25$, and 1.4 as well as doing the same for the eastbound and westbound movements.

The results of the analysis shows that the SPUI performs similarly compared to the tight diamond interchange for lower volume conditions, but perform very poorly for higher volume conditions. The SPUI in this location is more sensitive to volume change and does not perform as well as the tight diamond interchange. The SPUI performs better than the TDI by only 1.4 seconds for low ramp volume conditions with regards to average delay per vehicle and performs 31.2 seconds worst for high ramp volume conditions. Therefore, the SPUI should not be implemented at this location as it is not feasible for high volumes and not cost effective. SPUIs should be implemented carefully as it is not suitable for all places. 


\section{TABLE OF CONTENTS}













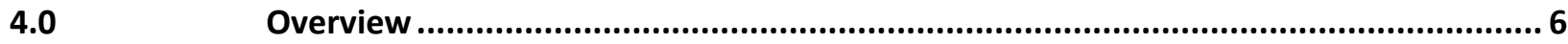

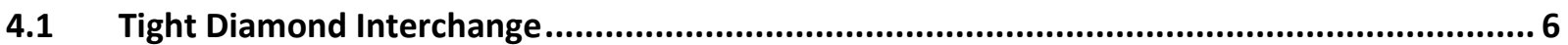



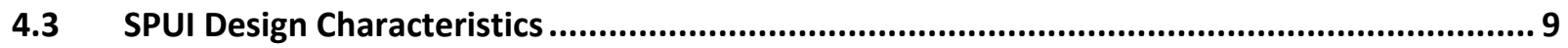

4.4 Advantages and Disadvantages of SPUI......................................................................... 11

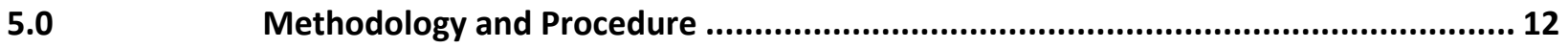





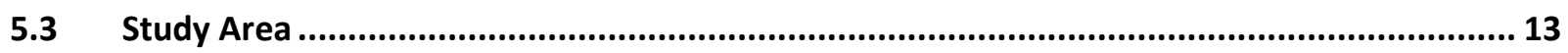



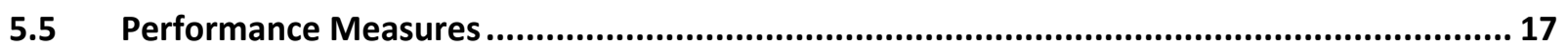

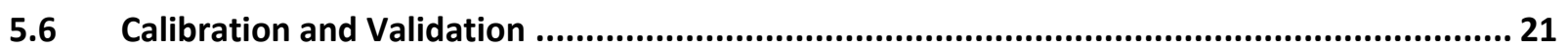

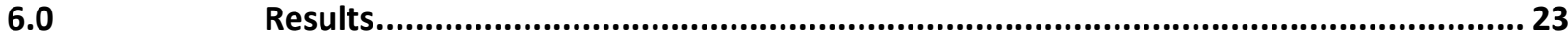

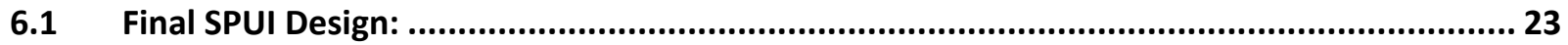

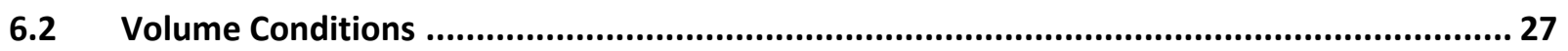





















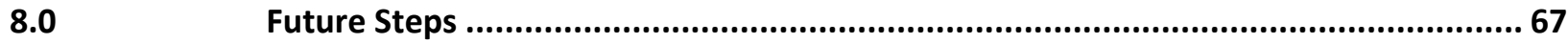










\section{LIST OF TABLES}

Table 1: Jones and Selinger's Simulation Results for Comparing a TUDI and SPUI (7) ......................... 2

Table 2: VISSIM Data Outputs and Field Data Comparison .............................................................. 22

Table 3: Time and Distance Estimates for bikes and pedestrians crossing the interchange ................ 25

Table 4: Percent Change in Performance from Diamond to SPUI for 0.75 Ramp Condition ................. 29

Table 5: Percent Change in Performance from Diamond to SPUI for Existing Condition ..................... 32

Table 6: Percent Change in Performance from Diamond to SPUI for 1.25 Ramp Condition ................ 34

Table 7: Percent Change in Performance from Diamond to SPUI for 1.4 Ramp Condition ................... 36

Table 8: Percent Change in Performance from Diamond to SPUI for 0.75 EW Condition .................... 39

Table 9: Percent Change in Performance from Diamond to SPUI for 1.25 EW Condition ..................... 41

Table 10: Percent Change in Performance from Diamond to SPUI for 1.4 EW Condition ..................... 43

Table 11: Best performing interchange as an entire network given the specific volume condition ...... 44

Table 12: Statistical values for average vehicle delay for all volume conditions ................................. 54

Table 13: Statistical values for average vehicle stop delay for all volume conditions ......................... 54

Table 14: Statistical values for average vehicle speed for all volume conditions ................................. 55 


\section{LIST OF FIGURES}

Figure L1: Average Delay Comparison under Low Volume Traffic Scenarios (5).................................. 3

Figure L2: Average Delay Comparison under High Volume Traffic Scenarios (5) ................................... 4



Figure 2: Diamond Interchange Signal Phasing (3) ............................................................................ 7

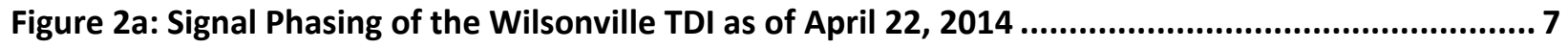

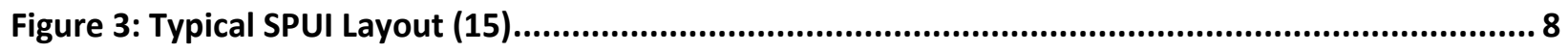

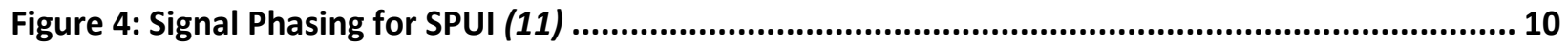

Figure 5: Length of the Wilsonville interchange Segment (Source: Google Maps) ............................. 14

Figure 6: Wilsonville Diamond Interchange (Source: Google Maps) ................................................ 15

Figure 7: Wilsonville Diamond Interchange Critical Characteristics (Source: Google Maps) ................. 16

Figure B1: Balanced traffic volumes at the Wilsonville Interchange .............................................. 18

Figure B3: Intersection to the East of the Interchange .................................................................... 18

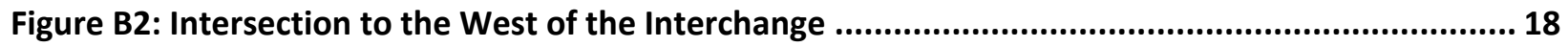

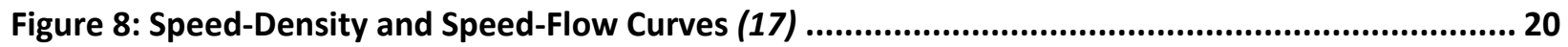

Figure 11: Project study area with the new SPUI Design .............................................................. 23

Figure 12: A closer look at the SPUI and how it can treat the pedestrians and bicyclists. ................... 25

Figure 12a: SPUI signal timing for both pedestrian/bicyclists and motorist. For points, refer to Figure

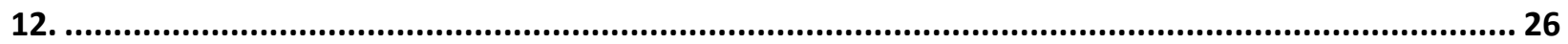

Figure 16: Average Pollution Emitted for 0.75 Ramp Condition ................................................... 28

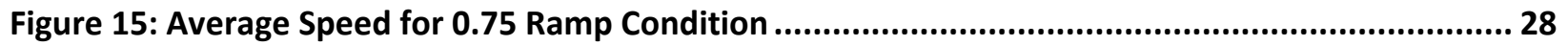



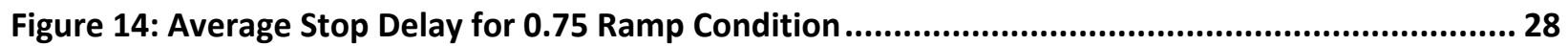

Figure 17: Percent change in interchange performance from Diamond to SPUI for 0.75 Ramp

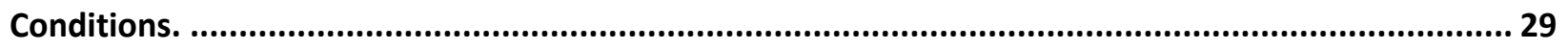

Table 3: Percent Change in Performance from Diamond to SPUI for 0.75 Ramp Condition ................. 29

Figure 20: Average Speed for Existing Condition13 ..................................................................... 30

Figure 21: Average CO and NOx Emitted for Existing Condition ....................................................... 30

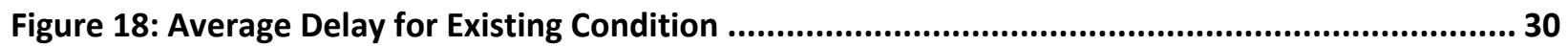

Figure 19: Average Stop Delay for Existing Condition .............................................................. 30

Figure 22: Percent Change in Interchange Performance from Diamond to SPUI for Existing Condition 31

Figure 23: Average Delay for 1.25 Ramp Condition ..................................................................... 32

Figure 24: Average Stop Delay for 1.25 Ramp Condition ................................................................... 32

Figure 26: Average Pollution Emitted for 1.25 Ramp Condition ........................................................ 33

Figure 25: Average Speed for 1.25 Ramp Condition ............................................................................ 33

Figure 27: Percent Change in Interchange Performance from Diamond to SPUI for Existing Condition 34

Figure 28: Average Delay for 1.4 Ramp Conditions .................................................................. 35

Figure 29: Average Stop Delay for 1.4 Ramp Condition...................................................................... 35

Figure 31: Average Pollution Emitted for 1.4 Ramp Condition .......................................................... 35

Figure 30: Average Speed for 1.4 Ramp Condition .................................................................................. 35

Figure 32: Percent Change in Interchange Performance from Diamond to SPUI for 1.4 Ramp Condition

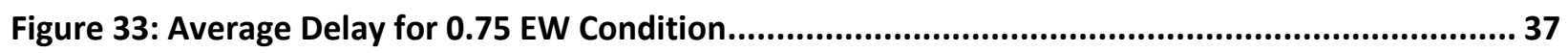

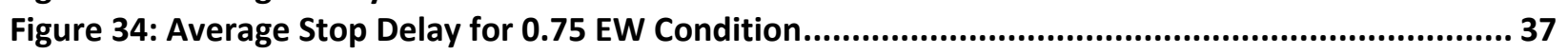

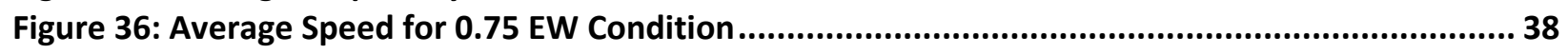


Figure 35: Average Speed for 0.75 EW Condition.

Figure 37: Percent Change in Interchange Performance from Diamond to SPUI for 0.75 EW Condition 38

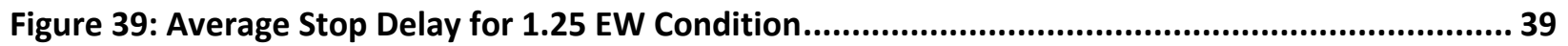

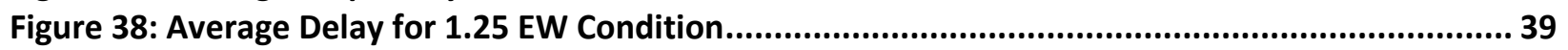

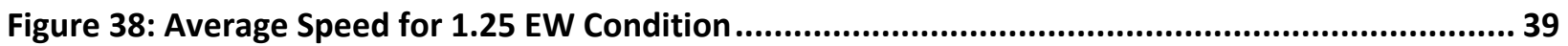

Figure 41: Average Pollution Emitted for 1.25 EW Condition ....................................................... 40

Figure 40: Average Speed for 1.25 EW Condition ....................................................................... 40

Figure 42: Percent Change in Interchange Performance from Diamond to SPUI for 1.25 EW Condition41

Figure 44: Average Pollution Emitted for 1.4 EW Condition ........................................................ 42

Figure 43: Average Speed for 1.4 EW Condition ..................................................................................... 42

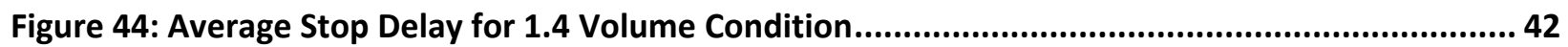

Figure 43: Average Delay for 1.4 EW Condition ........................................................................... 42

Figure 45: Percent Change in Interchange Performance from Diamond to SPUI for 1.4 EW Condition. 43

Figure 46: Average vehicle delay for different volume conditions shown as a bar graph..................... 45

Figure 47: Average vehicle delay for different volume conditions shown as a line graph .................... 45

Figure 48: Percent change in average vehicle delay from the interchange's existing condition ........... 46

Figure 49: Average vehicle stop delay for different volume conditions shown as a bar graph ............. 47

Figure 50: Average vehicle stop delay for different volume conditions shown as a line graph............. 48

Figure 51: Percent change in average vehicle stop delay from the interchange's existing condition.... 49

Figure 52: Average vehicle speed for different volume conditions shown as a bar graph .................... 50

Figure 53: Average vehicle speed for different volume conditions shown as a line graph ................... 50

Figure 54: Percent change in average vehicle speed from the interchange's existing condition .......... 51

Figure 55: Average NOx and CO emitted for different volume conditions shown as a bar graph ......... 52

Figure 56: Average $\mathrm{CO}$ and NOx emitted for different volume conditions shown as a line graph ........ 53

Figure 57: Double Roundabout interchange design for the Wilsonville interchange. .......................... 56

Figure 58: Average vehicle delay for different volume conditions shown as a bar graph ..................... 57

Figure 59: Average vehicle delay for different volume conditions shown as a line graph .................... 57

Figure 60: Percent change in average vehicle delay from the interchange's existing condition ........... 58

Figure 61: Average vehicle stop delay for different volume conditions shown as a bar graph ............. 59

Figure 62: Average vehicle stop delay for different volume conditions shown as a line graph............. 59

Figure 63: Percent change in average vehicle stop delay from the interchange's existing condition.... 60

Figure 64: Average vehicle speed for different volume conditions shown as a bar graph ....................61 61

Figure 65: Average vehicle speed for different volume conditions shown as a line graph ................... 61

Figure 66: Percent change in average vehicle stop delay from the interchange's existing condition.... 62

Figure 66: Average vehicle delay for different volume conditions when nearby intersections are

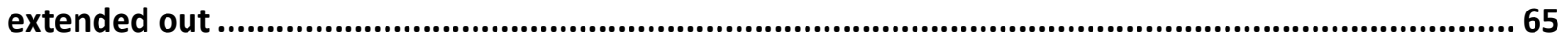

Figure 67: Percent change in average vehicle delay from the interchange's existing condition when

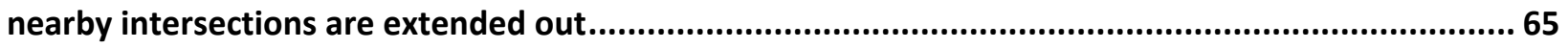

Figure A1: Research Project Study Area and the Location of the Diamond Interchange ..................... 69 


\subsection{INTRODUCTION}

A single point urban interchange (SPUI) is a type of highway interchange that is meant to help move large volumes of traffic through limited amount of space. This design is being used in the reconstruction of existing freeways as well as constructing new freeways. This simple design in theory makes the most of safety, capacity, and efficiency (12). In a way, the SPUI condenses the diamond interchange from two intersections into just one, therefore allowing higher flow per phase. To see whether a SPUI will truly perform better than a diamond interchange, this study uses simulation software such as PTV VISSIM and VISTRO to analyze and compare the performance of both interchanges.

This paper will explore the impacts of replacing a current diamond interchange also known as a Tight Diamond Interchange (TDI) in Wilsonville, Oregon with a (SPUI). This paper will investigate whether implementing a SPUI will improve traffic performance and if it is a viable solution for congestion mitigation at diamond interchanges similar to the one of Wilsonville, Oregon. The implementation of the SPUI would involve minor construction as the Wilsonville interchange already resembles a SPUI quite well and therefore, no heavy construction will be needed. If the SPUI design does enhance traffic performance, it will truly be a cost effective method and could be implemented on other similar diamond interchanges across the country. To analyze the performance, simulation software called PTV VISSIM and VISTRO will be used. The analysis of both interchange performances will be compared for the existing volume conditions as well as lower and higher volume conditions to see which interchange design preforms better. 


\subsection{LITERATURE REVIEW}

There have been some researchers that have done similar research to compare and analyze the performance of a SPUI and Diamond Interchange. This section will explore some of the author's findings and analysis.

\subsection{Jones and Selinger:}

In their paper, A Comparison of the Operations of Single Point and Tight Urban Diamond Interchanges, Jones and Selinger compare the operational analysis of a SPUI and a Tight Diamond Urban Interchange (TUDI) using the microscopic simulation analysis called CORSIM (7). A TUDI is a diamond interchange in which the ramp terminal intersections are more closely spaced than a traditional diamond. Their results showed that the SPUI did have a better traffic operation performance than the TUDI. The SPUI had a higher average travel speed, fewer phase failures, lower percentage of stops, and higher capability to serve traffic. The results also showed that the TUDI would reach capacity condition while the SPUI was operating at regular conditions. The simulation results can be seen in Table 1. As it can be seen, the SPUI performs better for all the performance measures (7).

Table 1: Jones and Selinger's Simulation Results for Comparing a TUDI and SPUI (7)

\begin{tabular}{|c|c|c|c|c|c|}
\hline Interchange & $\begin{array}{c}\text { Volume } \\
\text { Served }\end{array}$ & $\begin{array}{c}\text { Average } \\
\text { Speed }(\mathrm{mph})\end{array}$ & $\begin{array}{c}\text { Phase } \\
\text { Failures }\end{array}$ & $\begin{array}{c}\text { Percent } \\
\text { Stops }\end{array}$ & $\begin{array}{c}\text { Delay Time } \\
\text { (veh-min) }\end{array}$ \\
\hline SPUI & 3,798 & 23.7 & 0 & 64.8 & 2,289 \\
$T U D I$ & 3,796 & 22.0 & 0 & 85.0 & 2,446 \\
\hline SPUI & 6,454 & 22.0 & 10 & 68.6 & 4,177 \\
$T U D I$ & 4,817 & 11.4 & 114 & 133.6 & 23,225 \\
\hline SPUI & 7,516 & 16.6 & 95 & 80.5 & 7,685 \\
$T U D I$ & 3,885 & 4.5 & 220 & 193.2 & 43,458 \\
\hline SPUI & 7,415 & 11.7 & 130 & 130.0 & 12,108 \\
$T U D I$ & 3,580 & 3.8 & 231 & 231.3 & 46,917 \\
\hline SPUI & 7,355 & 10.0 & 140 & 105.8 & 14,511 \\
$T U D I$ & 3,504 & 3.6 & 235 & 213.5 & 47,895 \\
\hline
\end{tabular}




\subsection{Garber and Smith}

Garber and Smith compared the operational characteristics of the SPUI and Diamond Interchange using field data and simulation software called TRAF-NETSIM (5). In their study, they used 10 different volume scenarios with both low and high volume conditions. Their results showed that the diamond interchange performed better with regards to average delay per vehicle during low volume scenarios. However, during high volume traffic scenarios, the delay for SPUI was lower. The results can be seen in Figure L1 and L2 (5).

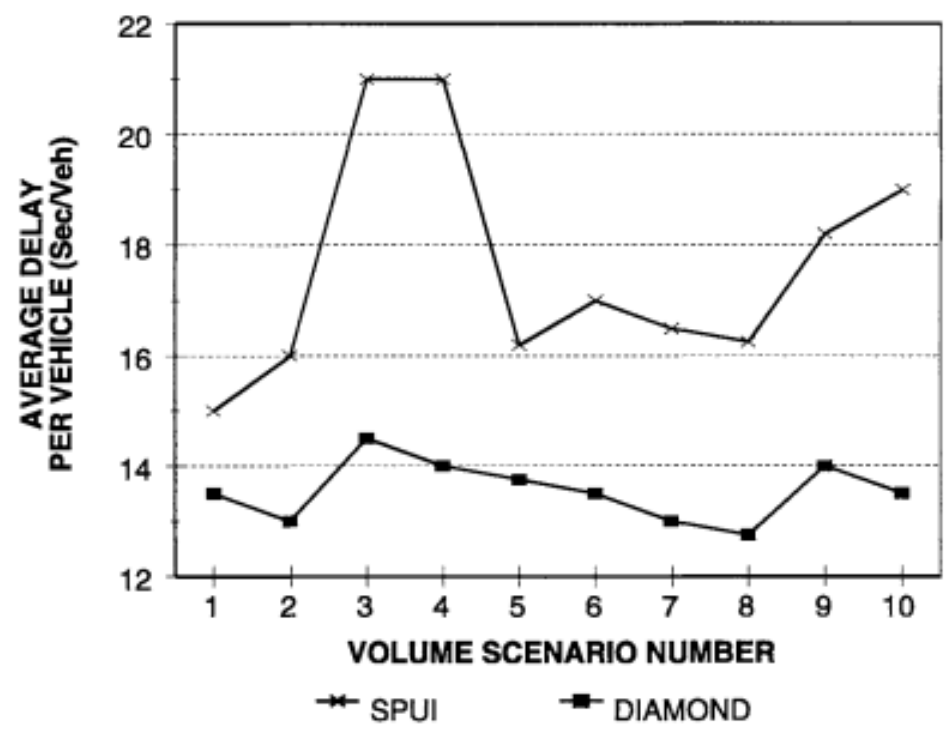

Figure L1: Average Delay Comparison under Low Volume Traffic Scenarios (5) 


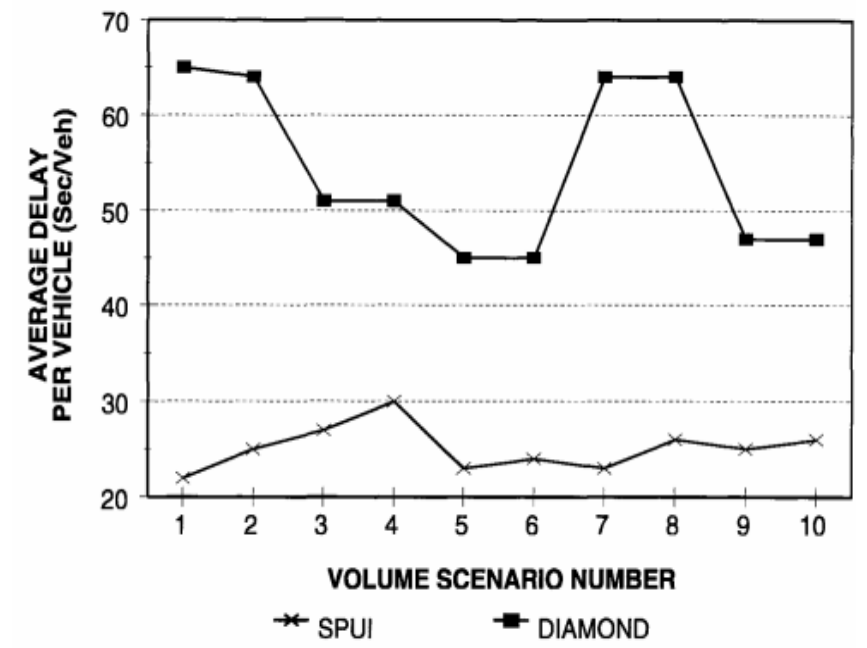

Figure L2: Average Delay Comparison under High Volume Traffic Scenarios (5)

Garber and Smith also discovered through the crash data that there were a greater amount of crashes on the ramps of the SPUI, but the proportion of accidents in the center of the signalized intersection was greater at the Diamond Interchanges. The angle crashes was greater at the diamond interchange, but rear-end, sideswipe, and fixed object crashes were greater at the SPUIs (5).

\subsection{Brian C. Fowler}

Fowler studied and compared the SPUI and TUDI using volume-to-capacity ratio as a performance measure for 12 different traffic volume scenarios (5 \&7). His results showed that the SPUI provided greater capacity than the TUDI for most volume conditions and that the TUDI was much more sensitive to variations in traffic volumes. 


\subsection{PURPOSE AND MOTIVATION}

SPUI and tight diamond interchanges are similar in many ways and are used as alternatives. The research of comparing the two interchange is limited and operational comparisons vary in their findings. Therefore, it makes it hard for engineers to decide which interchange to implement. It is generally assumed that SPUIs will perform better than or equal to a Diamond interchange. This paper will explore whether the implementation of a SPUI will improve interchange performance. Upon research it also appeared that most research regarding this topic were outdated and did not use the same simulation software.

Furthermore, there are a great deal interchanges that are seeking congestion mitigation and an improvement of overall traffic performance. Many of these interchanges tend to be diamond interchanges and they can be quite dangerous when congestion occurs as the queueing on the ramps can spill back to the freeway and therefore can result in unexpected sudden stops that can interrupt the high speed flow of the freeway and cause cars to crash.

Many engineers tend to solve this solution by doing heavy construction to the existing road. This study simply looks at redesigning the interchange by simply rerouting the lanes, adding new lane markings, and possibly implements new traffic lights. If the implementation of the SPUI does truly improve traffic performance and mitigate congestion, it would be an effective and easy solution of enhancing TDI. Now all TDIs might not be a good candidate for a SPUI implementation. To see what the desired characteristics of a TDI is, refer to the Study Area section of this paper. 


\subsection{OVERVIEW}

This section of the paper will discuss some of the key design and definitions of the TDI of Wilsonville and the SPUI that will be implemented.

\subsection{Tight Diamond Interchange}

A diamond interchange is a grade separated intersection with ramps that connects them. The ramps will connect the freeway onto the minor road directly without any loops (14). When heading towards the interchange from either direction, an off-ramp departs only slightly from the freeway and runs directly across the minor road, becoming an on-ramp that returns to the freeway (4). The diamond interchange is the most commonly used type of interchange. The interchange of Wilsonville is a tight diamond interchange, as it is more compressed with the intersections closer together. A TDI consists of two signalized intersection that is anywhere between 250 feet to 400 feet apart (14). The one of Wilsonville is approximately 390 feet apart. A typical TDI can be seen in Figure 1.

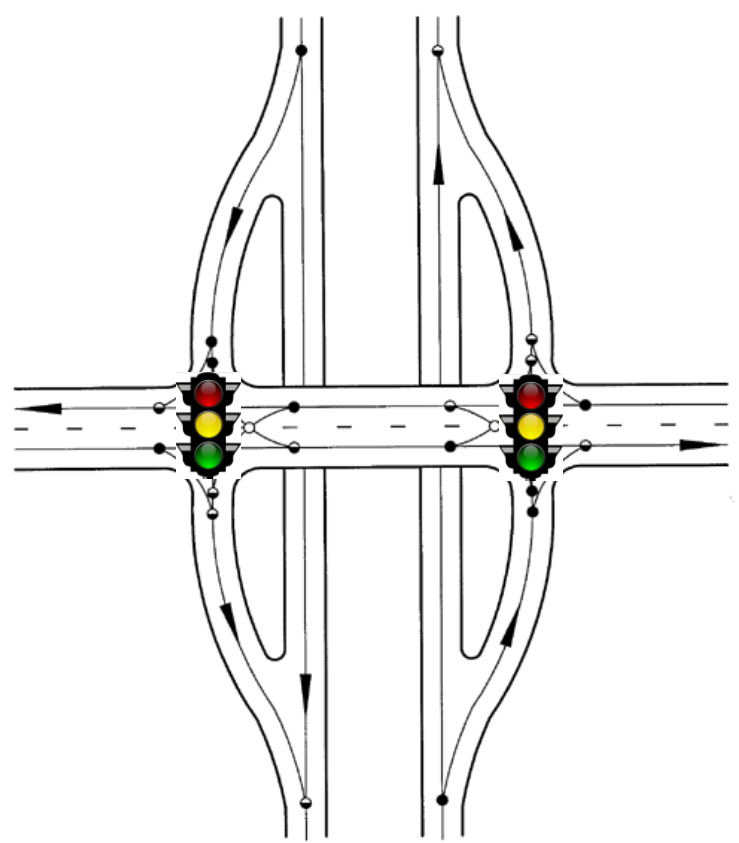

Figure 1: Typical Tight Diamond Interchange Layout (16) 
Most signalized diamond interchanges tend use 3 to 4 phase strategies for their intersection (3). The one of Wilsonville uses three phases. One phase is for the through movement of the arterial road and the on-ramp. The second phase is the movement from the off ramp on to the arterial road or straight through the on-ramp. The last phase is the through movements of the arterial roads. The acquisition of the signal timing information will be discussed in section 5.4 of this paper. The phasing can be seen in Figure 2 and 2 a.

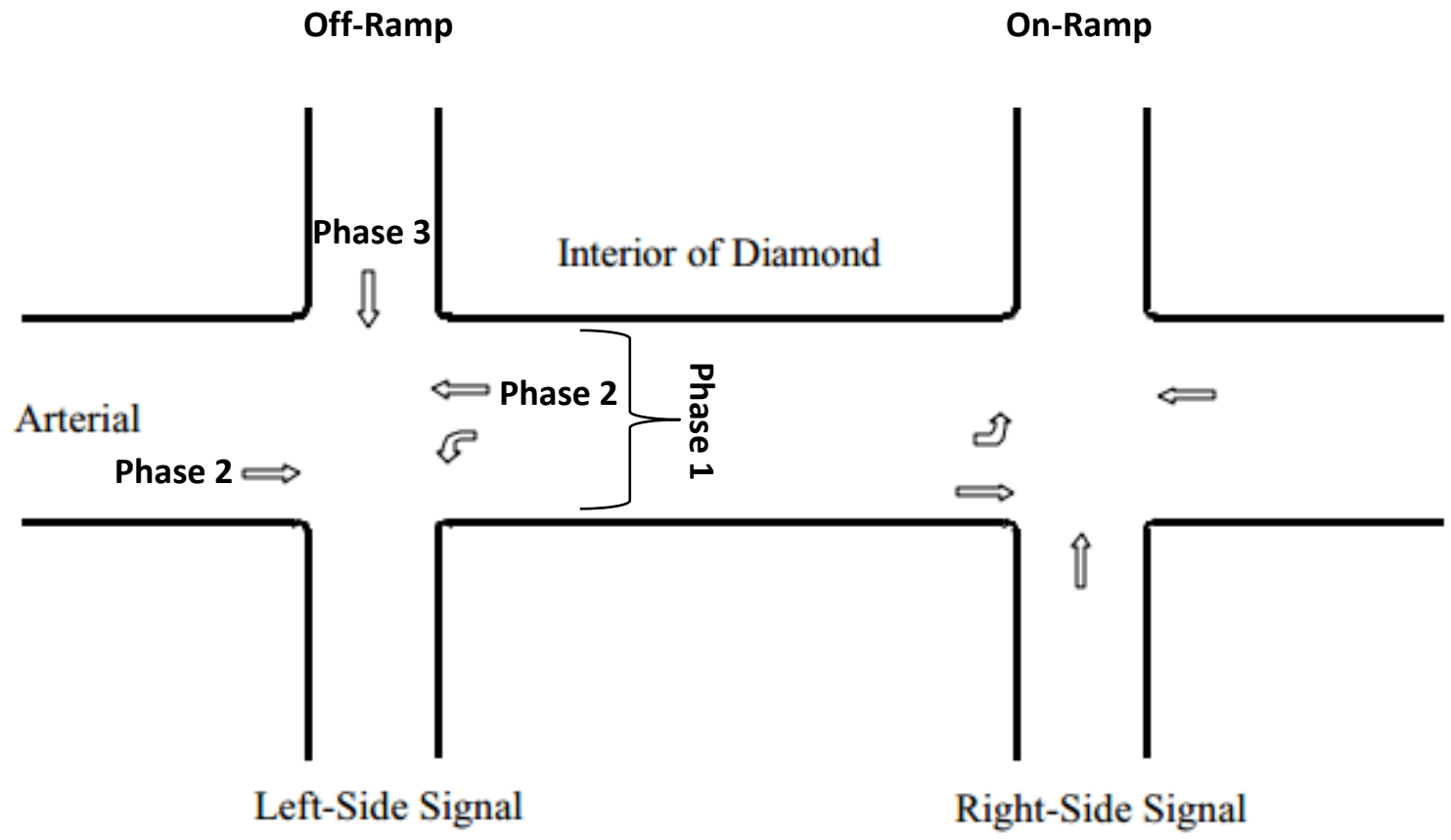

Figure 2: Diamond Interchange Signal Phasing (3)

Splits and Phases: 1 : Wilsonville Rd \& I-5 SB

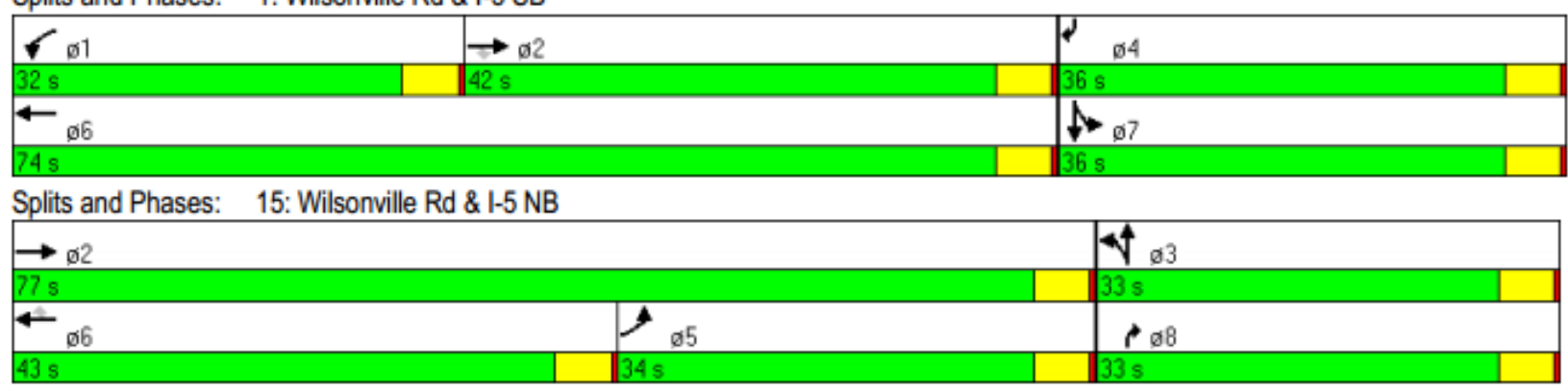

Figure 2a: Signal Phasing of the Wilsonville TDI as of April 22, 2014 


\section{$4.2 \quad$ SPUI}

The SPUI is similar to a TDI; however in this design the SPUI condenses the two intersection diamond interchange into a large single intersection. It is called a "Single Point" because all through traffic on the arterial street, as well as the traffic turning left onto or off the interchange, can be controlled from a single set of traffic signals (13). The SPUI will still be grade separated with the freeway on top of the bridge and the interchange at the bottom. A layout of the SPUI can be seen in Figure 3.



Figure 3: Typical SPUI Layout (15)

The biggest advantage of this design is that it allows opposing left turns to proceed simultaneously. This allows a higher flow than a Diamond Interchange. The SPUI design consists of three different phases. For a complete signal timing of the phases, please refer to section 6.1, labeled as Final SPUI Design within this document. The three phases include (12):

- Phase 1: Through traffic on the arterial street (Shown as grey in Figure 3). 
- Phase 2: Traffic leaving the freeway and turning left onto the arterial street (Shown as green in Figure 3).

- Phase 3: Traffic leaving the arterial street and turning left onto the freeway (Shown as red in Figure 3).

\subsection{SPUI Design Characteristics}

There are few design characteristics that the SPUI must obey by in order for it to have the full effectiveness that it can have.

\section{Number of Through, Left, and Right Lanes:}

Since the point of a SPUI is to flush out a great deal of vehicles per phase, it is desired that the through, left, the right lanes to be coupled (11). This works out quite well for the Wilsonville Diamond Interchange as it already has dual lanes for all movements.

The left turn lanes must have large radii as it provides the advantage of turning with higher speed and reducing the off-tracking of larger vehicles (11). The left turn angles in the SPUI are typically 45 to 60 degrees at the ramp stop bars and 90 degrees off the arterial street. The radii of left-turning roadways range from 170 to 400 feet for SPUI. To turn left from the arterial street to the ramp averages around 200 feet for both overpass and underpass design. The average left turn radii for the ramp-to-arterial street was found to be 205 feet for the underpass design (11).

For right turn lanes, the average right turn radius for both overpass and underpass design on the arterial road is 100 feet while for the off-ramp it is 120 feet. Right turn radii in SPUIs can range from 70 to 200 feet (11).

Islands: 
SPUI also requires an island that can separate the right turn from the left turn for the off-ramps. These islands are fairly large as they average anywhere from 2400 square feet to 33,000 square feet (11). These islands can provide safe crossing for pedestrians and can provide guidance to the drivers.

Signalization and Signing:

Since SPUls are new to the public, heavy signing and lighting should be used to guide the users efficiently and safely. Furthermore, the signal controller should be actuated and involve three phases. The three different phases can be seen in Figure 4.

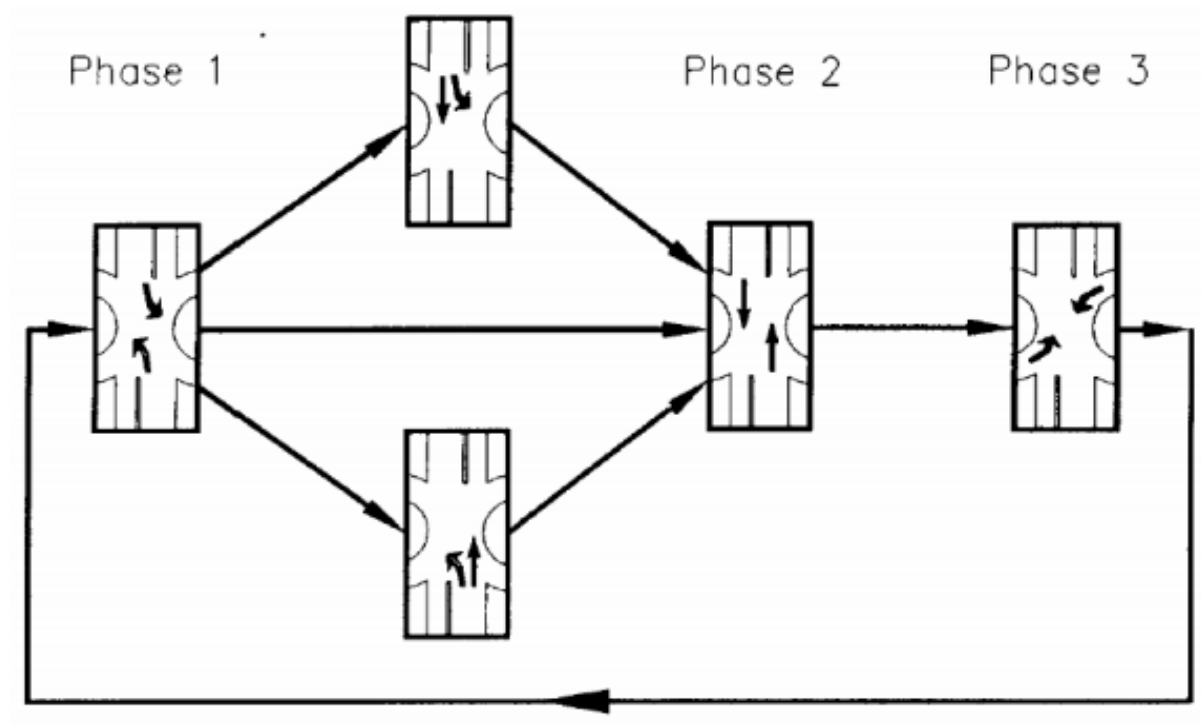

Figure 4: Signal Phasing for SPUI (11)

With regards to the Signal Cycles, the green signal should be long enough to allow a high flow and serve most of the vehicles. The green signal used for SPUIs for one phase tends to last approximately 20 to 40 seconds. SPUIs cycle lengths vary from 80 to 180 seconds (11).

It is also critical to have a clearance interval to make sure all vehicles make it across safely. All-red clearance intervals for SPUIs range from 1.0 to 10.0 seconds. The average red clearance interval is about 
$3.4 \mathrm{sec}$. A red clearance interval of 4 seconds for entrance ramp left turn and 6 seconds for exit ramp left turn is provided by most states (11).

\subsection{Advantages and Disadvantages of SPUI}

The main advantage of a SPUI is that it allows concurrent left turns in which eliminate the need of two intersections. This allows the interchange to be condensed and therefore take less space. It also allows the vehicles get through the interchange much more quickly. SPUls also allow wider turns in which makes it easier for larger vehicles. By eliminating an intersection you are also reducing the probability of collisions and fatality. SPUIs are also safer compared to a Diamond Interchange as the queue would rarely spillback to the freeway (6).

A major disadvantage of SPUIs is the fact that it does not accommodate pedestrians and bicyclists well. It would take the pedestrians more than one cycle to get across the arterial and bicyclist might not make it across on time when enters during a yellow. Furthermore, since SPUIs are not regularly used by drivers and therefore it might confuse them. Lastly, SPUIs could be quite costly as they would require bridge

widening or adding lanes (6). However, if the project is to replace a TDI that already matches the characteristics of a SPUI such as the one of Wilsonville, then the costs will be much lower. 


\subsection{METHODOLOGY AND PROCEDURE}

This part of the paper will discuss the methods used for conducting this research and what specific procedures were used in order to analyze and compare the TDI and the SPUI.

\subsection{Overall Strategy}

The overall strategy for analyzing the impact of replacing a TDI with a SPUI involved going through a few steps. At first, an ideal diamond interchange was chosen that best fit the characteristics of a SPUI. Once the ideal diamond interchange (Wilsonville Interchange) was chosen, the data was obtained through DKS Associates. The simulation software called PTV VISSIM and VISTRO were then used to develop both the TDI and SPUI network. Once these networks were drawn up, the volume data and other characteristics were entered into the software.

Finally, a report of the performance measures were analyzed and compared for both interchanges to see what the impacts were. Not only will the performance measurements will be done for existing volume conditions, but it will also be done for conditions where the volumes are increased by $25 \%$ on the ramps, $40 \%$ on the ramps, $25 \%$ for all volumes except the ramps, and $40 \%$ for all volumes except the ramps to see how the interchanges will perform at higher volumes. The volumes will also be decreased by $25 \%$ for both the ramp movements and the east and west bound movements.

\subsection{Software}

As mentioned earlier, the simulation software used to analyze the performance of the interchanges is PTV VISSIM and VISTRO. These software can analyze average delay per vehicle, average vehicle speed, emission testing, and more. These are appropriate performances to measure the interchanges by.

In the PTV software, a background image of the study area can be easily imported and the network can be drawn over it. Once the network is setup, traffic volumes and driver characteristics can be inserted. 
Once all the necessary data is inserted, a report is developed in order to analyze the performance of the network. This is done for both the Diamond and the Single Point Urban Interchange.

\subsection{Study Area}

The Wilsonville interchange located off of exit 283 from Interstate 5 at the intersection of Wilsonville Road and I-5 was chosen for a specific reason. The purpose of this research is not to focus on a heavy construction project in order to transform the diamond interchange into a SPUI, but to find an interchange that already resembles a SPUI in a way that heavy addition construction would not be necessary. In the Portland area, the Wilsonville interchange resembled a SPUI the most and fit perfectly for the purpose of this research. The study area can be seen in Appendix A as Figure A1. From this figure

it can also be seen that besides just the interchange the intersection to the west and east of the interchange will also be studied as it is important to see how the nearby areas will be impacted by the new design.

As stated earlier, this interchange was chosen for the reason that it resembles a SPUI in many ways and makes it easier to implement the SPUI design. The attractiveness of the Wilsonville interchange for this research is due to these following characteristics:

- Tight Diamond Interchange

- Freeway flow is over the bridge

- Large roadway dedicated to the interchange

- Low Pedestrian Volumes

Tight Diamond Interchange: 
First off, it is without any doubt that the current interchange must be a diamond interchange if it is desired to implement a SPUI, but it even helps more when it is a TDI. As mentioned earlier, the TDI operates as two closely spaced signalized intersections (1). Whereas, a regular diamond interchange can be spaced much further. It is important for the two intersections to be closely spaced because when we implement the SPUI, the vehicles do not have to travel a long distance in order to clear the intersection. The more it is compacted the less we have to rely on All Red and yellow signal phases. As it can be seen in Figure 5, the length of the segment of the interchange in Wilsonville is only $390 \mathrm{ft}$ and is much more compact than most of the Diamond interchanges around Portland.

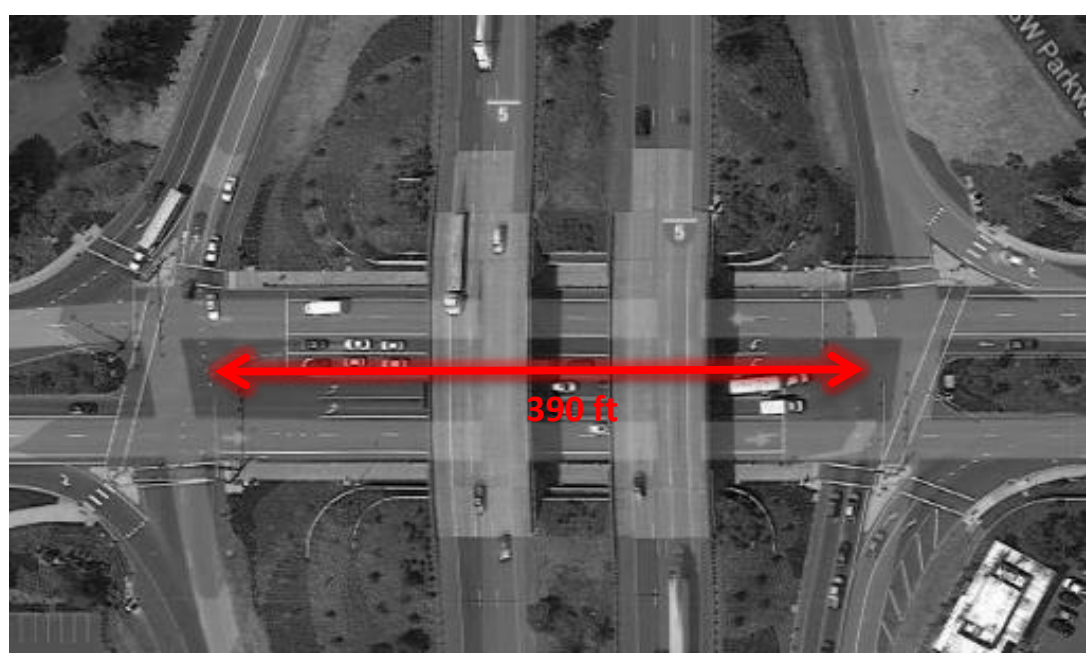

Figure 5: Length of the Wilsonville interchange Segment (Source: Google Maps)

\section{Freeway Flow is Over the Bridge:}

One of the most critical characteristic of the current TDI is that the interchange is below the bridge and not on it. This saves the project a great deal of money as the SPUI does not have to be implemented on a bridge, the bridge does not have to be widened, nor is it necessary to build a new bridge. This simply allows us to work with a great deal of land below the bridge without worrying about widening anything. It can be seen in Figure 6 how the interchange looks like. 


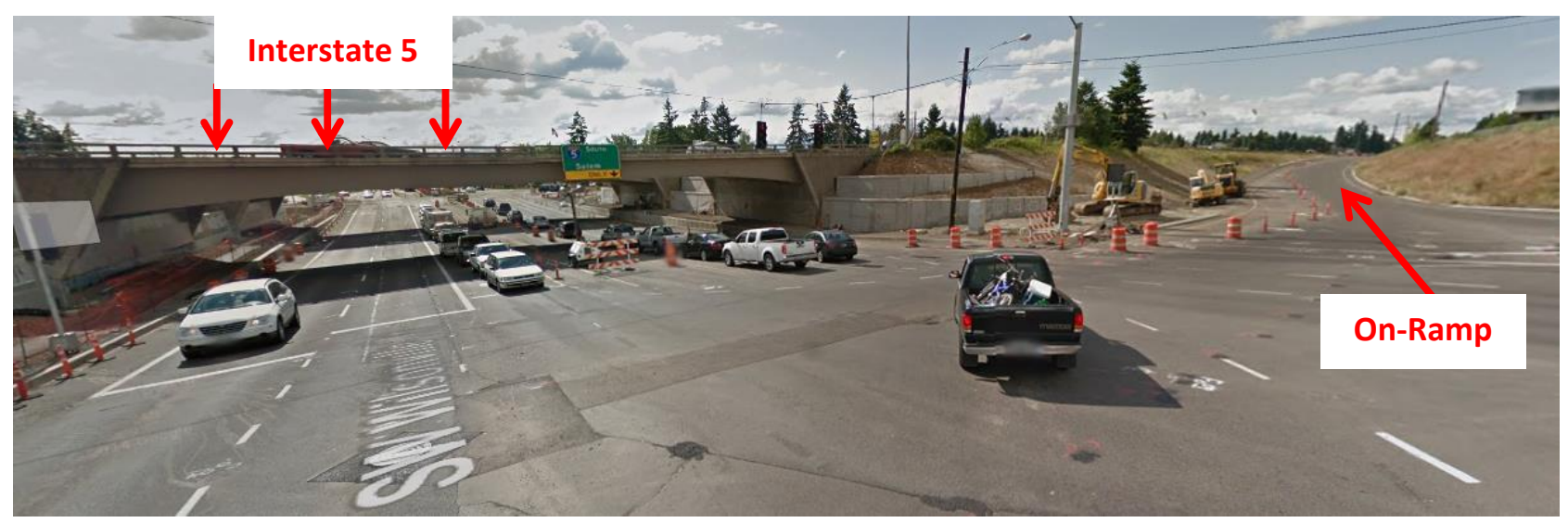

Figure 6: Wilsonville Diamond Interchange (Source: Google Maps)

\section{Large Roadway Dedicated to the Interchange:}

Another positive characteristic of the current TDI at Wilsonville is that it has plenty of space dedicated for lanes. This is great as a SPUI does require a great deal of roadway space. It is ideal for a SPUI to have dual left turns, right turns, and through lanes as it can flush out more vehicles per phase (11). SPUIs also require an island that separates the left turn and right turn movement. As it can be seen from Figure 7, the current diamond interchange fits all these characteristics perfectly as it does have dual turns as well as islands that separate the left and the right turn movements (11). 


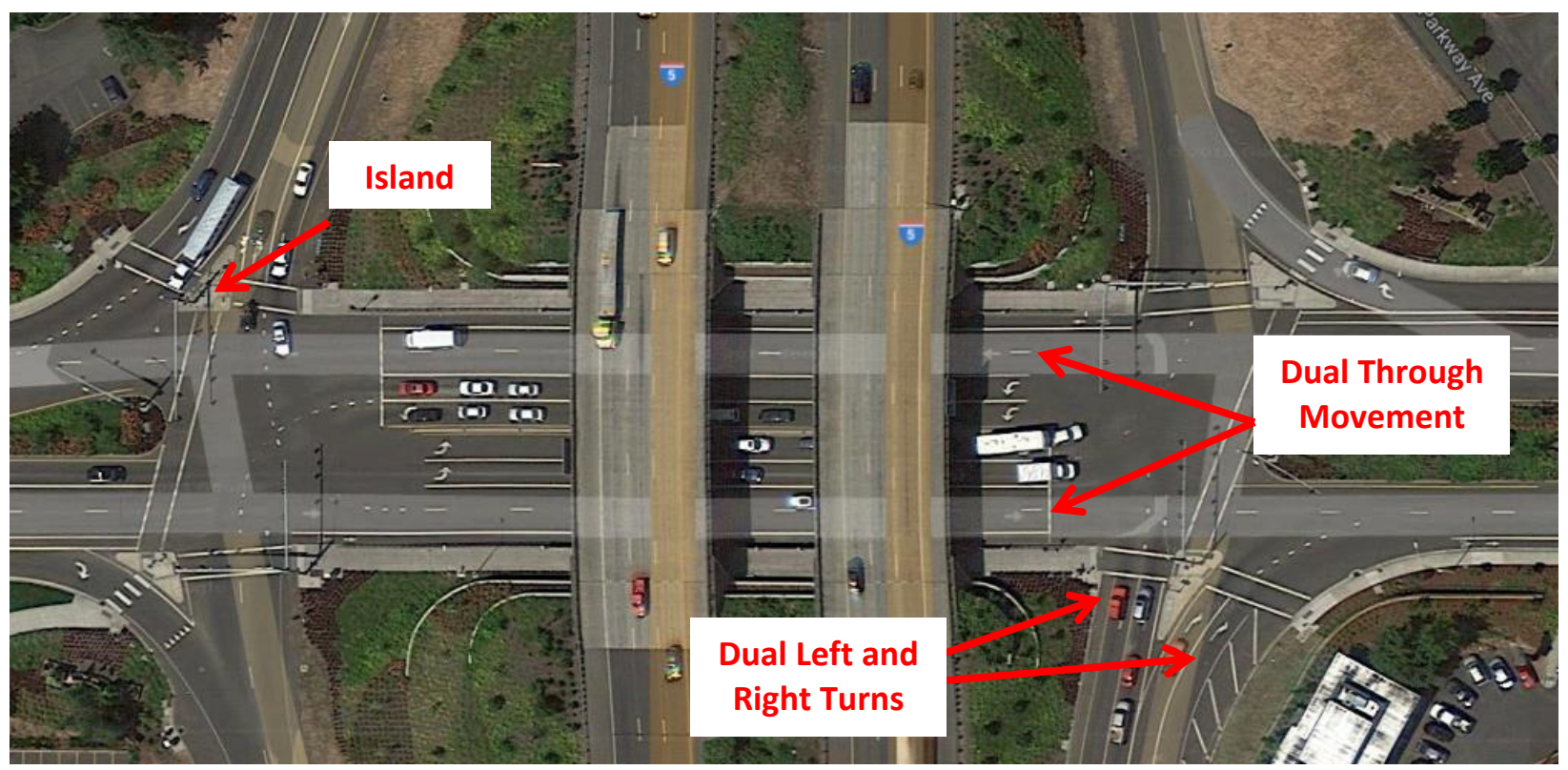

Figure 7: Wilsonville Diamond Interchange Critical Characteristics (Source: Google Maps)

\section{Low Pedestrian Volumes:}

In general, it is hard for pedestrians and bicyclists to cross a SPUI and it is not recommended to be used at an interchange where high pedestrian and bicycle volumes exist. The SPUI can be treated to accommodate pedestrians and bicyclists, but due to it's the signal phasing sequence and geometry it could make it harder and unfamiliar to the users (8). It is easy for the pedestrians to move parallel to the cross road (Wilsonville Rd), but it would be difficult for them to cross the cross road in the SPUI as the signal phasing allows the traffic to move through there at all times. Also, there are 8 lanes for the pedestrians to get across in which might not be enough time (11). Luckily, this interchange has nearby intersections that can be used to cross the main road.

Overall, the characteristics of a diamond interchange listed above makes it a perfect candidate for a SPUI implementation. These characteristics can save a great deal of engineering design and time. In general, if there is ever a desire to replace a TDI with a SPUI, it would be a good idea to run through the characteristics listed above and see if it is a match. 


\subsection{Data Acquisition}

The turning movement traffic counts for the Wilsonville interchange was obtained from an employee of DKS Associates. The data is for PM peak hours and all signal timings were included with it. The date in which the data was collected was on April 4, 2014. The turning movements of the study can be seen in Figures B1-B3. Figure B1 is the turning movements of the interchange and Figure B2 and B3 are the nearby intersections to the west and east of the interchange that have the potential of being impacted. Furthermore, all turning volumes were balanced.

\subsection{Performance Measures}

The performance measurements used for this research involved and were limited to whatever the software provided. These measurements include average delay per vehicle, carbon monoxide and nitrogen oxides emission, average speed per vehicle, average stopped delay, average queue length, and the number of stops. These measurements will be compared between the TDI and the SPUI for all volume conditions.

\section{Average Delay per Vehicle:}

The average delay per vehicle is the additional time required to pass a signal-controlled intersection compared to a free through route (9). The value for this variable is measured in seconds and is a good way to see whether implementing a SPUI would improve delay or not. Improving delay can mitigate congestion and improve level of service. 
Figure B1-B3: Existing Balanced Turning Movement Volume for PM Peak Hour

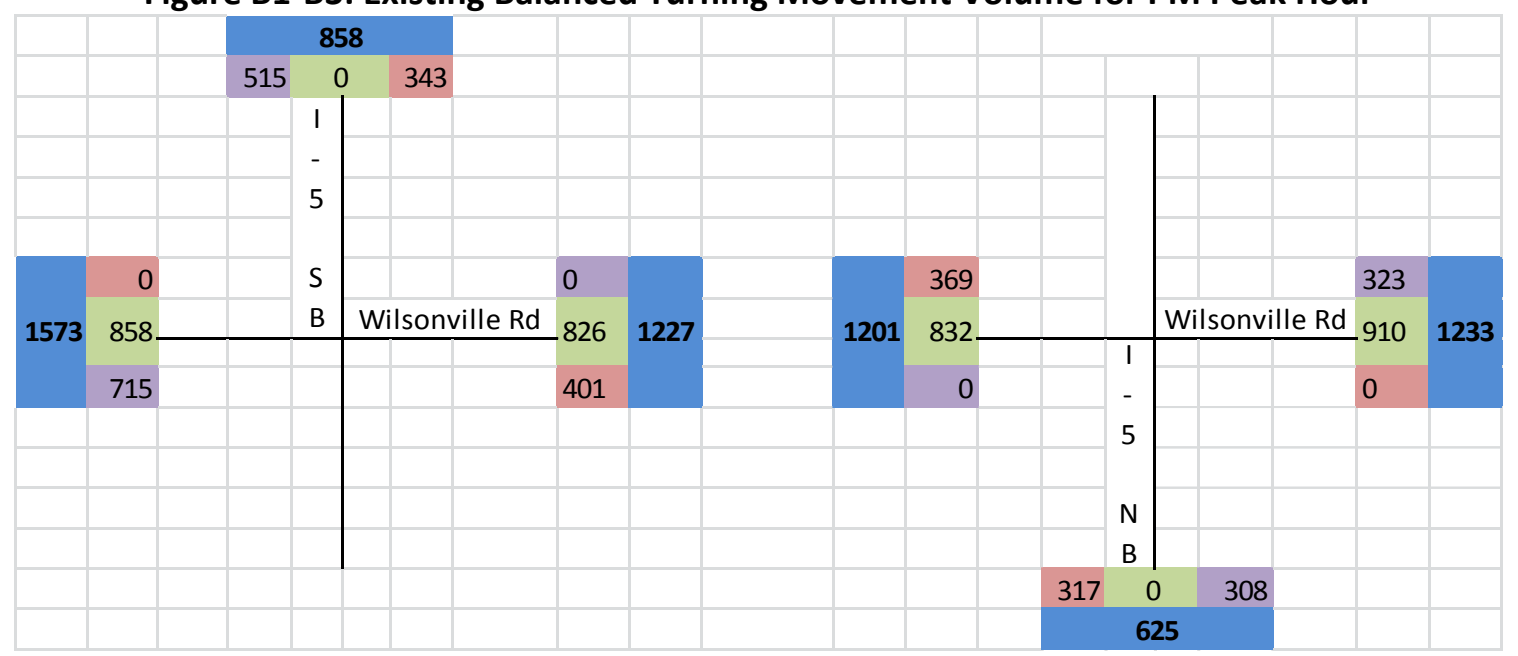

Figure B1: Balanced traffic volumes at the Wilsonville Interchange

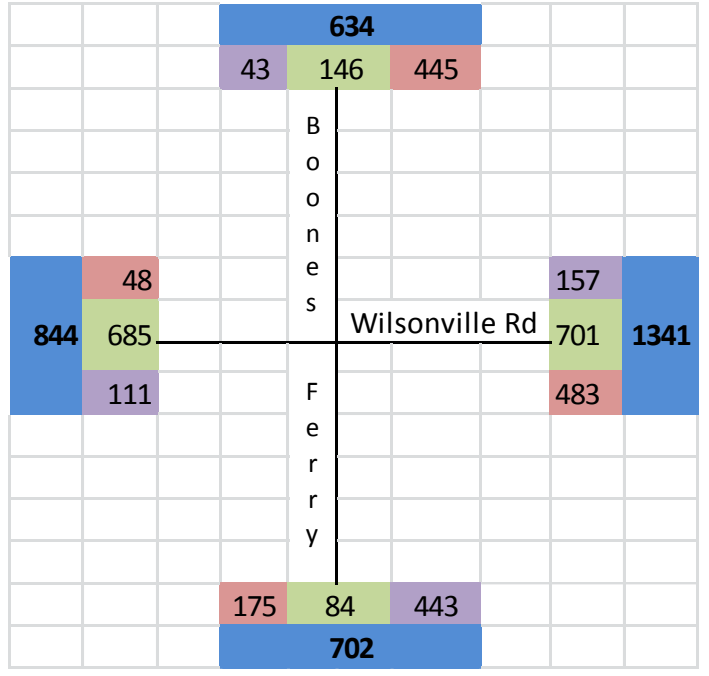

Figure B2: Intersection to the West of the Interchange

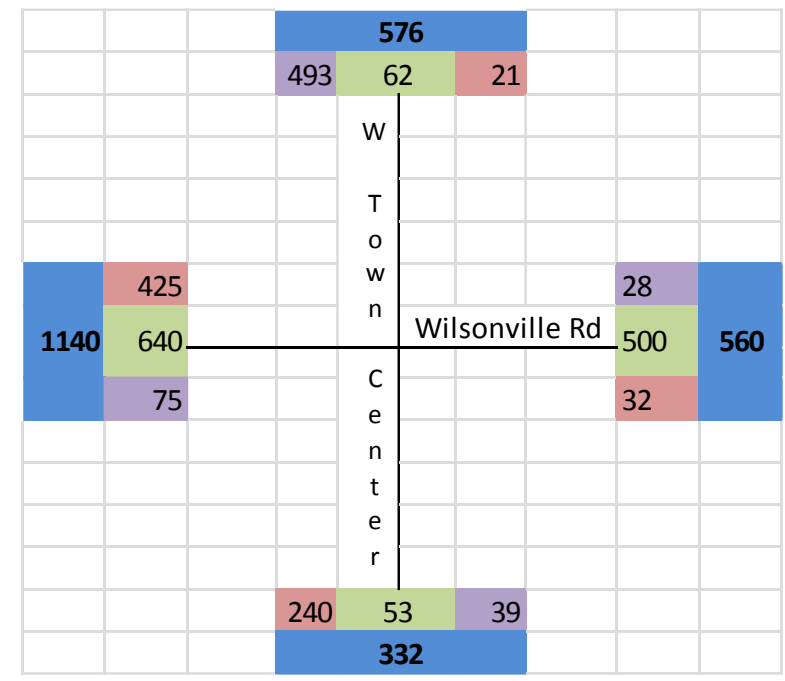

Figure B3: Intersection to the East of the Interchange 


\section{Carbon Monoxide and Nitrogen Oxides Emission:}

Another measure of performance for the comparison of the two interchanges is with regards to emissions. Both Carbon Monoxide (CO) and Nitrogen Oxides $\left(\mathrm{NO}_{\mathrm{x}}\right)$ are toxic gases that are emitted through the air during combustion usually in areas with high motor vehicle travel.

$\mathrm{CO}$ is a deadly, colorless, odorless, poisonous gas and is produced by the incomplete burning of various fuels, including coal, wood, charcoal, oil, kerosene, propane, and natural gas. Machines powered by internal combustion engines such as cars produce $\mathrm{CO}$ (2). The unit of measurement for $\mathrm{CO}$ will be in grams for this study.

Nitrogen Oxides $\left(\mathrm{NO}_{\mathrm{x}}\right)$ is the term used to describe the sum of nitric oxide (NO), nitrogen dioxide (NO2), and other oxides of nitrogen. Again, operations of motor vehicles can emit these gases and can play a major role in several important environmental and human health issues (18). The unit of measurement for $\mathrm{NO}_{\mathrm{x}}$ will be in grams for this this study.

\section{Average Speed per Vehicle:}

If the average speeds of vehicles are quite low, we can suspect congestion, high density, or additional delays. At high speeds the vehicles will be traveling at their desired speed or free-flow speed (17). Therefore, if the average speed is improved by implementing the SPUI we can identify a positive impact. To better visualize this, we can refer to Figure 8 . 

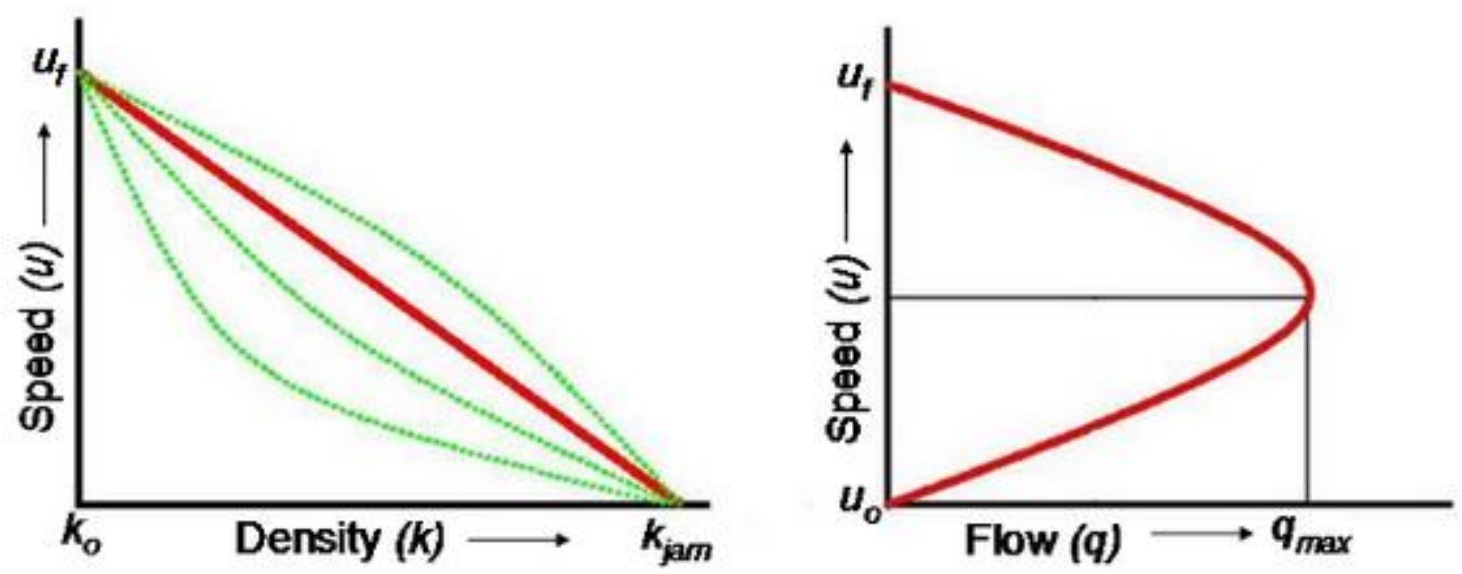

Figure 8: Speed-Density and Speed-Flow Curves (17)

Average Stopped Delay:

The average stopped delay will tell us the average stopped delay per vehicle. Therefore, this would be the average time stopped per active and arrived vehicles. In VISSIM this is calculated as the total stopped time of all vehicles divided by the total amount of active and arrived vehicles (10). This performance measure will be calculated in seconds.

\section{Average Queue Length:}

Measuring the average queue length can illustrate to us which interchange causes the traffic not to get backed up too much. This can be quite hazardous, especially for interchanges, as a long queue can spill back to the interstate and cause crashes. Long queues can also clog up the interchange itself and possibly cause vehicles to get stuck in the middle. Generally a longer queue leads to bad performance as it is a sign of congestion and hazardous conditions. The unit for the measurement of the queue length for this study will be in feet.

Number of Stops: 
This performance will calculate the average number of stops per vehicle. The lower the number of stops the better the interchange will perform. This can also impact emissions as there will be fewer stop and go scenarios. A stop is counted if the speed of the vehicle was greater than zero at the end of the previous time step and is zero at the end of the current time step.

\subsection{Calibration and Validation}

According to the ODOT VISSIM Protocol, the calibration is the process used to achieve validity of the model by establishing suitable parameter values so that the model replicates local traffic conditions as closely as possible. The first step in calibration is to compare input and output traffic volumes. We must validate that the field volumes match the simulation output volumes. To do this we must use the GEH formula to compare simulation inputs and outputs.

For hourly flows, the GEH formula is:

$$
G E H=\sqrt{\frac{2(m-c)^{2}}{m+c}}
$$

Where,

$$
\begin{aligned}
& m=\text { output traffic volume from the simulation model (vph) } \\
& \qquad=\text { input traffic volume (vph) }
\end{aligned}
$$

\begin{tabular}{|c|c|}
\hline $\boldsymbol{G E} \boldsymbol{H}<\mathbf{5 . 0}$ & Acceptable fit \\
\hline $\mathbf{5 . 0} \leq \boldsymbol{G E} \boldsymbol{H} \leq \mathbf{1 0 . 0}$ & Caution: Possible model error or bad data \\
\hline $\boldsymbol{G E} \boldsymbol{H}<\mathbf{5 . 0}$ & Unacceptable \\
\hline
\end{tabular}

To see the validation of the VISSIM data outputs, Table 2 was put together to compare the GEH overall network traffic volumes and individual turn movements. It can be seen that the GEH of all individual turning movements are below 5 and the GEH for the overall network is close to 5 . 
Table 2: VISSIM Data Outputs and Field Data Comparison

\begin{tabular}{|c|c|c|c|c|c|}
\hline $\begin{array}{l}\text { Intersection } \\
\text { of Wil. Rd \& }\end{array}$ & Direction & $\begin{array}{c}\text { \# of } \\
\text { Vehicles } \\
\text { (VISSIM) }\end{array}$ & $\begin{array}{c}\text { Balanced } \\
\text { Field } \\
\text { Volumes }\end{array}$ & Difference & GEH \\
\hline \multirow{9}{*}{$\begin{array}{l}\text { W Town } \\
\text { Center }\end{array}$} & EB L & 30 & 32 & -2 & 0.36 \\
\hline & EB T & 471 & 500 & -29 & 1.32 \\
\hline & EB R & 31 & 28 & 3 & 0.55 \\
\hline & SB L & 23 & 21 & 2 & 0.43 \\
\hline & SB T & 61 & 62 & -1 & 0.13 \\
\hline & SB R & 450 & 493 & -43 & 1.98 \\
\hline & NB L & 226 & 240 & -14 & 0.92 \\
\hline & NB T & 43 & 53 & -10 & 1.44 \\
\hline & NB R & 33 & 39 & -6 & 1.00 \\
\hline \multirow{3}{*}{ I-5 NB } & NB L & 290 & 317 & -27 & 1.55 \\
\hline & NB T & 0 & 0 & 0 & 0.00 \\
\hline & NB R & 235 & 308 & -73 & 4.43 \\
\hline \multirow{3}{*}{ I-5 SB } & SB R & 489 & 515 & -26 & 1.16 \\
\hline & SB T & 0 & 0 & 0 & 0.00 \\
\hline & SB L & 260 & 343 & -83 & 4.78 \\
\hline \multirow{9}{*}{$\begin{array}{c}\text { Boones Ferry } \\
\text { Road }\end{array}$} & NB L & 162 & 175 & -13 & 1.00 \\
\hline & NB T & 87 & 84 & 3 & 0.32 \\
\hline & NB R & 423 & 443 & -20 & 0.96 \\
\hline & EB L & 43 & 48 & -5 & 0.74 \\
\hline & EB T & 633 & 685 & -52 & 2.03 \\
\hline & EB R & 114 & 111 & 3 & 0.28 \\
\hline & SB L & 395 & 445 & -50 & 2.44 \\
\hline & SB T & 141 & 146 & -5 & 0.42 \\
\hline & SB R & 45 & 43 & 2 & 0.30 \\
\hline \multicolumn{2}{|c|}{ Total Network } & 4685 & 5131 & -446 & 6.37 \\
\hline
\end{tabular}

The ODOT VISSIM Protocol also calls for a comparison of VISSIM data output and field data for spot speeds and/or travel time measurements as well as visual inspections of congestion levels and duration, queue lengths, and overall driver behavior. Due to the limited time allowed for this project and lack of field data, these verifications were not conducted. 


\subsection{RESULTS}

\subsection{Final SPUI Design:}

The final design of the SPUI and the network studied can be seen in Figure 11. A more close up of the SPUI can be seen in Figure 12. As it can be seen, with the new SPUI design, the interchange has been condensed and all vehicles will go through a single point. With large radii that are approximately 200 feet, the turning movement approaches are now separated by a big island. The big islands make it friendlier for bicyclists and pedestrians to travel.

\section{Lane Configuration:}

The Northbound and Southbound ramp movements coming out of the freeway have a total number of 4 lanes each ( 2 for Left turns and 2 for right turns). The right turn the left turn movements will have a permitted signal. The movements turning left onto the freeway from the arterial will also have two lanes for each bound and will also have permitted left turns. The through movements will have two lanes for each bound as well. Lastly, the right turn movements heading towards the freeway will have one lane and needs to only yield to the pedestrians and the oncoming traffic.

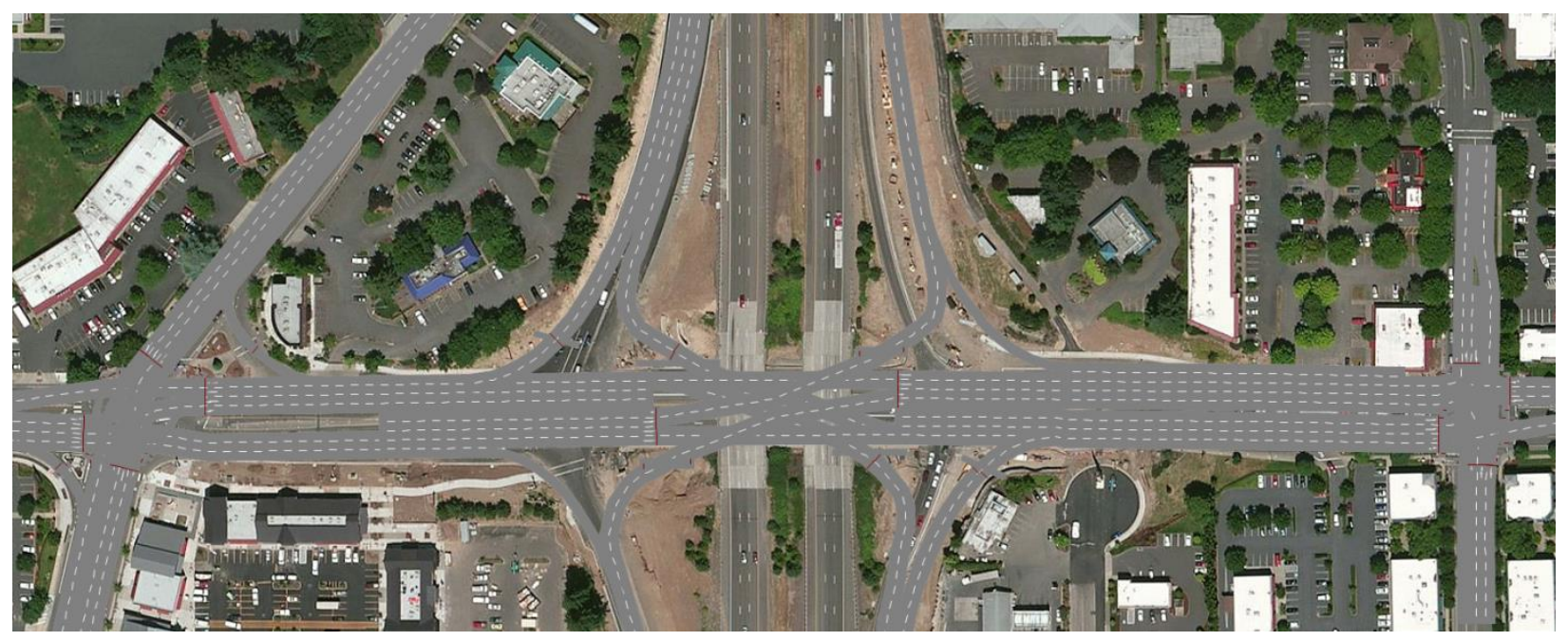

Figure 9: Project study area with the new SPUI Design 


\section{Pedestrian and Bicyclist Signalization:}

For this specific SPUI design the pedestrians and bicyclists will travel only eastward or westward on either side of the intersection. To cross the arterial, it would be unsafe and therefore should be avoided. If pedestrians need to cross the intersection, they can do so at the nearest intersection to the interchange. To cross the interchange, the pedestrians and bicyclists will have to go through 8 different points. These points are denoted from $\mathrm{A}$ to $\mathrm{H}$ in Figure 12.

If heading westwards, the pedestrian or bicyclist will press the pedestrian signal button wait for the signal to turn green. The pedestrian must then wait again at the end of the median for the pedestrian signal to turn green (Point C). Once the pedestrian signal is green and activated, the pedestrian can go to the next island (Point F). If the Pedestrian cannot make it to the island on time, they may wait at point $\mathrm{E}$ for the next phase. Finally, they can make their final cross by waiting for the on-ramp vehicles to yield and reach point $\mathrm{H}$. 


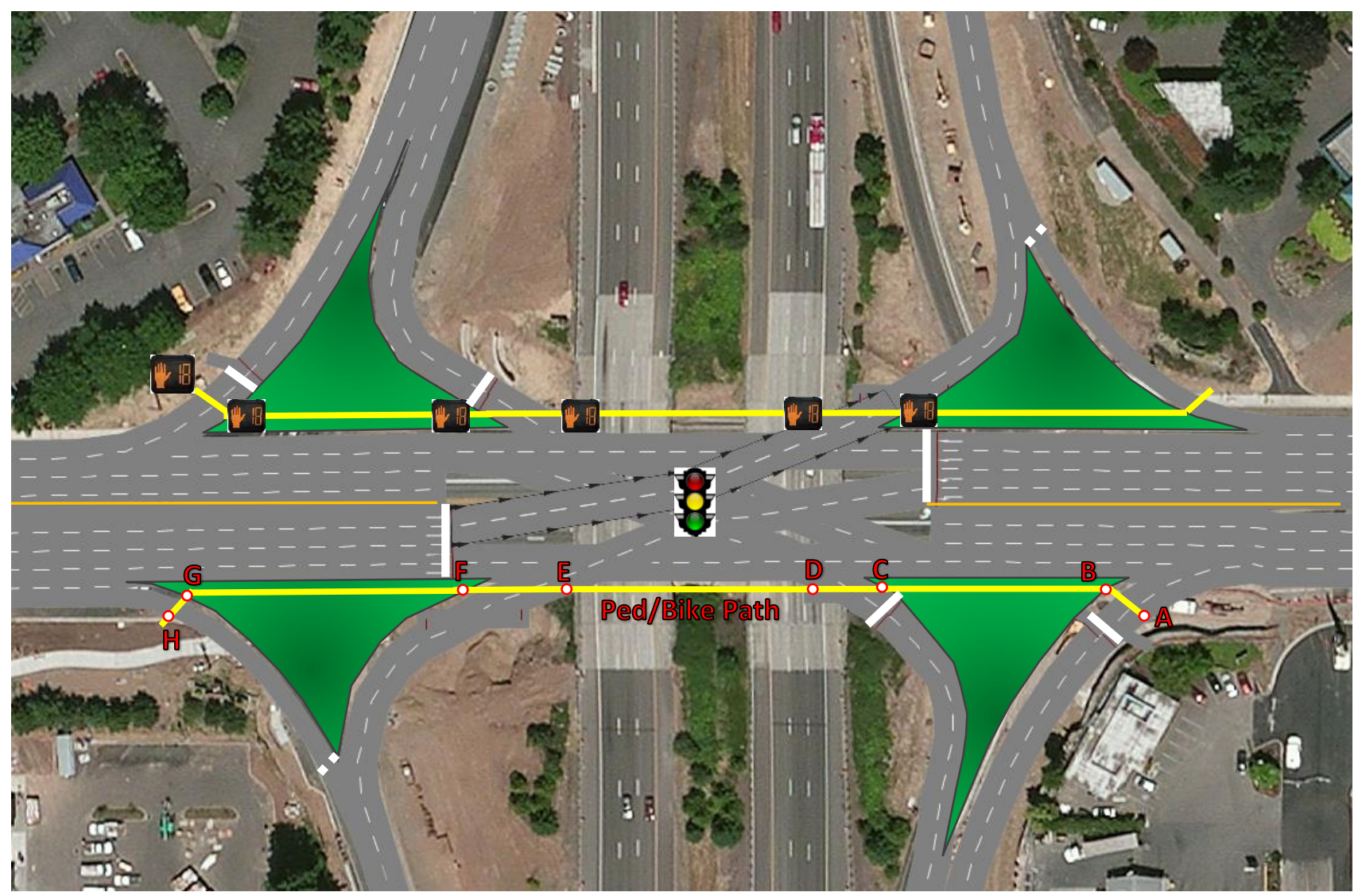

Figure 10: A closer look at the SPUI and how it can treat the pedestrians and bicyclists.

To put Figure 12 into perspective, the following Table was created to show the approximate distances and time needed to cover those distances:

Table 3: Time and Distance Estimates for bikes and pedestrians crossing the interchange

\begin{tabular}{|c|c|c|c|c|c|}
\hline $\begin{array}{c}\text { Location } \\
\text { Points }\end{array}$ & $\begin{array}{c}\text { Distance } \\
(\mathbf{f t})\end{array}$ & $\begin{array}{c}\text { Ped. Avg. } \\
\text { Speed (ft/s) }\end{array}$ & $\begin{array}{c}\text { Bike Avg. } \\
\text { Speed (ft/s) }\end{array}$ & $\begin{array}{c}\text { Ped Time } \\
\text { Spent (s) }\end{array}$ & $\begin{array}{c}\text { Bike Time } \\
\text { Spent (s) }\end{array}$ \\
\hline A to B & 30 & 3.5 & 14 & 8.57 & 2.14 \\
\hline B to C & 130 & 3.5 & 14 & 37.14 & 9.29 \\
\hline C to D & 35 & 3.5 & 14 & 10.00 & 2.50 \\
\hline D to E & 150 & 3.5 & 14 & 42.86 & 10.71 \\
\hline E to F & 55 & 3.5 & 14 & 15.71 & 3.93 \\
\hline F to G & 170 & 3.5 & 14 & 48.57 & 12.14 \\
\hline G to H & 18 & 3.5 & 14 & 5.14 & 1.29 \\
\hline
\end{tabular}


From the table above we can see that the Pedestrians would need at least 68.57 seconds to get from point $\mathrm{C}$ to $\mathrm{F}$ or $\mathrm{F}$ to $\mathrm{C}$. The SPUI interchange's signal timing can be seen for both the pedestrians/bicyclists and the motorists in Figure 12a. The pedestrians can go from point $A$ to $E$ only during phases 1 and 2 . This would take them approximately 114.28 seconds and the pedestrian phase is only 80 seconds. However, they can get to point $\mathrm{D}$ in 55.71 seconds which is plenty of time to clear the phase. Once they are at point $D$, they can safely walk over to Point $E$. From point $A$ to $E$, it would take 98 second, so they would only have to wait about another minute for the next phase to start. Pedestrians can go from Point $\mathrm{E}$ to $\mathrm{H}$ during phases 2 and 3 in which they have 77 seconds to do so. From point $\mathrm{G}$ to $\mathrm{H}$, the vehicles must yield to pedestrians and bicyclists. The good thing about the SPUI is that there are plenty of stops on the way for the pedestrians and bicyclists to wait if they do not feel safe to cross. The signal timing also allows 10 seconds of flashing red and 4 seconds of all red. With the long pedestrian/bicyclist phases and low pedestrian/bicyclist volumes, pedestrian and bicyclist delay should be minimal.

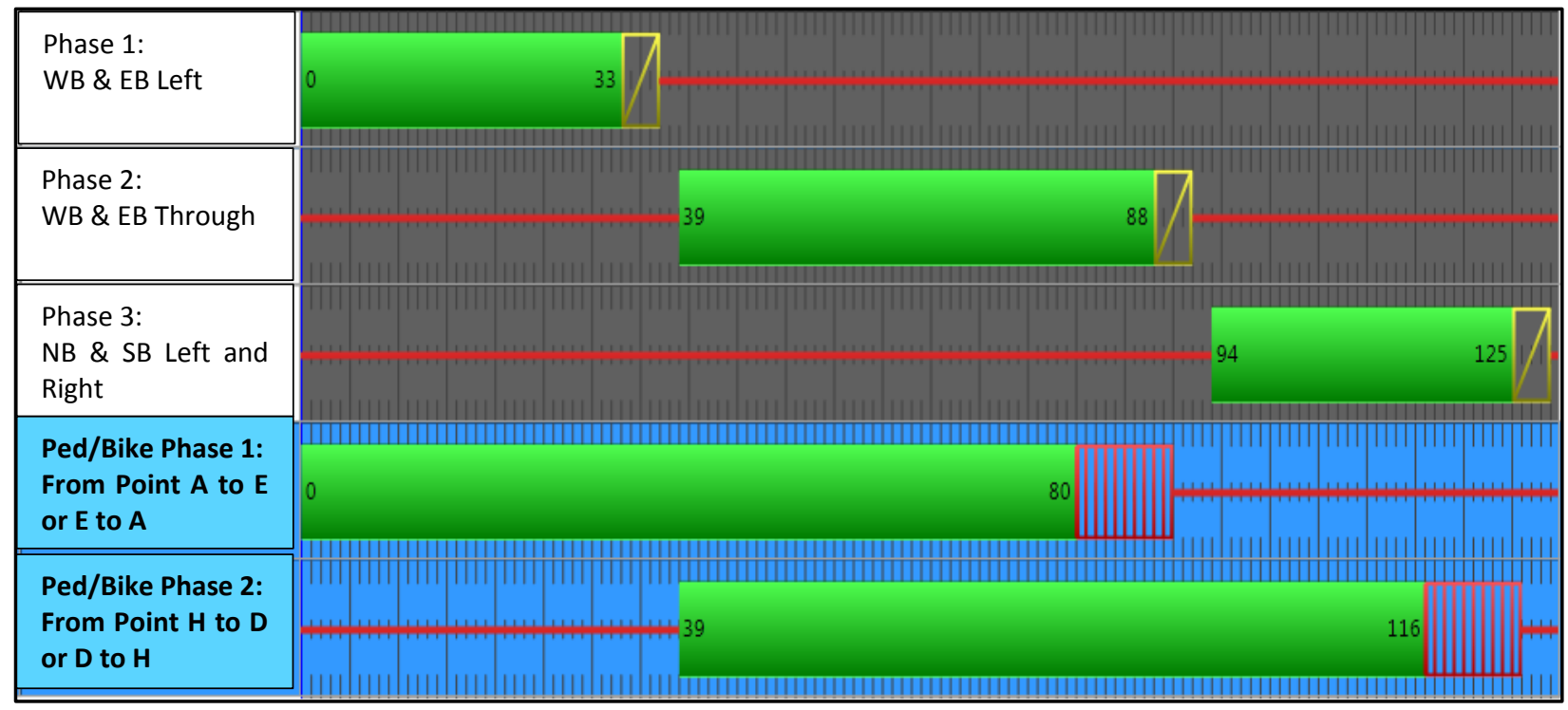

Figure 12a: SPUI signal timing for both pedestrian/bicyclists and motorist. For points, refer to Figure 12. 


\subsection{Volume Conditions}

As mentioned before, the measurement of the performances will be compared for the existing volume conditions and six other conditions to see how increasing the volume will have an impact on the interchange. To make it more clear, the different volume conditions will be denoted as the following:

- Existing: Existing peak hour volume conditions

- $\mathbf{0 . 7 5}$ Ramp: Decreasing all volumes on the off-ramps by $25 \%$.

- 1.25 Ramp: Increasing all volumes on the off-ramps by $25 \%$.

- $\quad$ 1.4 Ramp: Increasing all volumes on the off-ramps by $40 \%$.

- $\quad 0.75$ EW: Decreasing the west bound and east bound movements by $25 \%$.

- $\quad$ 1.25 EW: Increasing the west bound and east bound movements by $25 \%$.

- $\quad 1.4 \mathrm{EW}$ : Increasing the west bound and east bound movements by $40 \%$.

All these different conditions were analyzed and simulated in PTV VISSIM. Each condition had 10 simulation runs and the average value was taken from all the simulations runs.

\section{$6.3 \quad 0.75$ Ramp Volume Condition Analysis}

As mentioned before, this condition will look at $75 \%$ of the existing PM peak hour volume condition for only the ramps. This is done to see how both interchanges will perform when the volumes are well below their capacity. The analysis was done for the entire network and also for each specific approach. The following 4 graphs were conducted for the entire network. 
Average Delay for 0.75 Ramp

Condition

Diamond SPUI

61.00

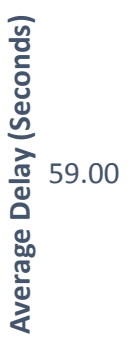

57.00
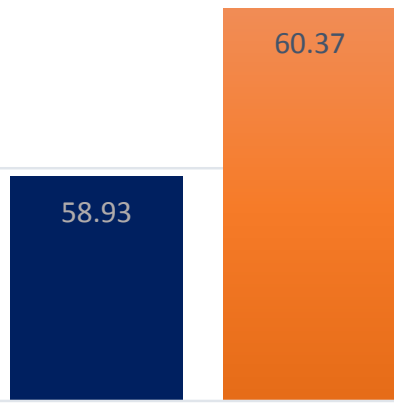

Figure 13: Average Delay for 0.75 Ramp condition

Average Speed for 0.75 Ramp

Condition

- Diamond SPUI

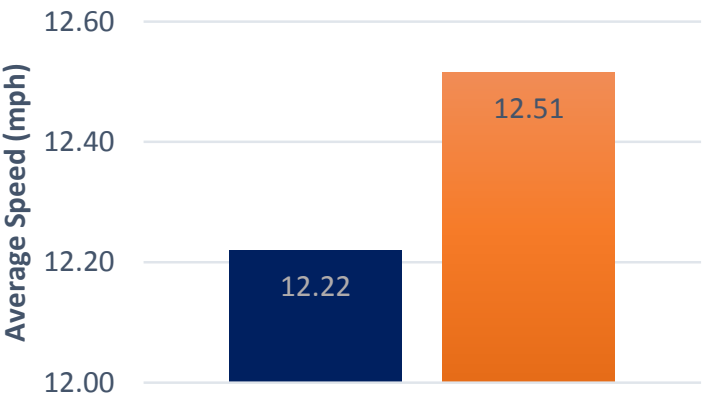

Figure 15: Average Speed for 0.75 Ramp Condition
Average Stop Delay for 0.75 Ramp

Condition

- Diamond SPUI

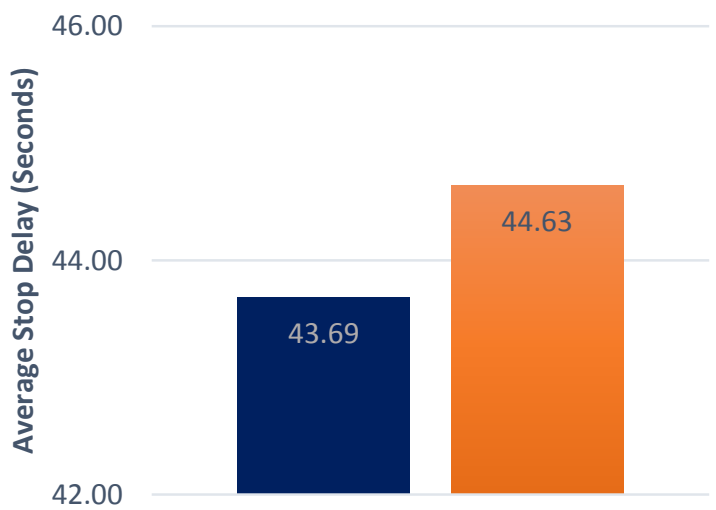

Figure 14: Average Stop Delay for 0.75 Ramp Condition

\section{Average CO and NOx Emitted for}

0.75 Ramp Condition

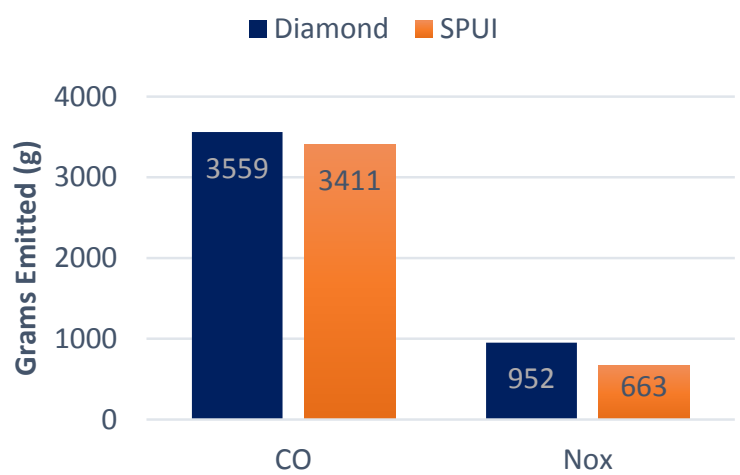

Figure 16: Average Pollution Emitted for 0.75 Ramp Condition

When looking at the four performance measures for the entire network, we can see that the SPUI is performing slightly lower than the diamond interchange with respect to delay. However, the SPUI performs better in both emissions and the average speed. To see how the interchange itself is doing, we must look at the performances for each approach. The following graph shows the percent change from the existing diamond interchange for volume condition 0.75 Ramp. A negative percent change value means that the performance has worsened with the implementation of the SPUI. 


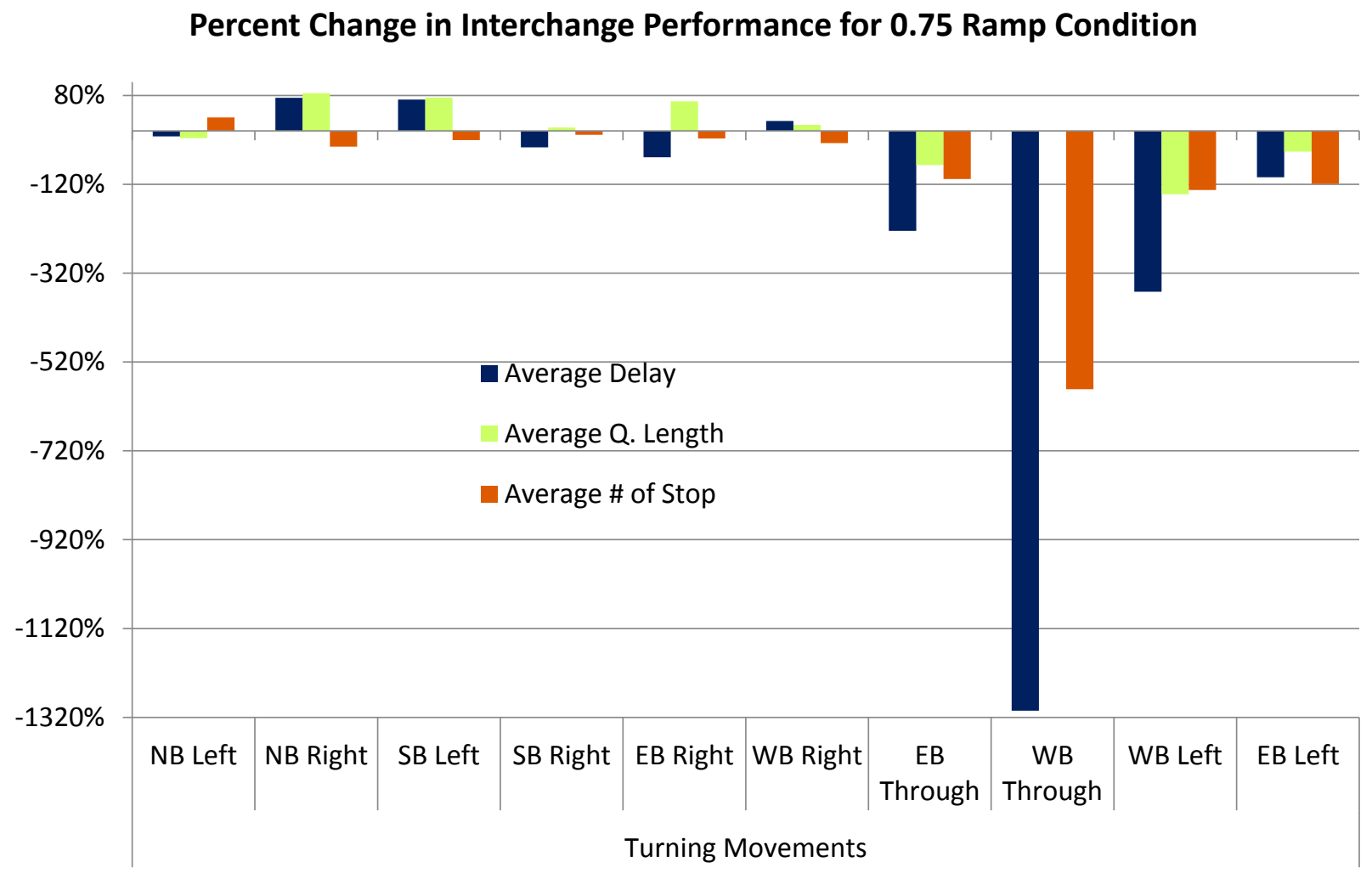

Figure 17: Percent change in interchange performance from Diamond to SPUI for 0.75 Ramp Conditions.

From the graph above we can see while the average queue length has improved when implementing the SPUI, the average delay and the average number of stops has worsened. In terms of delay, the only improvements we see are for the NB right, SB left, and WB right approaches. For the exact percentage values, please refer to Table 4. The red cells in Table 4 mean that the interchange has worsened when the SPUI was implemented.

Table 4: Percent Change in Performance from Diamond to SPUI for 0.75 Ramp Condition

\begin{tabular}{|l|c|c|c|c|c|c|c|c|c|c|}
\hline & \multicolumn{8}{|c|}{ Percent Change in Performance for 0.75 Ramp Condition } \\
\hline & $\begin{array}{c}\text { NB } \\
\text { Left }\end{array}$ & $\begin{array}{c}\text { NB } \\
\text { Right }\end{array}$ & $\begin{array}{c}\text { SB } \\
\text { Left }\end{array}$ & $\begin{array}{c}\text { SB } \\
\text { Right }\end{array}$ & $\begin{array}{c}\text { EB } \\
\text { Right }\end{array}$ & $\begin{array}{c}\text { WB } \\
\text { Right }\end{array}$ & $\begin{array}{c}\text { EB } \\
\text { Through }\end{array}$ & $\begin{array}{c}\text { WB } \\
\text { Through }\end{array}$ & $\begin{array}{c}\text { WB } \\
\text { Left }\end{array}$ & EB Left \\
\hline Average Delay & $-12 \%$ & $75 \%$ & $70 \%$ & $-37 \%$ & $-59 \%$ & $22 \%$ & $-225 \%$ & $-1305 \%$ & $-362 \%$ & $-104 \%$ \\
\hline Average Q. Length & $-16 \%$ & $85 \%$ & $75 \%$ & $8 \%$ & $67 \%$ & $14 \%$ & $-77 \%$ & - & $-142 \%$ & $-46 \%$ \\
\hline Average \# of Stop & $30 \%$ & $-35 \%$ & $-20 \%$ & $-8 \%$ & $-17 \%$ & $-27 \%$ & $-108 \%$ & $-581 \%$ & $-133 \%$ & $-119 \%$ \\
\hline
\end{tabular}




\subsection{Existing Volume Condition Analysis}

Next we look at the analysis for the current volume condition in which is for the PM peak hours. The analysis was done for the entire network and also each specific approach. The following 4 graphs were conducted for the entire network.

Average Delay for Existing Volume Condition

- Diamond SPUI

66.00

$$
\begin{aligned}
& \text { ตั } 64.00 \\
& \text { 엉 } 62.00 \\
& \text { 气 } 60.00 \\
& \text { त } 58.00 \\
& \text { 口 } \\
& \text { 品 } \\
& \text { 뜐 } 54.00 \\
& \text { \ } 52.00
\end{aligned}
$$
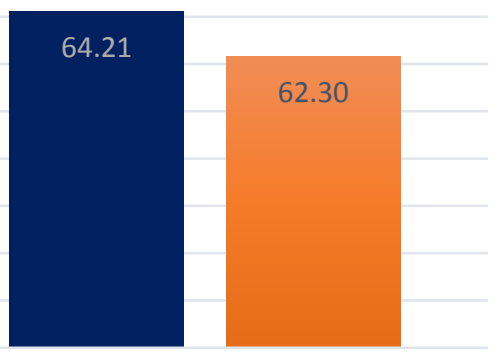

Figure 18: Average Delay for Existing Condition

\section{Average Speed for Existing Volume Conditions}

- Diamond $\quad$ SPUI

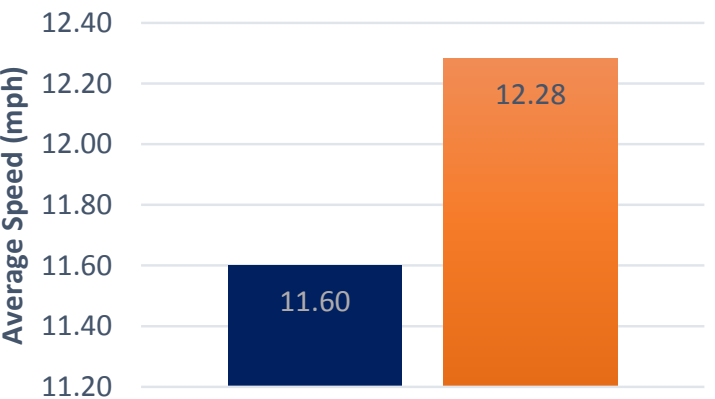

Figure 20: Average Speed for Existing Condition11

\section{Average Stop Delay for Existing Volume Condition}

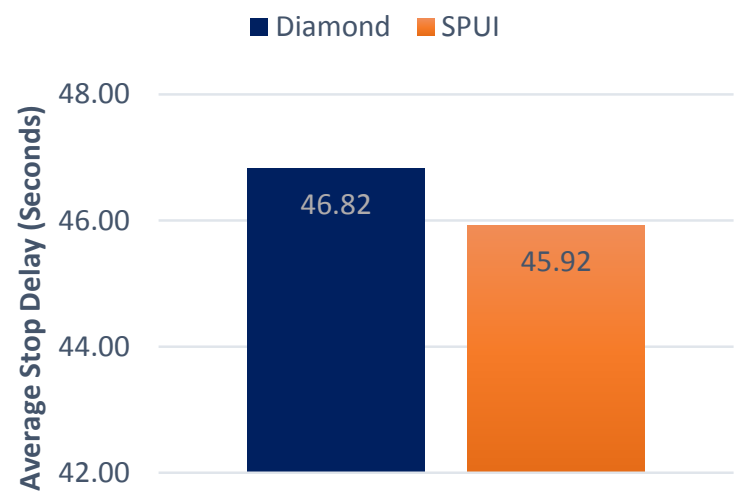

Figure 19: Average Stop Delay for Existing Condition

Average $\mathrm{CO}$ and NOx Emitted for Existing Volume Condition

- Diamond SPUI

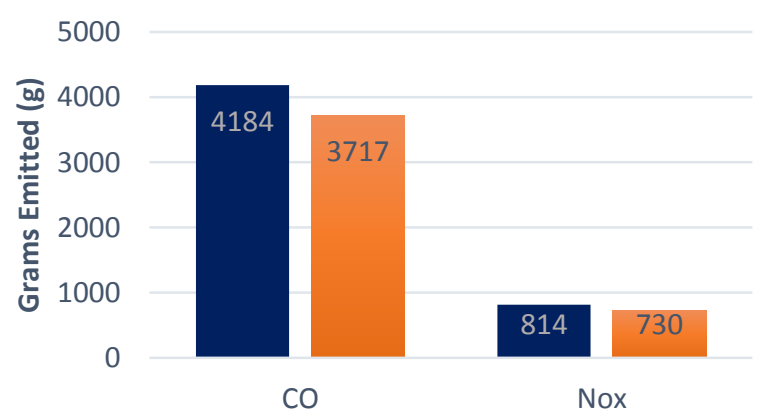

Figure 21: Average CO and NOx Emitted for Existing Condition 
The four graphs above resulting from the existing volume conditions give SPUI a better performance than the diamond interchange. As it can be seen, the SPUI is performing slightly better in delay, speed, and pollution emitted. However this is for the entire network. We will explore the interchange approaches to see how they will perform. The following graph shows the percent change from the existing diamond interchange for the Existing volume condition. A negative percent change value means that the performance has worsened with the implementation of the SPUI.

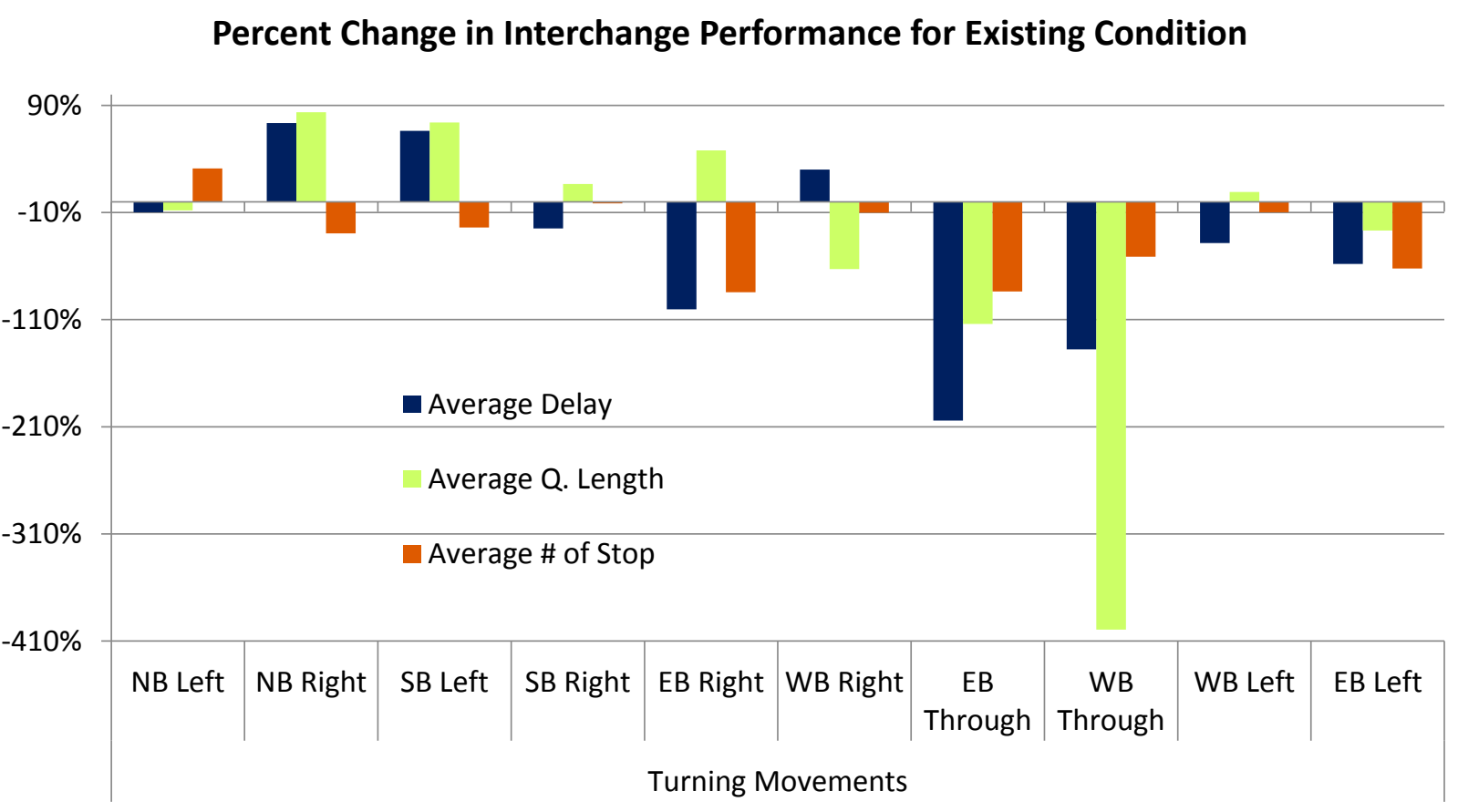

Figure 22: Percent Change in Interchange Performance from Diamond to SPUI for Existing Condition

From the graph above we can see similar results as we saw for the 0.75 Ramp condition. We can still see that the NB Right, SB Left, and WB right movements are performing better in terms of delay than the Diamond Interchange. Another important thing to note is that some of the negative percent changes have improved compared for the 0.75 Ramp condition. For example, we see a lower percent change in NB Left, SB right, EB Through, and WB Through with regards to delay. We also see significant 
improvements to WB and EB Left. This shows that the SPUI is less sensitive to volume change compared to the Diamond interchange when going from the 0.75 Ramp condition to the Existing condition.

Table 5: Percent Change in Performance from Diamond to SPUI for Existing Condition

\begin{tabular}{|l|c|c|c|c|c|c|c|c|c|c|}
\hline & \multicolumn{10}{|c|}{ Percent Change in Performance for Existing Condition } \\
\hline & $\begin{array}{c}\text { NB } \\
\text { Left }\end{array}$ & $\begin{array}{c}\text { NB } \\
\text { Right }\end{array}$ & $\begin{array}{c}\text { SB } \\
\text { Left }\end{array}$ & $\begin{array}{c}\text { SB } \\
\text { Right }\end{array}$ & $\begin{array}{c}\text { EB } \\
\text { Right }\end{array}$ & $\begin{array}{c}\text { WB } \\
\text { Right }\end{array}$ & $\begin{array}{c}\text { EB } \\
\text { Through }\end{array}$ & $\begin{array}{c}\text { WB } \\
\text { Through }\end{array}$ & $\begin{array}{c}\text { WB } \\
\text { Left }\end{array}$ & $\begin{array}{c}\text { EB } \\
\text { Left }\end{array}$ \\
\hline Average Delay & $-10 \%$ & $73 \%$ & $66 \%$ & $-25 \%$ & $-100 \%$ & $30 \%$ & $-204 \%$ & $-138 \%$ & $-38 \%$ & $-58 \%$ \\
\hline $\begin{array}{l}\text { Average Q. } \\
\text { Length }\end{array}$ & $-8 \%$ & $83 \%$ & $74 \%$ & $17 \%$ & $48 \%$ & $-63 \%$ & $-114 \%$ & $-399 \%$ & $9 \%$ & $-27 \%$ \\
\hline Average \# of Stop & $31 \%$ & $-30 \%$ & $-24 \%$ & $-1 \%$ & $-84 \%$ & $-10 \%$ & $-84 \%$ & $-51 \%$ & $-10 \%$ & $-62 \%$ \\
\hline
\end{tabular}

\subsection{25 Ramp Volume Condition Analysis}

Next we look at increasing the ramp volumes by 25 percent to see which interchange can handle higher volumes better. The analysis was done for the entire network and also for each specific approach. The following 4 graphs were conducted for the entire network.

\section{Average Delay for 1.25 Ramp Condition}

- Diamond $\quad$ SPUI

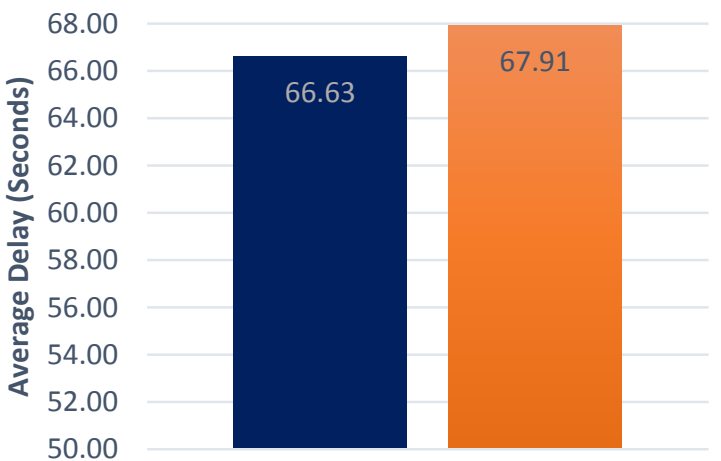

Figure 23: Average Delay for 1.25 Ramp Condition
Average Stop Delay for 1.25 Ramp Condition

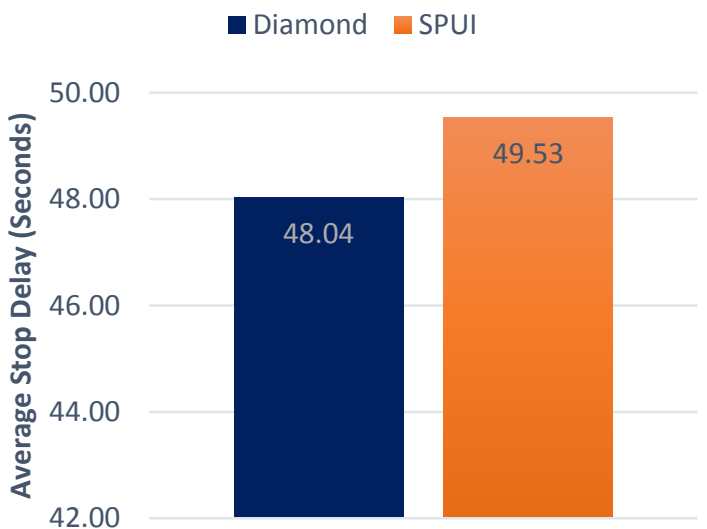

Figure 24: Average Stop Delay for 1.25 Ramp Condition 
Average Speed for 1.25 Ramp

Condition

- Diamond SPUI

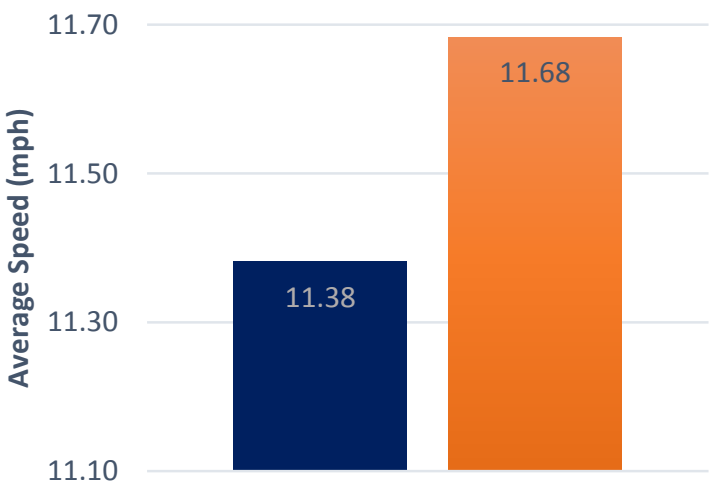

Figure 25: Average Speed for 1.25 Ramp Condition
Average $\mathrm{CO}$ and NOx Emitted for

1.25 Ramp Condition

- Diamond SPUI

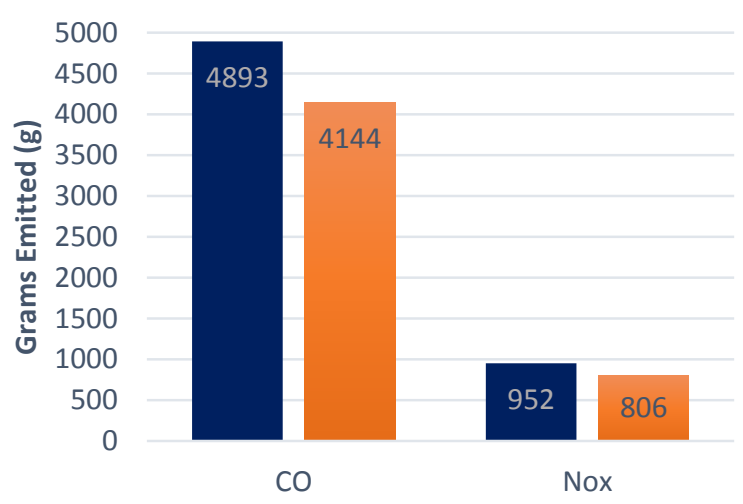

Figure 26: Average Pollution Emitted for 1.25 Ramp Condition

The four graphs above show us that for the 1.25 ramp condition, the Diamond interchange performs barely better with regards to average delay per vehicle and average stop delay per vehicle. The average speed also comes very close, but the SPUI still does slightly better. Lastly, the SPUI emits fewer CO and NOx due to the compaction of the interchange. We will now explore the interchange approaches to see how they will perform. The following graph shows the percent change from the existing diamond interchange for the 1.25 Ramp condition. A negative percent change value means that the performance has worsened with the implementation of the SPUI.

Again from the percent change values graph shown in Figure 27 we can see that the NB Right, SB Left, and WB right movements are performing better in terms of delay than the Diamond Interchange. However, this time the NB left, WB Left, and EB Left movements are doing much better in terms of all the performances as percent change than the two previous conditions. This means that the Diamond interchange is especially sensitive to volume change when it comes to left turns coming from north bound, west bound, and east bound. The EB and the WB through movements are still performing poorly 
at the SPUI as, the heavy ramp movements could be causing a longer queue that spills back and effects these movements.

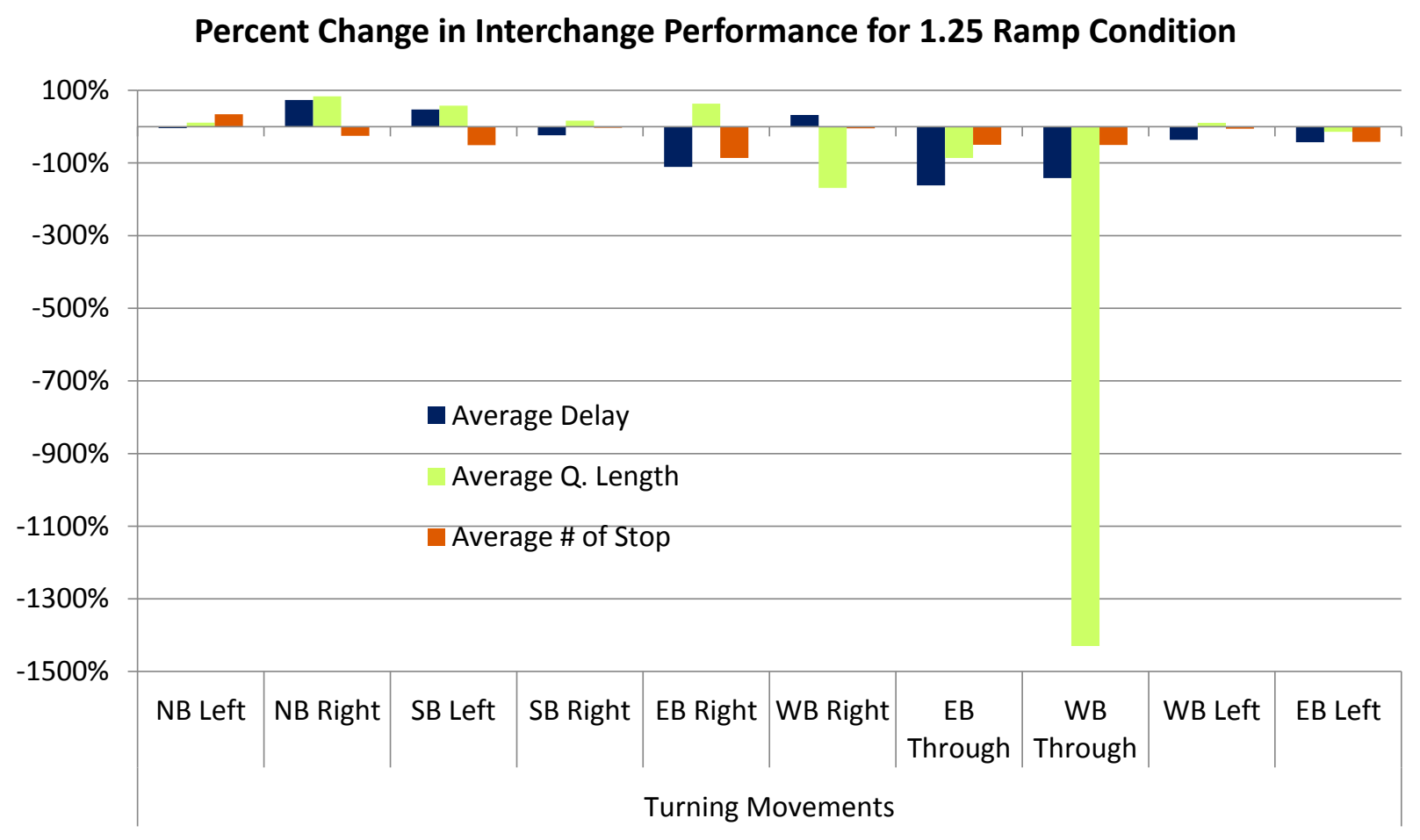

Figure 27: Percent Change in Interchange Performance from Diamond to SPUI for Existing Condition

Table 6: Percent Change in Performance from Diamond to SPUI for 1.25 Ramp Condition

\begin{tabular}{|l|c|c|c|c|c|c|c|c|c|c|}
\hline & \multicolumn{7}{|c|}{ Turning Movements } & & \\
\hline & $\begin{array}{c}\text { NB } \\
\text { Left }\end{array}$ & $\begin{array}{c}\text { NB } \\
\text { Right }\end{array}$ & $\begin{array}{c}\text { SB } \\
\text { Left }\end{array}$ & $\begin{array}{c}\text { SB } \\
\text { Right }\end{array}$ & $\begin{array}{c}\text { EB } \\
\text { Right }\end{array}$ & $\begin{array}{c}\text { WB } \\
\text { Right }\end{array}$ & $\begin{array}{c}\text { EB } \\
\text { Through }\end{array}$ & $\begin{array}{c}\text { WB } \\
\text { Through }\end{array}$ & $\begin{array}{c}\text { WB } \\
\text { Left }\end{array}$ & $\begin{array}{c}\text { EB } \\
\text { Left }\end{array}$ \\
\hline Average Delay & $-4 \%$ & $73 \%$ & $47 \%$ & $-24 \%$ & $-111 \%$ & $32 \%$ & $-162 \%$ & $-141 \%$ & $-36 \%$ & $-43 \%$ \\
\hline Average Q. Length & $11 \%$ & $84 \%$ & $58 \%$ & $17 \%$ & $63 \%$ & $-169 \%$ & $-86 \%$ & $-1430 \%$ & $10 \%$ & $-14 \%$ \\
\hline Average \# of Stop & $34 \%$ & $-25 \%$ & $-51 \%$ & $-3 \%$ & $-86 \%$ & $-5 \%$ & $-50 \%$ & $-51 \%$ & $-5 \%$ & $-42 \%$ \\
\hline
\end{tabular}

6.6 1.4 Ramp Volume Condition Analysis 
This is going to be the last volume condition for the ramps. Here we increase the ramp volume by $40 \%$ to see how the interchanges will react. The analysis was done for the entire network and also each specific approach. The following 4 graphs were conducted for the entire network.

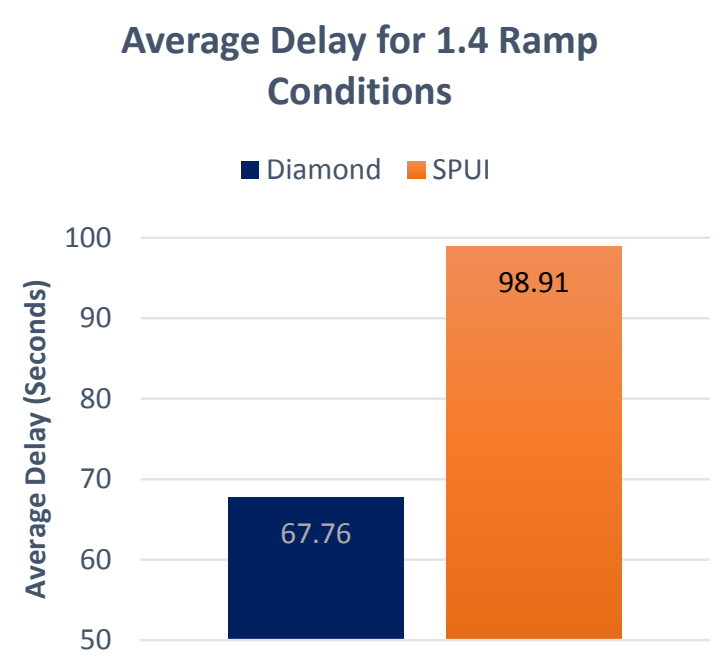

Figure 28: Average Delay for 1.4 Ramp Conditions

Average Speed for 1.4 Ramp Condition

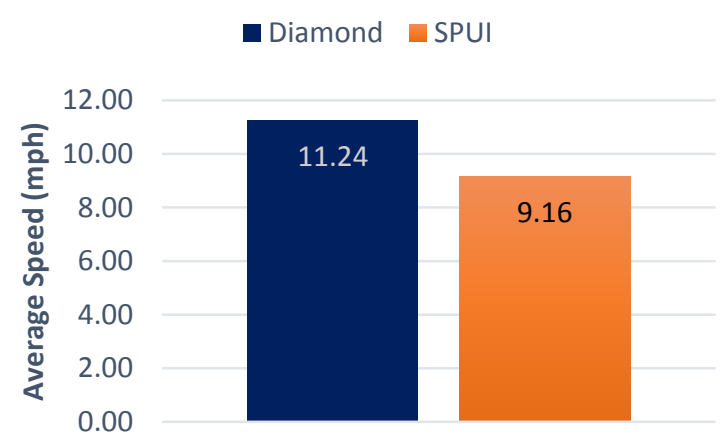

Figure 30: Average Speed for 1.4 Ramp Condition

\section{Average Stop Delay for 1.4 Ramp} Condition

- Diamond SPUI

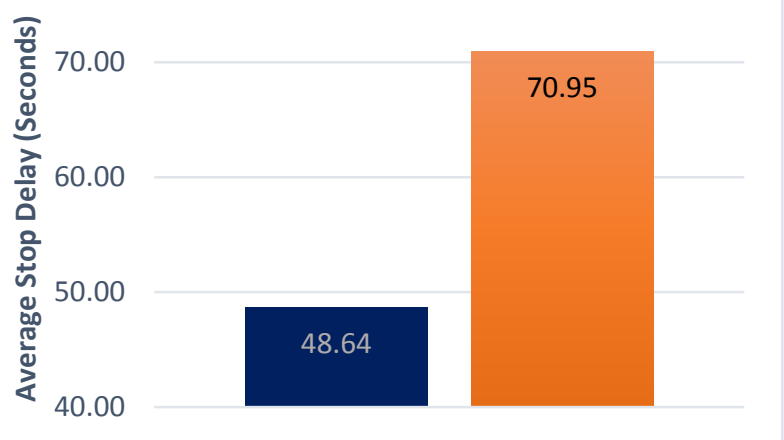

Figure 29: Average Stop Delay for 1.4 Ramp Condition

Average CO and NOx Emitted 1.4 Ramp Condition

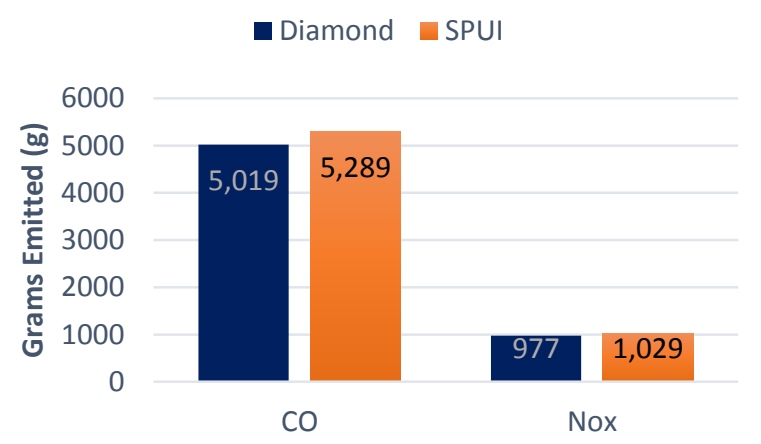

Figure 31: Average Pollution Emitted for 1.4 Ramp Condition

The four graphs above show us that for the 1.4 ramp condition, the TDI performs much better for all the performances measured. It appears that the SPUI has reached its capacity and failed to keep the flow of traffic. Therefore, somewhere between 1.25 Ramp condition and 1.4 Ramp Condition, the SPUI 
completely fails and major congestions starts to form. We will now explore the interchange approaches to see how they will perform. The following graph shows the percent change from the existing diamond interchange for the 1.4 Ramp condition. A negative percent change value means that the performance has worsened with the implementation of the SPUI.

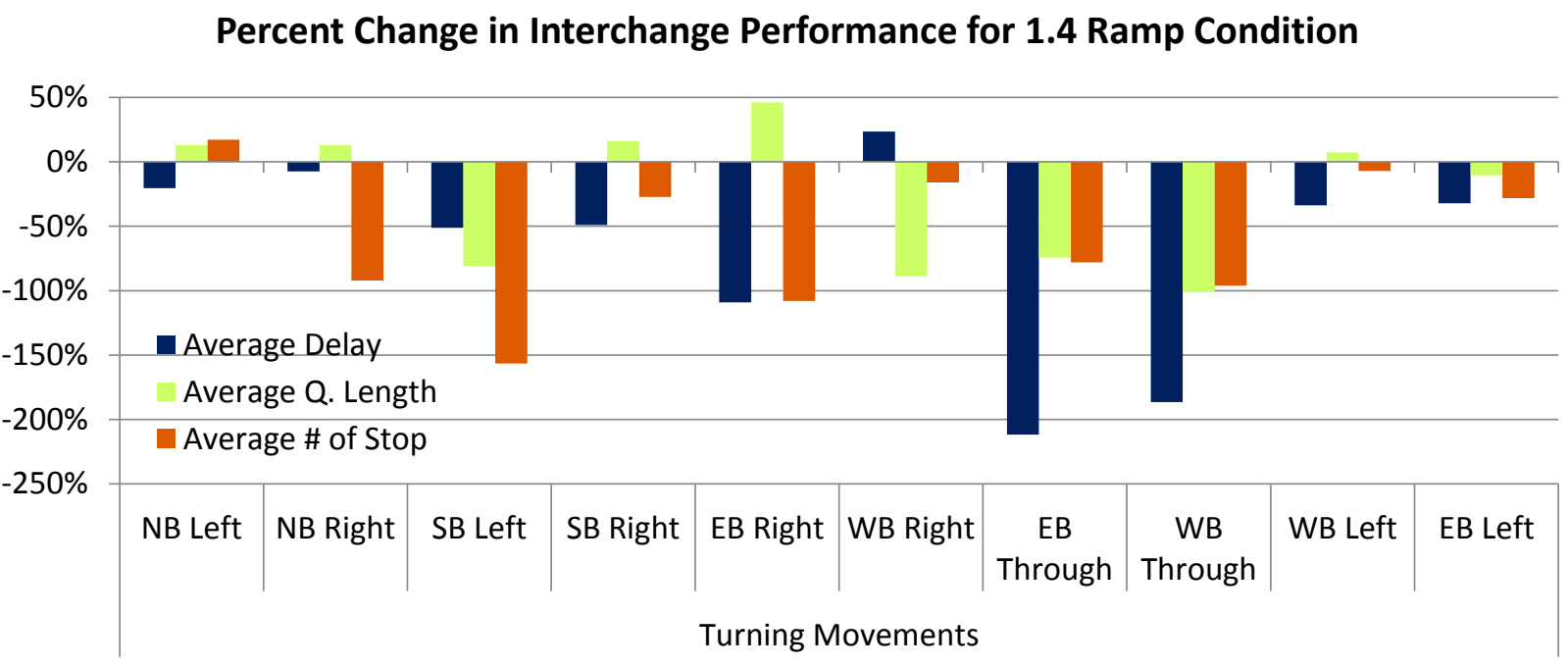

Figure 32: Percent Change in Interchange Performance from Diamond to SPUI for 1.4 Ramp Condition

From the percent change values we can see that the SPUI is not performing so well. It appears that the SPUI has gotten worst and the only movement that is performing better than the TDI in terms of delay is the WB right movement. Therefore, the SPUI is very sensitive when volume conditions change from 1.25 ramp condition to 1.4 ramp condition.

Table 7: Percent Change in Performance from Diamond to SPUI for 1.4 Ramp Condition

\begin{tabular}{|l|c|c|c|c|c|c|c|c|c|c|}
\hline & \multicolumn{10}{|c|}{ Turning Movements } \\
\hline & $\begin{array}{c}\text { NB } \\
\text { Left }\end{array}$ & $\begin{array}{c}\text { NB } \\
\text { Right }\end{array}$ & $\begin{array}{c}\text { SB } \\
\text { Left }\end{array}$ & $\begin{array}{c}\text { SB } \\
\text { Right }\end{array}$ & $\begin{array}{c}\text { EB } \\
\text { Right }\end{array}$ & $\begin{array}{c}\text { WB } \\
\text { Right }\end{array}$ & $\begin{array}{c}\text { EB } \\
\text { Through }\end{array}$ & $\begin{array}{c}\text { WB } \\
\text { Through }\end{array}$ & $\begin{array}{c}\text { WB } \\
\text { Left }\end{array}$ & $\begin{array}{c}\text { EB } \\
\text { Left }\end{array}$ \\
\hline Average Delay & $-20 \%$ & $-7 \%$ & $-51 \%$ & $-49 \%$ & $-109 \%$ & $23 \%$ & $-212 \%$ & $-187 \%$ & $-34 \%$ & $-32 \%$ \\
\hline Average Q. Length & $13 \%$ & $13 \%$ & $-81 \%$ & $16 \%$ & $46 \%$ & $-89 \%$ & $-74 \%$ & $-101 \%$ & $7 \%$ & $-10 \%$ \\
\hline Average \# of Stop & $17 \%$ & $-92 \%$ & $-157 \%$ & $-27 \%$ & $-108 \%$ & $-16 \%$ & $-78 \%$ & $-96 \%$ & $-7 \%$ & $-28 \%$ \\
\hline
\end{tabular}




\section{7 $\quad 0.75$ EW Volume Condition Analysis}

We are now going to look at different types of volume conditions. We have been looking at increasing and decreasing volumes regarding the ramps, but now we will look at modifying volumes heading towards the interchange from the east and the west. Our first volume condition will look at decreasing the east and west bound movement by $25 \%$ to see how the interchanges will react. The analysis was done for the entire network and also for each specific approach. The following 4 graphs were conducted for the entire network.

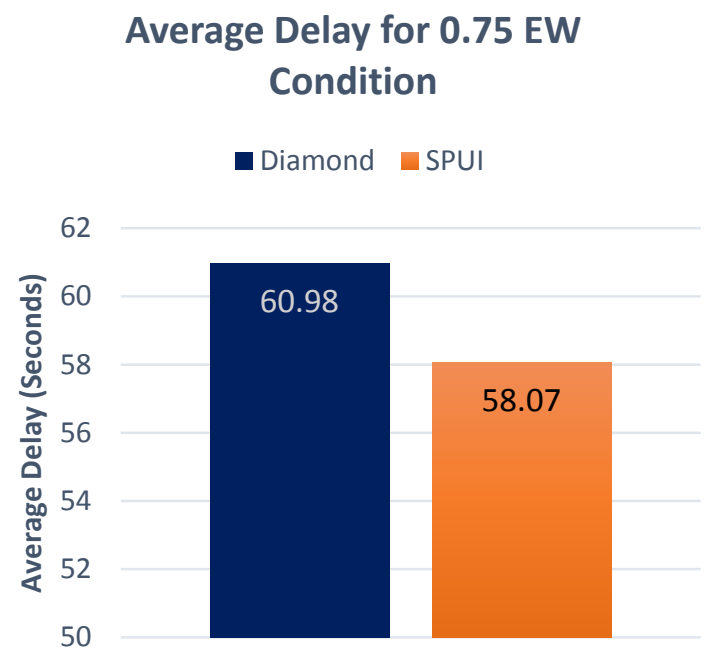

Figure 33: Average Delay for 0.75 EW Condition
Average Stop Delay for $0.75 \mathrm{EW}$ Condition

Diamond SPUI

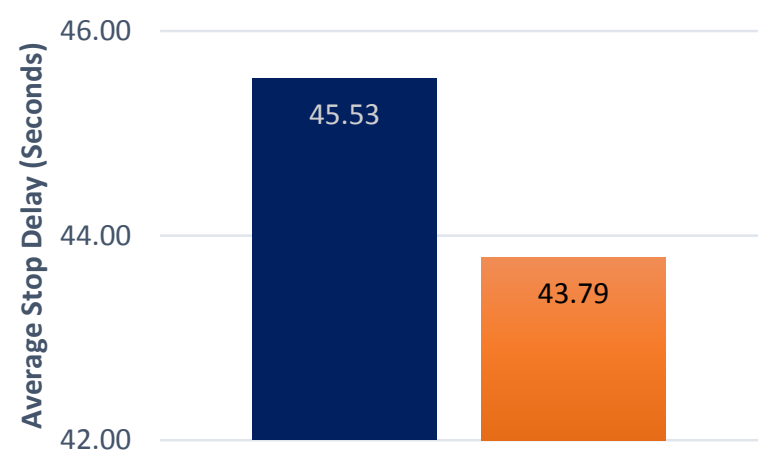

Figure 34: Average Stop Delay for 0.75 EW Condition 
Average Speed for $0.75 \mathrm{EW}$

Conditions

- Diamond $\quad$ SPUI

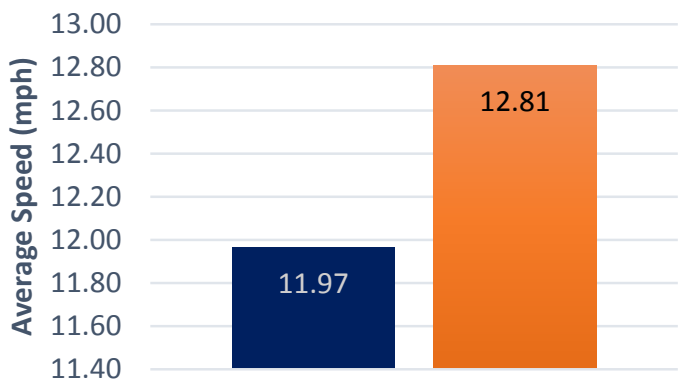

Figure 35: Average Speed for 0.75 EW Condition
Average $\mathrm{CO}$ and NOx Emitted for

0.75 EW Condition

- Diamond $\mathbf{S P U I}$

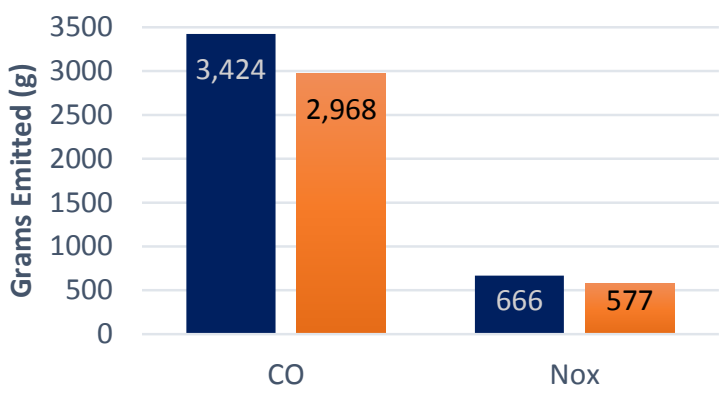

Figure 36: Average Speed for 0.75 EW Condition

The four graphs above show us that for the $0.75 \mathrm{EW}$ condition, SPUI performs slightly better for all the performances measured. We will now explore the interchange approaches to see how they will perform. The following graph shows the percent change from the existing diamond interchange for the $0.75 \mathrm{EW}$ condition. A negative percent change value means that the performance has worsened with the implementation of the SPUI.

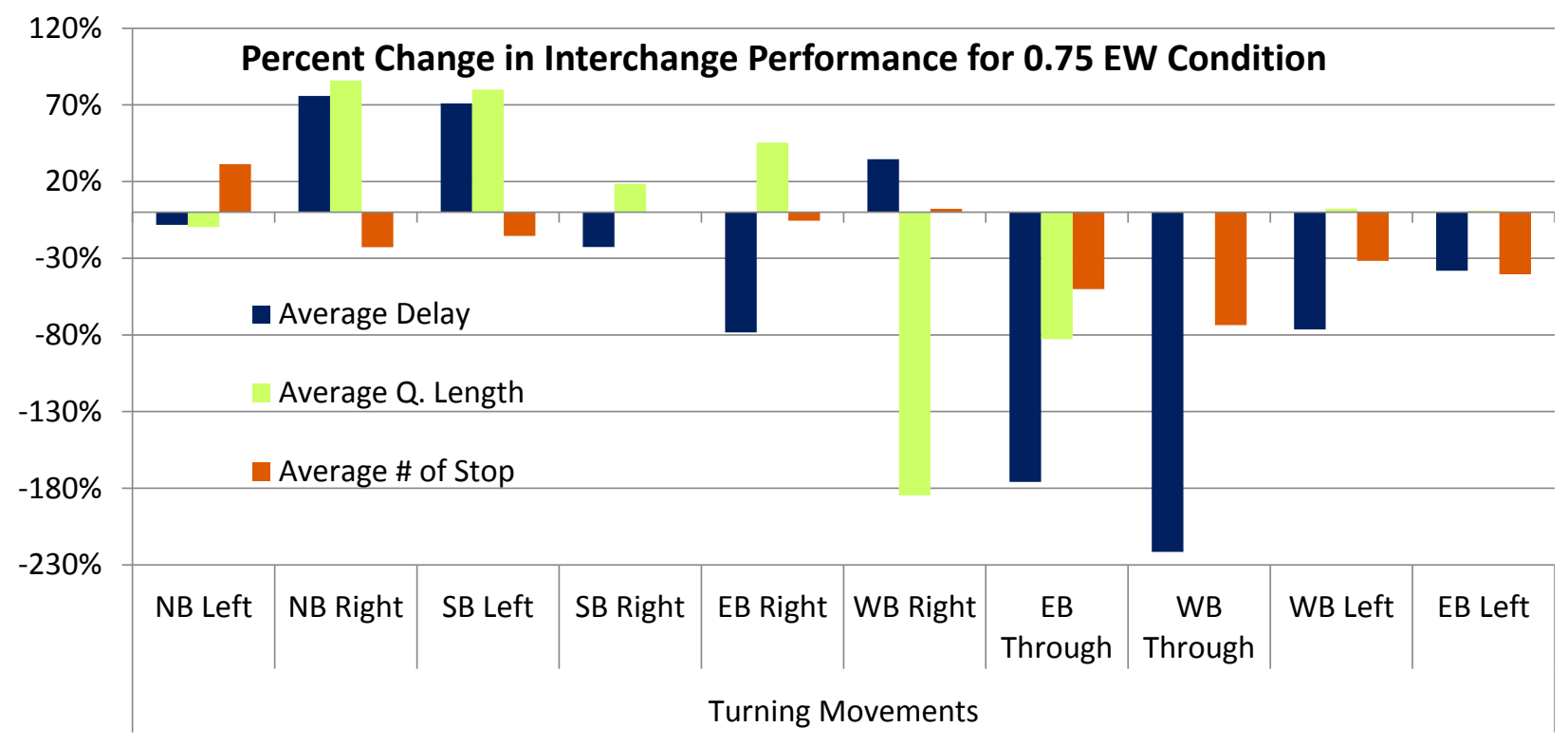

Figure 37: Percent Change in Interchange Performance from Diamond to SPUI for 0.75 EW Condition 
From the percent change values we can see that the SPUI is performing similarly to 0.75 Ramp condition. Again, we can see that the NB Right, SB Left, and WB right movements are performing better in terms of delay than the TDI.

Table 8: Percent Change in Performance from Diamond to SPUI for 0.75 EW Condition

\begin{tabular}{|l|c|c|c|c|c|c|c|c|c|c|}
\hline & \multicolumn{10}{|c|}{ Turning Movements } \\
\hline & $\begin{array}{c}\text { NB } \\
\text { Left }\end{array}$ & $\begin{array}{c}\text { NB } \\
\text { Right }\end{array}$ & $\begin{array}{c}\text { SB } \\
\text { Left }\end{array}$ & $\begin{array}{c}\text { SB } \\
\text { Right }\end{array}$ & $\begin{array}{c}\text { EB } \\
\text { Right }\end{array}$ & $\begin{array}{c}\text { WB } \\
\text { Right }\end{array}$ & $\begin{array}{c}\text { EB } \\
\text { Through }\end{array}$ & $\begin{array}{c}\text { WB } \\
\text { Through }\end{array}$ & $\begin{array}{c}\text { WB } \\
\text { Left }\end{array}$ & $\begin{array}{c}\text { EB } \\
\text { Left }\end{array}$ \\
\hline Average Delay & $-8 \%$ & $76 \%$ & $71 \%$ & $-23 \%$ & $-78 \%$ & $35 \%$ & $-176 \%$ & $-221 \%$ & $-76 \%$ & $-38 \%$ \\
\hline Average Q. Length & $-10 \%$ & $86 \%$ & $80 \%$ & $18 \%$ & $45 \%$ & $-185 \%$ & $-83 \%$ & $0 \%$ & $2 \%$ & $1 \%$ \\
\hline Average \# of Stop & $31 \%$ & $-23 \%$ & $-15 \%$ & $0.2 \%$ & $-6 \%$ & $2 \%$ & $-50 \%$ & $-74 \%$ & $-32 \%$ & $-40 \%$ \\
\hline
\end{tabular}

\section{8 $\quad 1.25$ EW Volume Condition Analysis}

Next we will look at increasing the east and west bound movement by $25 \%$ from the existing condition to see how the interchanges will react. The analysis was done for the entire network and also for each specific approach. The following 4 graphs were conducted for the entire network.

\section{Average Delay for 1.25 EW Condition}

- Diamond SPUI

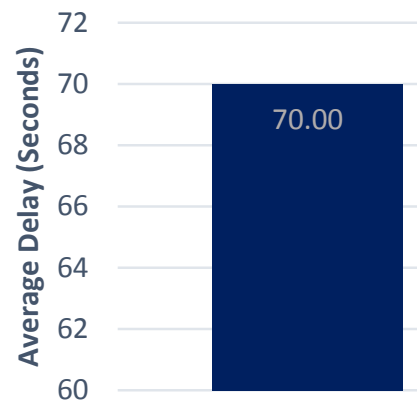

Figure 38: Average Delay for 1.25 EW Condition
Average Stop Delay for 1.25 EW Condition

Diamond SPUI

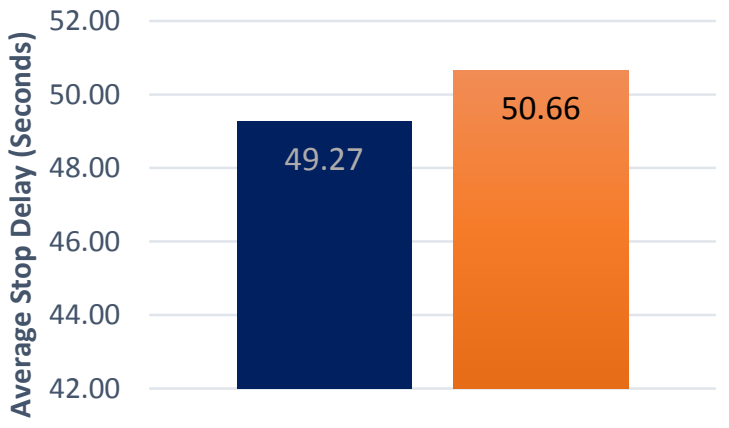

Figure 39: Average Stop Delay for 1.25 EW Condition 
Average Speed for $1.25 \mathrm{EW}$

Condition

Diamond $\mathbf{S P U I}$

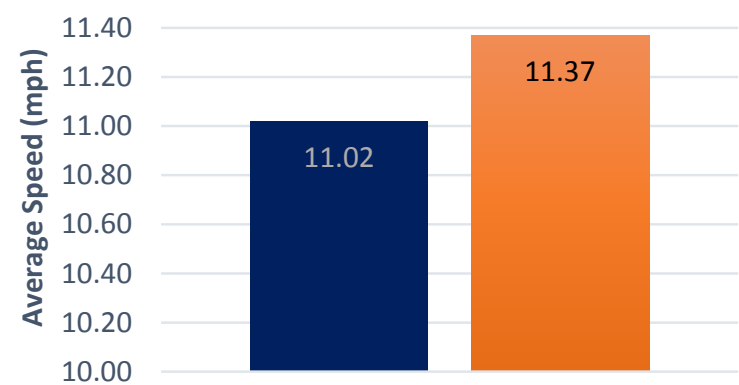

Figure 40: Average Speed for 1.25 EW Condition
Average $\mathrm{CO}$ and NOx Emitted for

1.25 EW Condition

Diamond SPUI

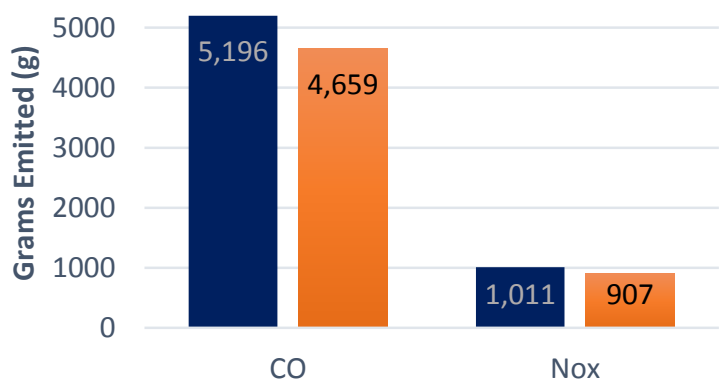

Figure 41: Average Pollution Emitted for 1.25 EW Condition

The four graphs above show us that for the $1.25 \mathrm{EW}$ condition, the TDI performs slightly better with regards to delay. SPUI still performs better in both pollutions emitted and speed. We will now explore the interchange approaches to see how they will perform. The following graph shows the percent change from the existing diamond interchange for the 1.25 EW condition. A negative percent change value means that the performance has worsened with the implementation of the SPUI.

From the percent change values below we can see that the NB Right, SB Left, and WB right movements are still performing better in terms of delay than the TDI. Overall, we see similar results as the $0.75 \mathrm{EW}$ volume conditions with minor improvements in some of the percent change values. 


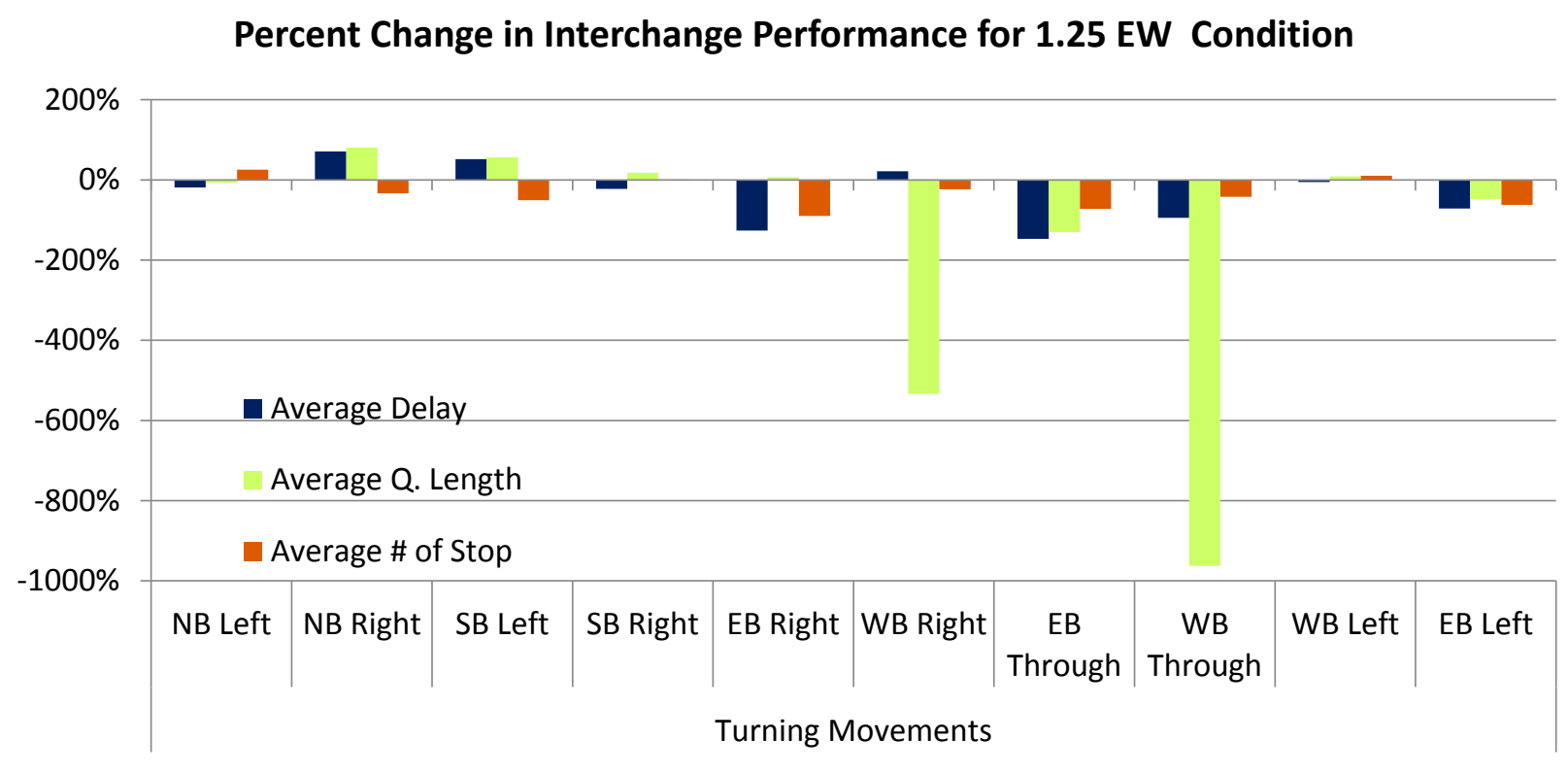

Figure 42: Percent Change in Interchange Performance from Diamond to SPUI for 1.25 EW Condition

Table 9: Percent Change in Performance from Diamond to SPUI for 1.25 EW Condition

\begin{tabular}{|l|c|c|c|c|c|c|c|c|c|c|}
\hline & \multicolumn{10}{|c|}{ Turning Movements } \\
\hline & $\begin{array}{c}\text { NB } \\
\text { Left }\end{array}$ & $\begin{array}{c}\text { NB } \\
\text { Right }\end{array}$ & $\begin{array}{c}\text { SB } \\
\text { Left }\end{array}$ & $\begin{array}{c}\text { SB } \\
\text { Right }\end{array}$ & $\begin{array}{c}\text { EB } \\
\text { Right }\end{array}$ & $\begin{array}{c}\text { WB } \\
\text { Right }\end{array}$ & $\begin{array}{c}\text { EB } \\
\text { Through }\end{array}$ & $\begin{array}{c}\text { WB } \\
\text { Through }\end{array}$ & $\begin{array}{c}\text { WB } \\
\text { Left }\end{array}$ & $\begin{array}{c}\text { EB } \\
\text { Left }\end{array}$ \\
\hline Average Delay & $-19 \%$ & $71 \%$ & $52 \%$ & $-23 \%$ & $-126 \%$ & $21 \%$ & $-147 \%$ & $-95 \%$ & $-5 \%$ & $-71 \%$ \\
\hline Average Q. Length & $-7 \%$ & $81 \%$ & $56 \%$ & $18 \%$ & $7 \%$ & $-534 \%$ & $-131 \%$ & $-962 \%$ & $9 \%$ & $-48 \%$ \\
\hline Average \# of Stop & $26 \%$ & $-33 \%$ & $-51 \%$ & $1 \%$ & $-90 \%$ & $-23 \%$ & $-73 \%$ & $-42 \%$ & $10 \%$ & $-62 \%$ \\
\hline
\end{tabular}

\subsection{4 EW Volume Condition Analysis}

Lastly, we will look at increasing the east and west bound movement by $25 \%$ from the existing condition to see how the interchanges will react. The analysis was done for the entire network and also for each specific approach. The following 4 graphs were conducted for the entire network. 
Average Delay for 1.4 EW Condition

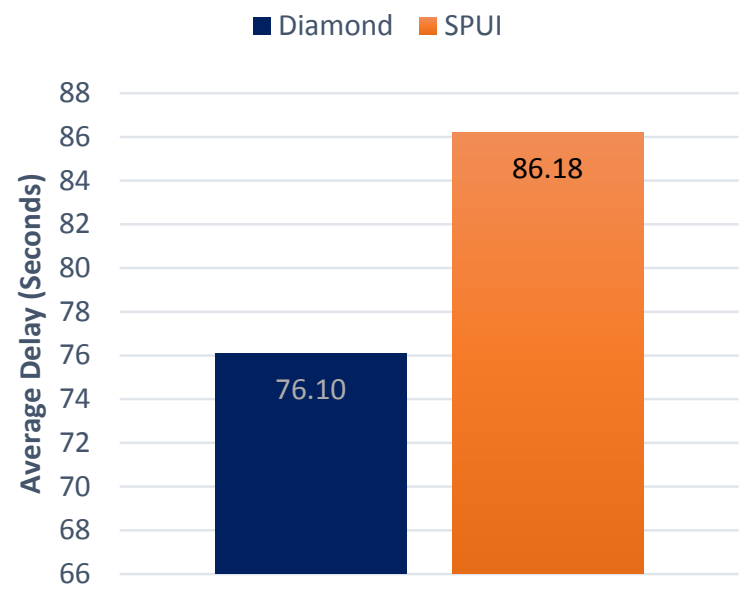

Figure 43: Average Delay for 1.4 EW Condition

\section{Average Speed for 1.4 EW \\ Condition}

- Diamond $\mathrm{SPUI}$

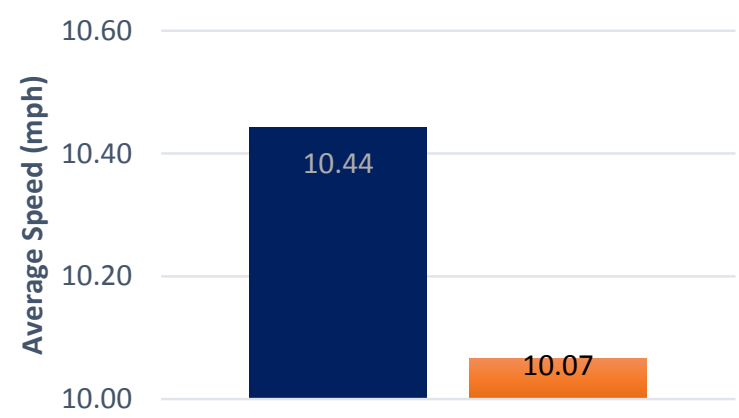

Figure 43: Average Speed for 1.4 EW Condition
Average Stop Delay for 1.4 EW

Condition

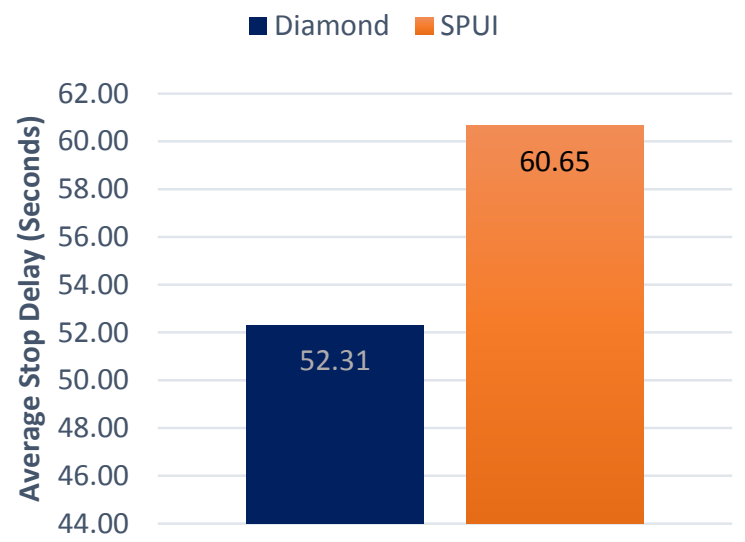

Figure 44: Average Stop Delay for 1.4 Volume Condition

Average CO and NOx Emitted for

\subsection{EW Condition}

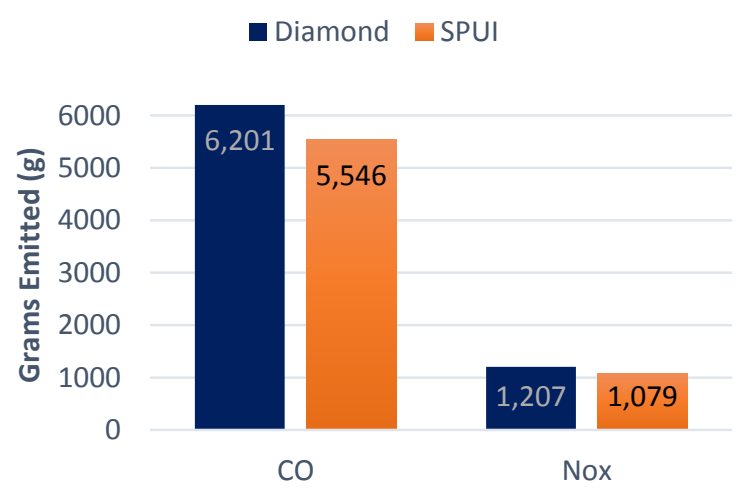

Figure 44: Average Pollution Emitted for 1.4 EW Condition

The four graphs above show us that for the $1.4 \mathrm{EW}$ condition, the TDI performs much better with regards to delay and average speed. The SPUI still performs better in pollutions emitted. It appears that the SPUI also reaches its capacity here as it did for the 1.4 Ramp Condition. We will now explore the interchange approaches to see how they will perform. The following graph shows the percent change from the existing diamond interchange for the 1.4 EW condition. A negative percent change value means that the performance has worsened with the implementation of the SPUI. 


\section{Percent Change in Interchange Performance for 1.4 EW Condition}

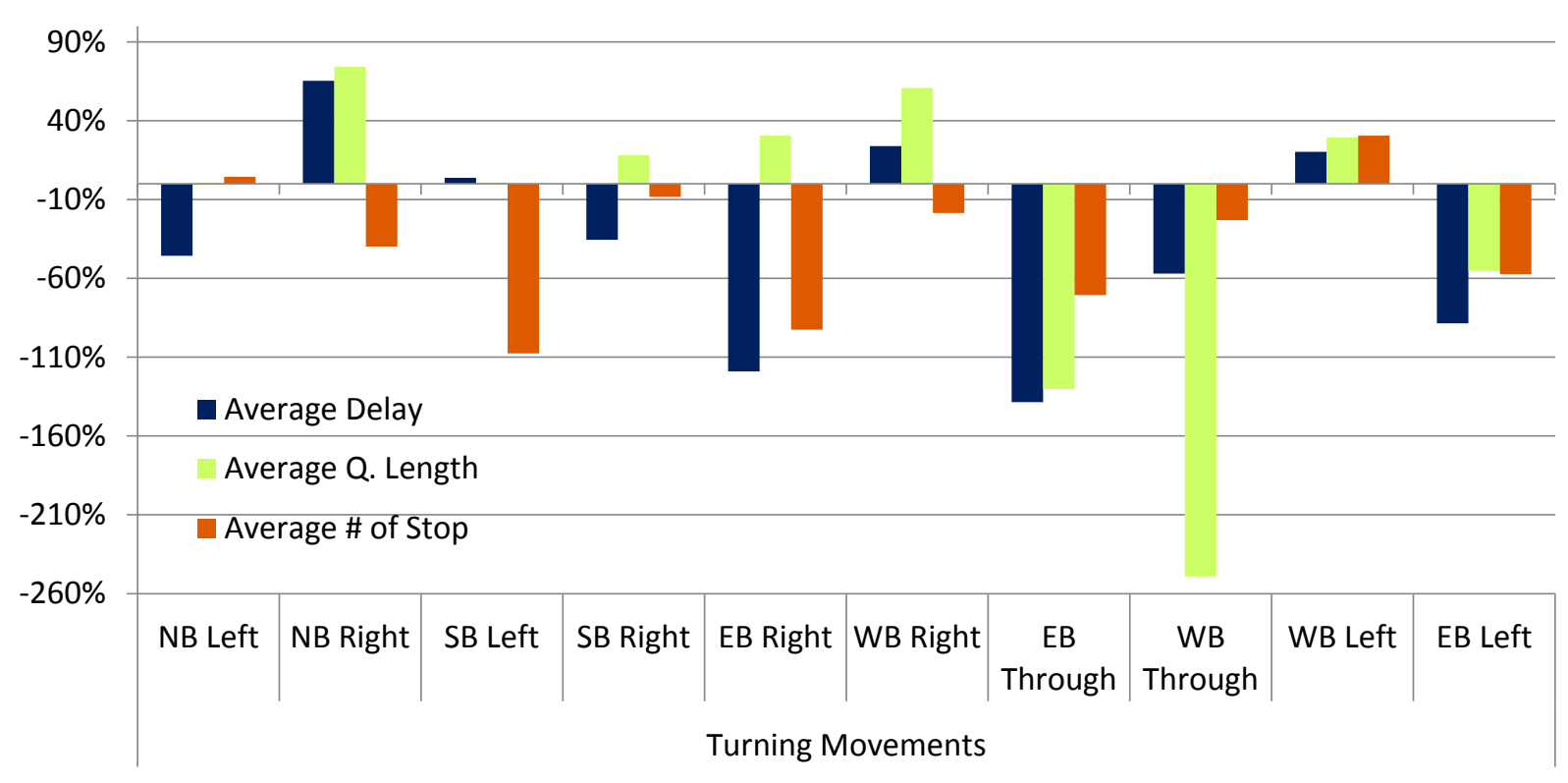

Figure 45: Percent Change in Interchange Performance from Diamond to SPUI for 1.4 EW Condition

From the percent change values we can see that the NB Right, SB Left, and WB right movements are still performing better in terms of delay than the TDI. However, we now see that the WB Left movement is doing better than the Diamond and the EB and WB through movements have improved as a percent change. Again this means that the TDI is a bit more sensitive for these movements but still performing better.

Table 10: Percent Change in Performance from Diamond to SPUI for 1.4 EW Condition

\begin{tabular}{|l|c|c|c|c|c|c|c|c|c|c|}
\hline & \multicolumn{10}{|c|}{ Turning Movements } \\
\hline & $\begin{array}{c}\text { NB } \\
\text { Left }\end{array}$ & $\begin{array}{c}\text { NB } \\
\text { Right }\end{array}$ & $\begin{array}{c}\text { SB } \\
\text { Left }\end{array}$ & $\begin{array}{c}\text { SB } \\
\text { Right }\end{array}$ & $\begin{array}{c}\text { EB } \\
\text { Right }\end{array}$ & $\begin{array}{c}\text { WB } \\
\text { Right }\end{array}$ & $\begin{array}{c}\text { EB } \\
\text { Through }\end{array}$ & $\begin{array}{c}\text { WB } \\
\text { Through }\end{array}$ & $\begin{array}{c}\text { WB } \\
\text { Left }\end{array}$ & $\begin{array}{c}\text { EB } \\
\text { Left }\end{array}$ \\
\hline Average Delay & $-46 \%$ & $65 \%$ & $4 \%$ & $-36 \%$ & $-119 \%$ & $24 \%$ & $-139 \%$ & $-57 \%$ & $20 \%$ & $-89 \%$ \\
\hline Average Q. Length & $-1 \%$ & $74 \%$ & $1 \%$ & $18 \%$ & $31 \%$ & $61 \%$ & $-130 \%$ & $-249 \%$ & $29 \%$ & $-55 \%$ \\
\hline Average \# of Stop & $4 \%$ & $-40 \%$ & $-108 \%$ & $-8 \%$ & $-92 \%$ & $-19 \%$ & $-71 \%$ & $-23 \%$ & $31 \%$ & $-57 \%$ \\
\hline
\end{tabular}




\subsection{Analysis Summary}

A great deal of information has been covered within the analysis portion of this paper. To conclude, a few charts and tables are created in this section. Table 11 looks at the entire network and identifies which interchanges are the best performers. Blue Represents the TDI and orange represent the SPUI.

Table 11: Best performing interchange as an entire network given the specific volume condition

\begin{tabular}{|c|c|c|c|c|c|}
\hline \multicolumn{6}{|c|}{ Best Performing Interchange with Respect to their Volume Conditions } \\
\hline & Average Delay & $\begin{array}{c}\text { Average Stop } \\
\text { Delay }\end{array}$ & Average Speed & CO Emissions & NOx Emissions \\
\hline 0.75 Ramp & Diamond & Diamond & SPUI & SPUI & SPUI \\
\hline Existing & SPUI & SPUI & SPUI & SPUI & SPUI \\
\hline 1.25 Ramp & Diamond & Diamond & SPUI & SPUI & SPUI \\
\hline 1.4 Ramp & Diamond & Diamond & Diamond & Diamond & Diamond \\
\hline $0.75 \mathrm{EW}$ & SPUI & SPUI & SPUI & SPUI & SPUI \\
\hline $1.25 \mathrm{EW}$ & Diamond & Diamond & SPUI & SPUI & SPUI \\
\hline $1.4 \mathrm{EW}$ & Diamond & Diamond & Diamond & Diamond & SPUI \\
\hline
\end{tabular}

If we purely look at the traffic operations stance of point (Excluding Emissions), we can see that the TDI is performing better in most conditions. The SPUI does do a good job of allowing higher speeds, but it does not improve delay or level of service. Even for the conditions that the SPUI did perform better, it only did so by a small amount.

\section{Average Vehicle Delay Summary:}

Seven different volume conditions were looked at for the analysis of the two interchanges. These analyses can be seen in one graph to see how the interchanges react as the volume conditions increase. 
These analyses can be seen for the average vehicle delay in Figures 46 and 47 . Each graphic is split to the Ramp volume conditions and EW volume conditions. Figure 46 shows the average vehicle delay in bar chart format and Figure 47 will show it as line graph format.

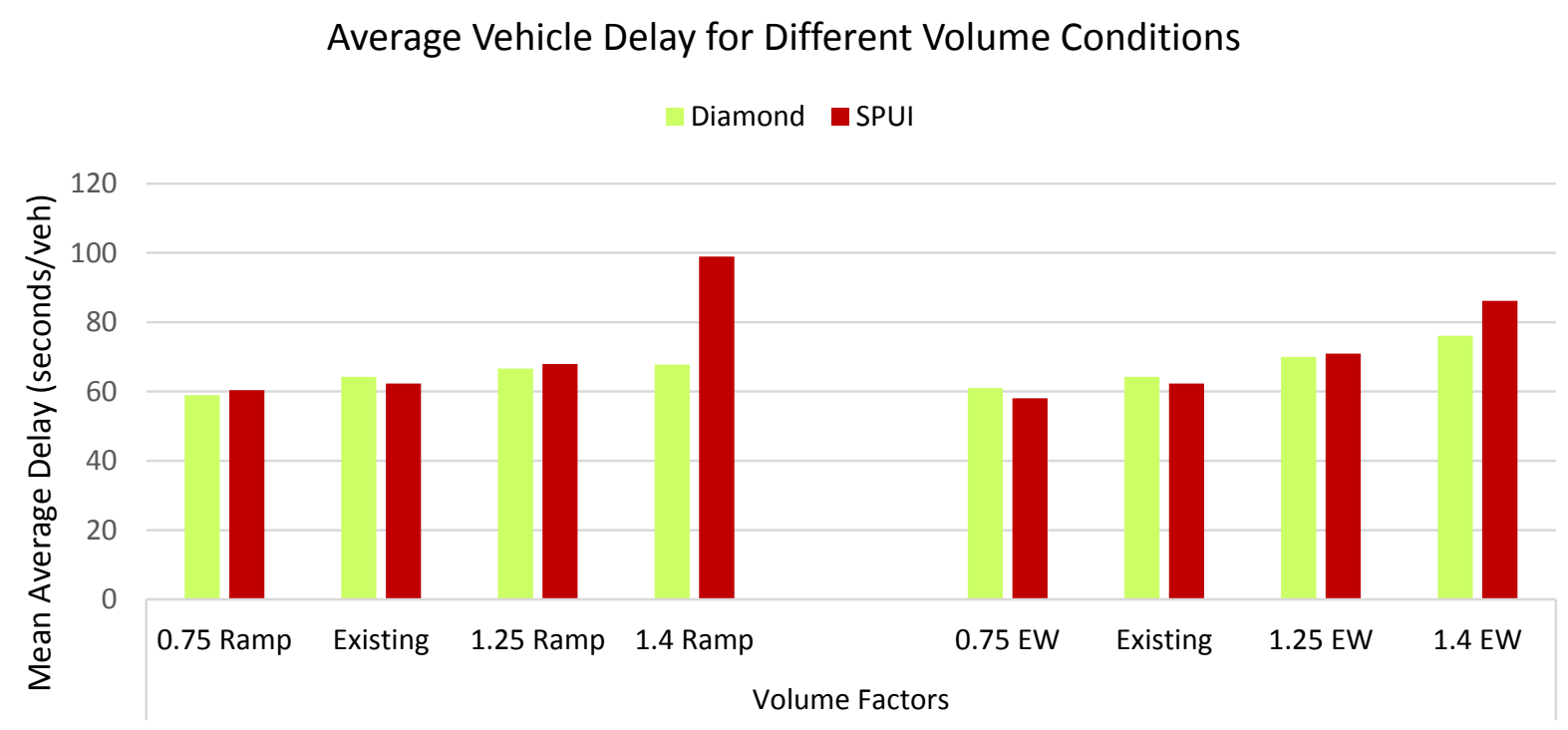

Figure 46: Average vehicle delay for different volume conditions shown as a bar graph

Average Vehicle Delay as Volume Increases

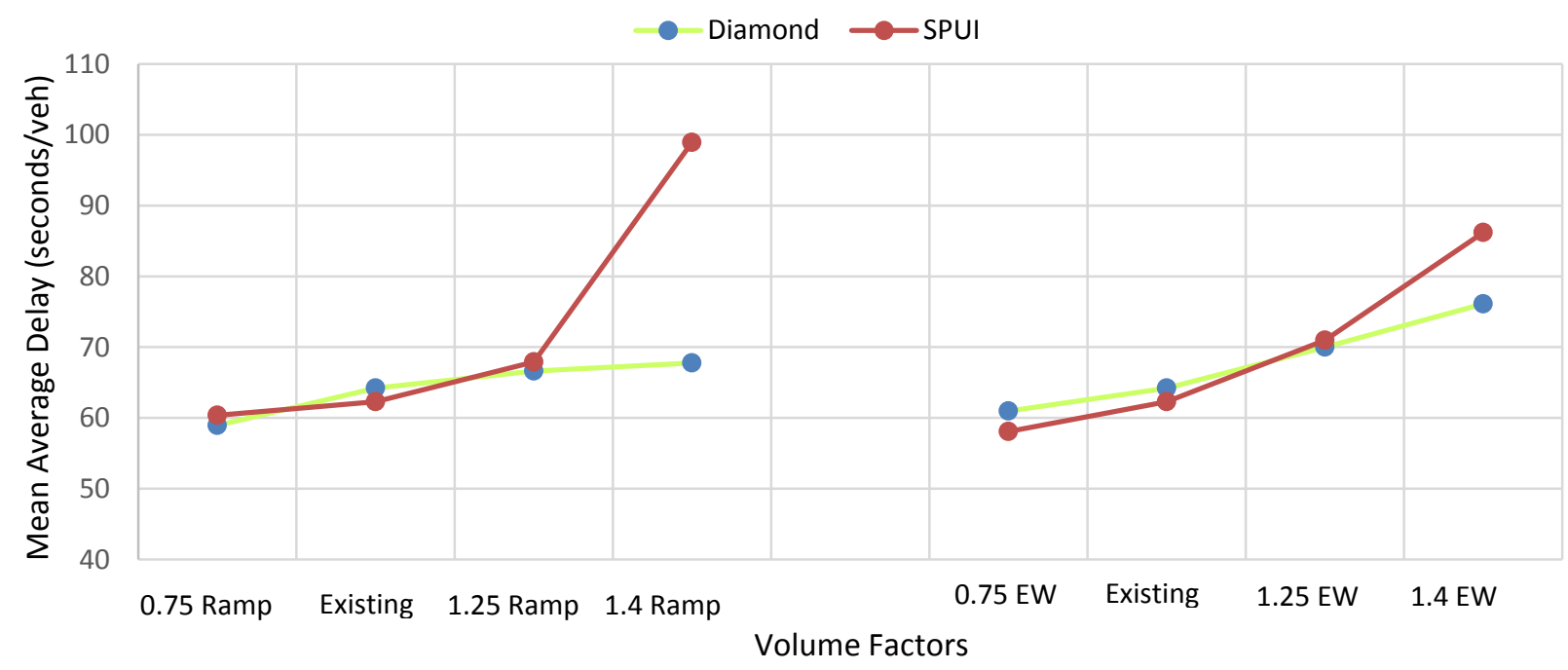

Figure 47: Average vehicle delay for different volume conditions shown as a line graph 
From the two graphs above we can see that in both the EW and Ramp conditions, the SPUI does a good job of keeping up with the TDI up to the point we increase the volumes by $25 \%$. However, when we increase the volumes by 40 percent, the SPUI performs especially poorly and is no longer feasible. Figure 47 does a good job showing the sensitivity of the SPUI compared to the TDI. Where the two lines diverge is where the SPUI fails. The divergence of the EW condition is less severe than the one of the Ramp. The sensitivity of the interchanges can be seen more clearly in Figure 47 . This figure shows the percent change in average vehicle delay from the interchange's existing condition.

\section{Average Vehicle Delay Percent Change from Existing Interchange Condition to new Volume Condition}

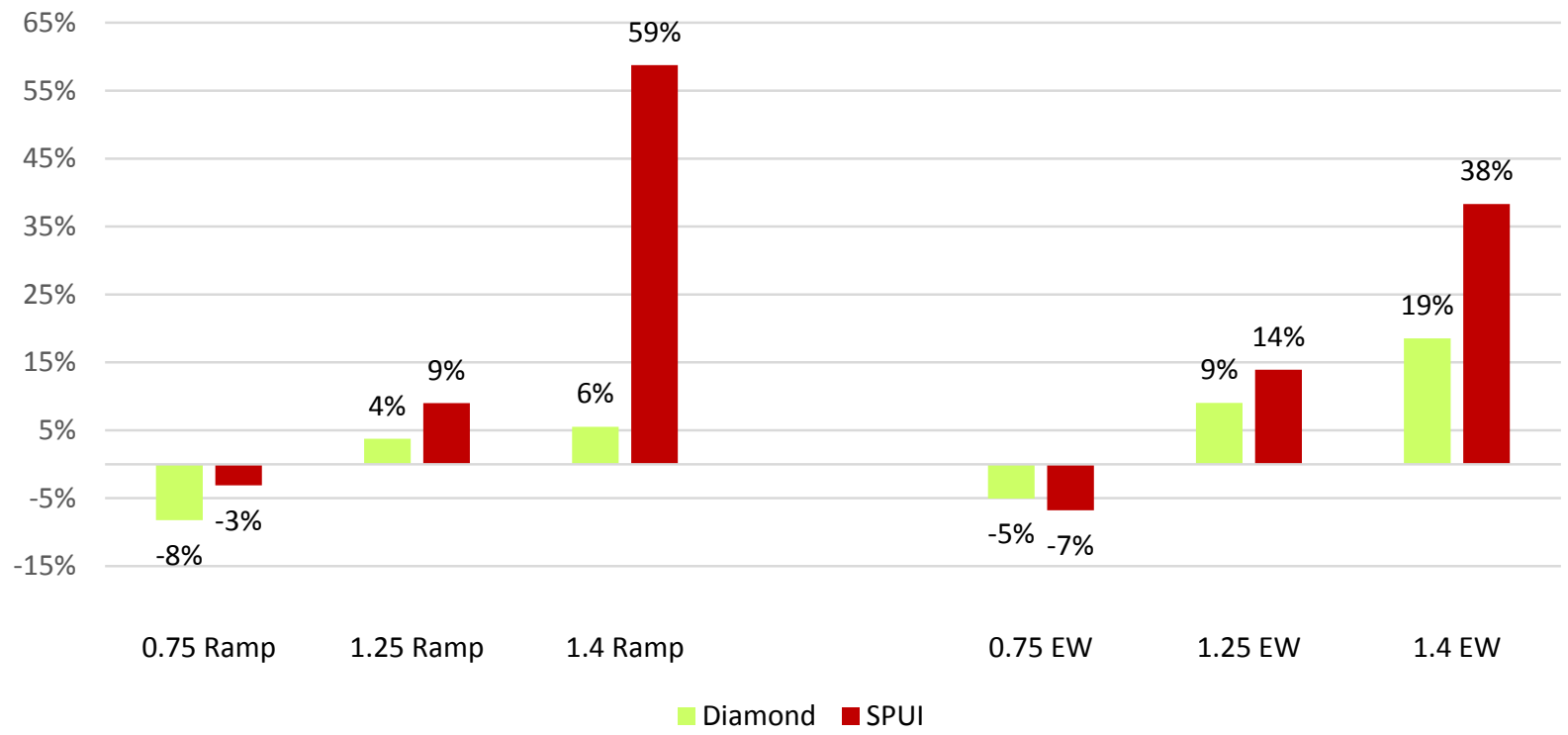

Figure 48: Percent change in average vehicle delay from the interchange's existing condition

From Figure 48 we can see that the percent changes for the SPUI are quite small for the first two Ramp conditions, but it dramatically increases when we increase the volume by 40 percent. The TDI stays at a nice steady pace. The percent changes for the SPUI and TDI are a bit higher for the first two EW conditions compared to the Ramp condition. The percent change still shoots up when we increase the 
EW volume by $40 \%$. So to conclude, the SPUI reacts dramatically when the EW volume conditions are raised by $40 \%$, but not as dramatically as when we increase the Ramp volumes by $40 \%$.

\section{Average Vehicle Stop Delay Summary:}

We will perform the same analysis of the 7 volume conditions for the average vehicle stop delay. Again, Figure 49 shows the average vehicle delay for all volume conditions in bar chart format and Figure 50 will show it as line graph format.

\section{Average Vehicle Stop Delay for Different Volume Conditions}

Diamond $\square$ SPUI

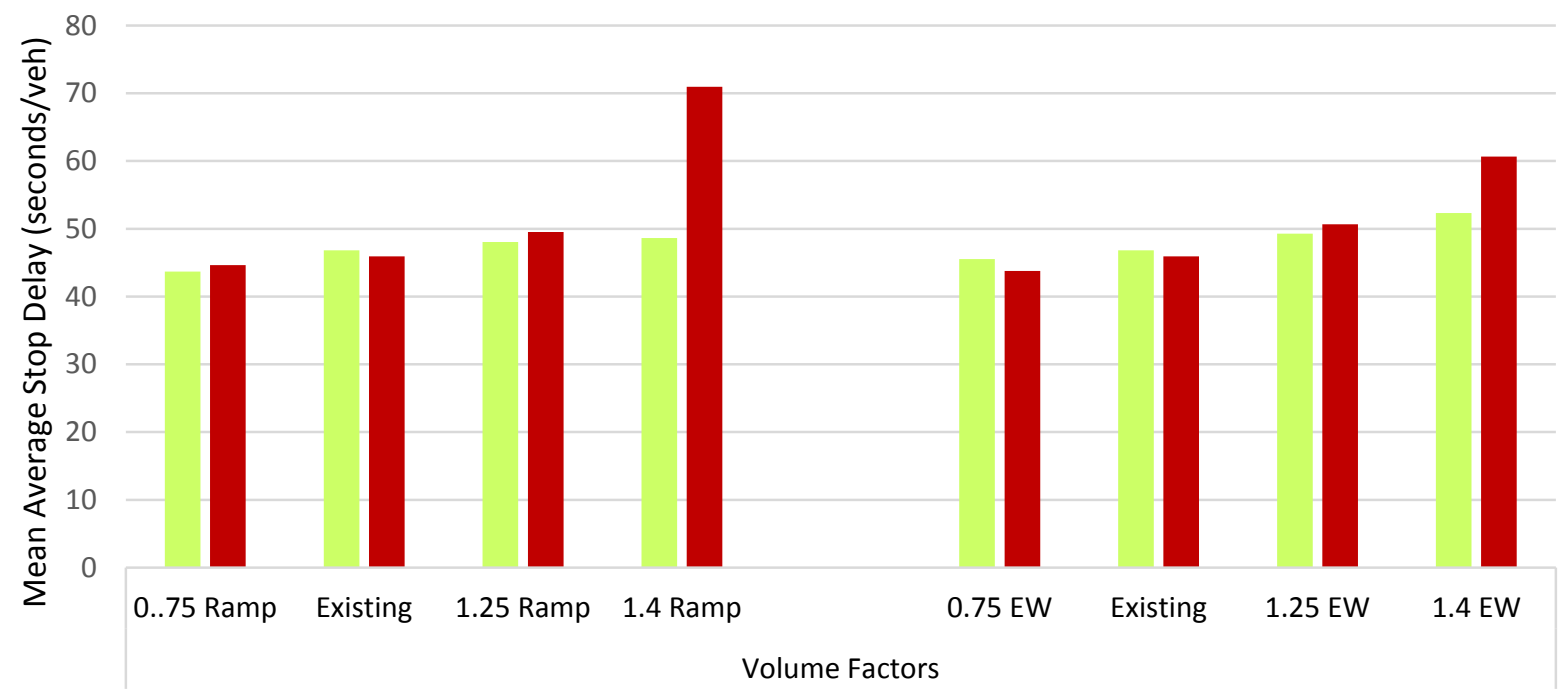

Figure 49: Average vehicle stop delay for different volume conditions shown as a bar graph 


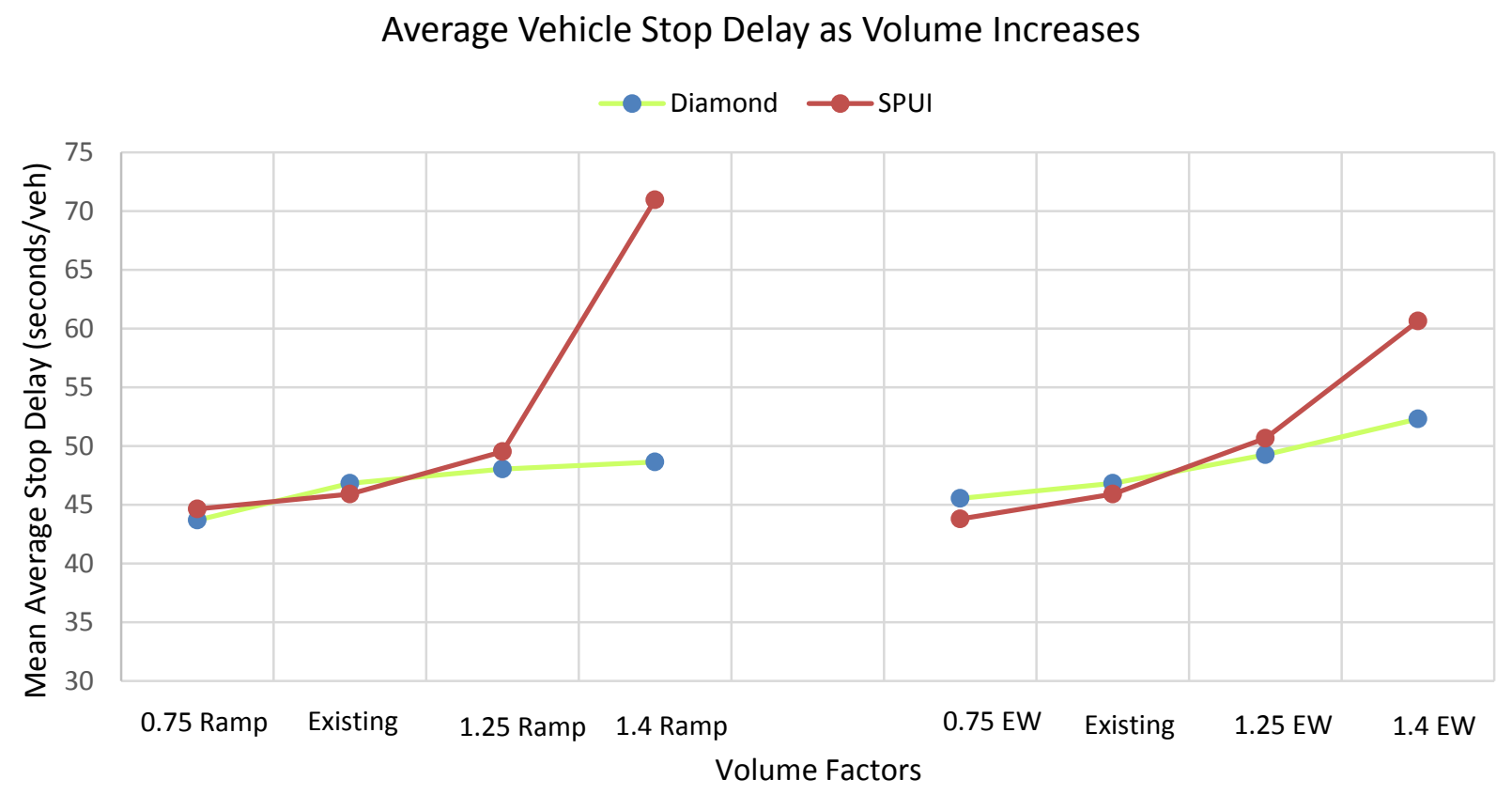

Figure 50: Average vehicle stop delay for different volume conditions shown as a line graph

As mentioned before, this performance measure would give us the average time stopped per active and arrived vehicles. The mean average stop delay gives us lower values than the average vehicle delay, but as we can see from the line graphs, the trends are the same. Again, we can see the divergence in performance between the two interchanges when we increase the volume by $40 \%$. The sensitivity of the interchanges can be seen more clearly in Figure 51. This figure shows the percent change in average vehicle stop delay from the interchange's existing condition. 
Average Stop Delay Percent Change from Existing Interchange Condition to new Volume Condition

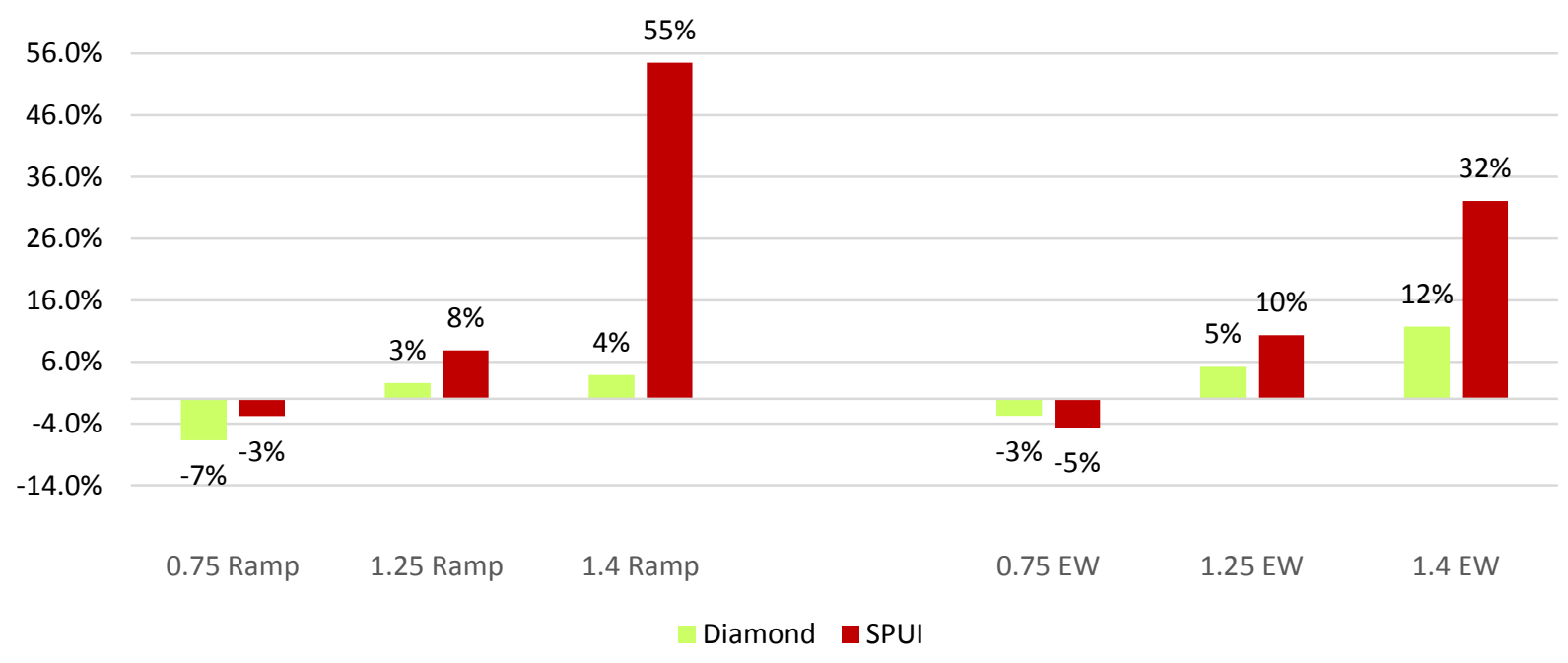

Figure 51: Percent change in average vehicle stop delay from the interchange's existing condition

Again from Figure 51, we can see the same trends as the percent change for the average delay. We can see that the SPUI is much more sensitive for the 1.4 Ramp and 1.4 EW condition than the TDI.

\section{Average Speed Summary:}

We will now perform the same analysis of the 7 volume conditions for the average vehicle speed. Again, Figure 52 shows the average vehicle delay for all volume conditions in bar chart format and Figure 53 will show it as a line graph format. 
Average Vehicle Speed for Different Volume Conditions

Diamond $\quad$ SPUI

14

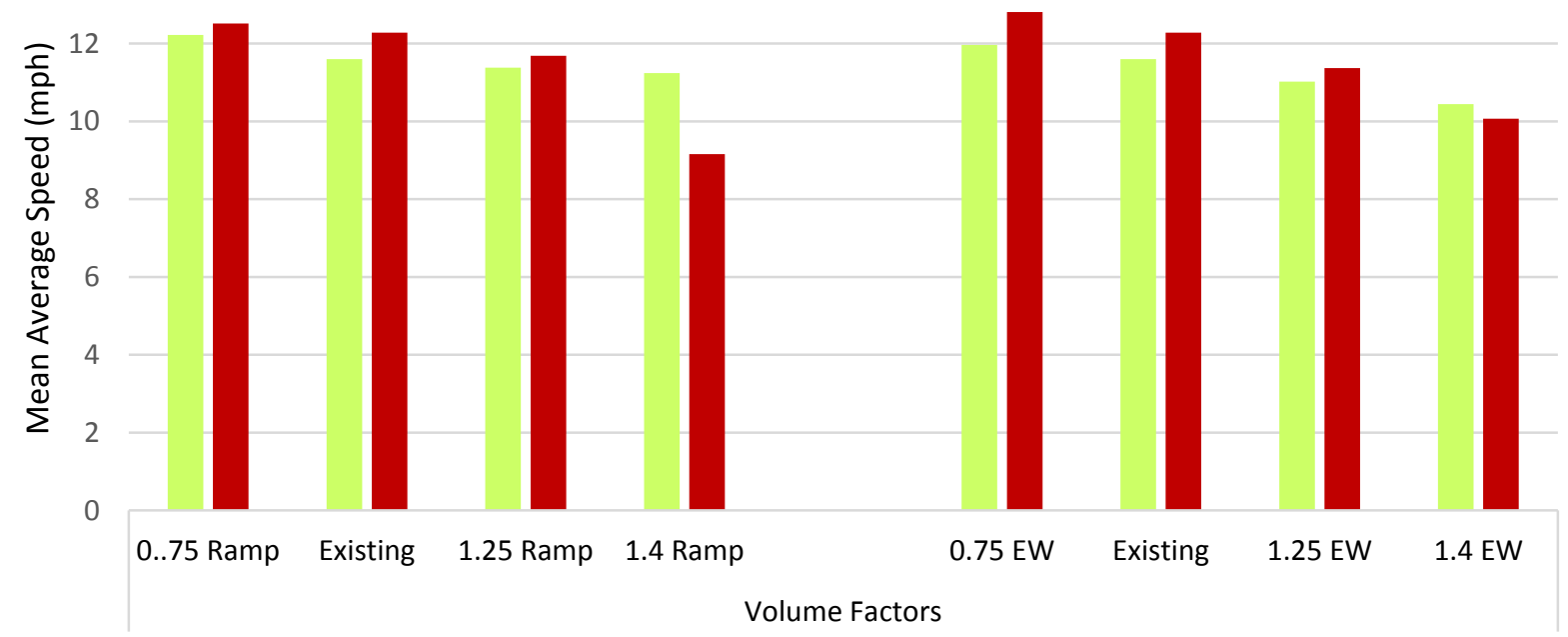

Figure 52: Average vehicle speed for different volume conditions shown as a bar graph

Average Vehicle Speed as Volume Increases

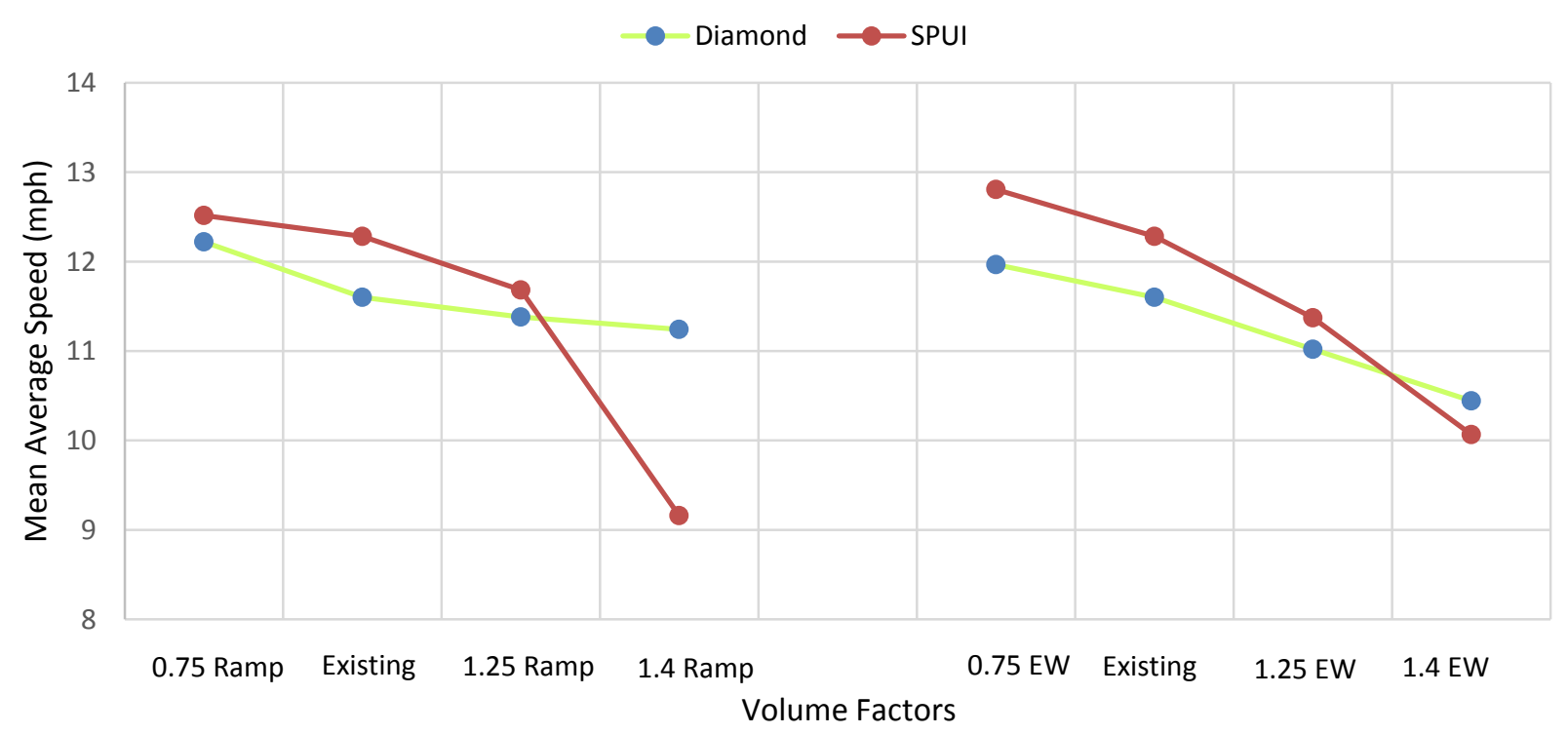

Figure 53: Average vehicle speed for different volume conditions shown as a line graph 
From the graph above we can see that the average vehicle speed decreases as the volume conditions increase. It can also be said that as the average vehicle delay increases the average vehicle speed decreases. This makes sense since when the average delay goes up it means that vehicles are taking longer than when there is free flow and therefore congestion is starting to form. Once congestion is formed, the average speed per vehicle will decrease. Again we know from our fundamental diagram of flow traffic that if the average speeds of vehicles are low, we can suspect congestion, high density, or additional delays. At high speeds the vehicles will be traveling at their desired speed or free-flow speed (17). We can see from the line graph that the average vehicle speed of the Diamond and SPUI cross each other right after we increase the volume conditions by $25 \%$. Therefore once again, the SPUI is more sensitive to volume change than the TDI when it comes to speed. The sensitivity of the interchanges can be seen more clearly in Figure 54. This figure shows the percent change in average vehicle speed from the interchange's existing condition.

\section{Average Speed Percent Change from Existing Interchange Condition to new Volume Condition}

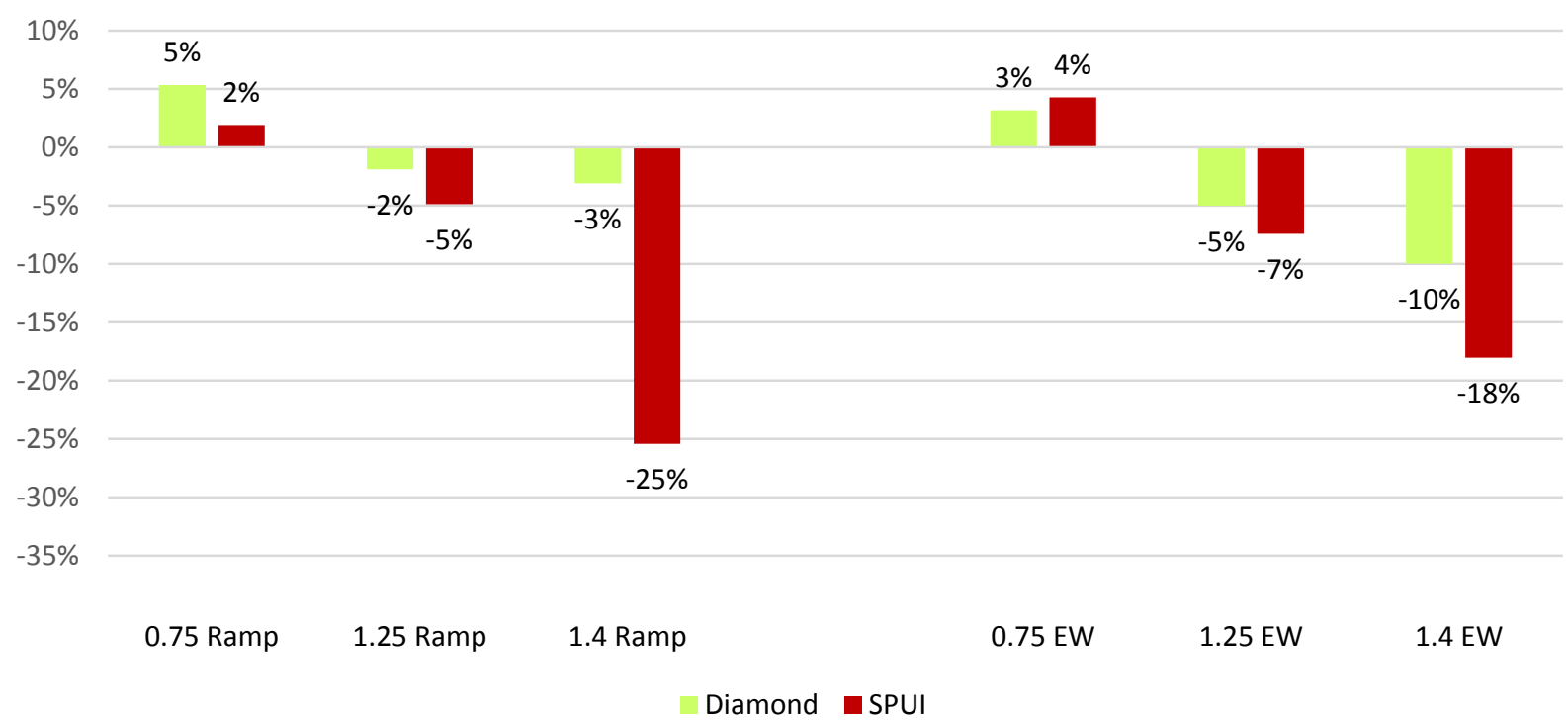

Figure 54: Percent change in average vehicle speed from the interchange's existing condition 
Again we can see that the SPUI is only less sensitive than the Diamond interchange for only the 0.75 Ramp condition. For all the other conditions the SPUI is more sensitive to volume change, especially when we increase the volumes by $40 \%$.

Average CO and NOx Emitted:

We will now perform the same analysis of the 7 volume conditions for the average $\mathrm{CO}$ and NOx emitted into the network. Again, Figure 55 shows the average $\mathrm{CO}$ and NOx emitted for all volume conditions in bar chart format and Figure 56 will show it as line graph format.

Average CO and NOx Emitted for Different Volume Conditions

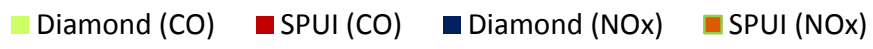

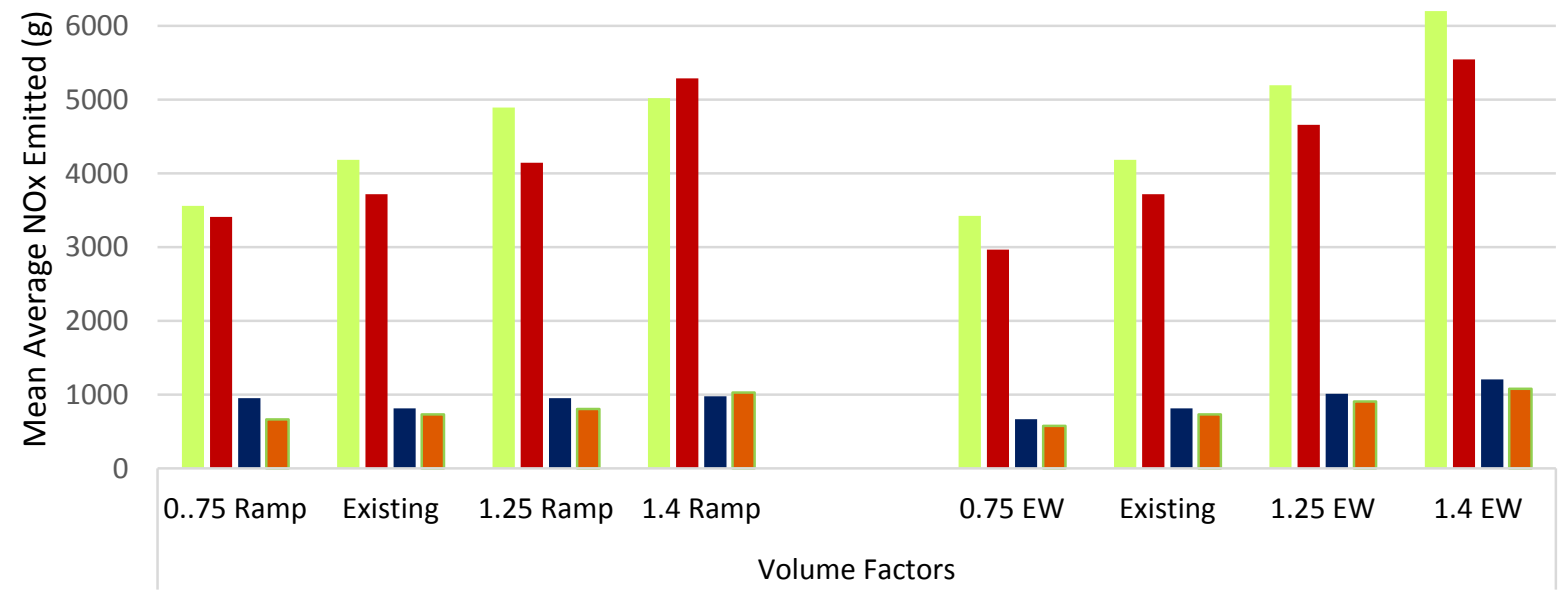

Figure 55: Average NOx and CO emitted for different volume conditions shown as a bar graph 


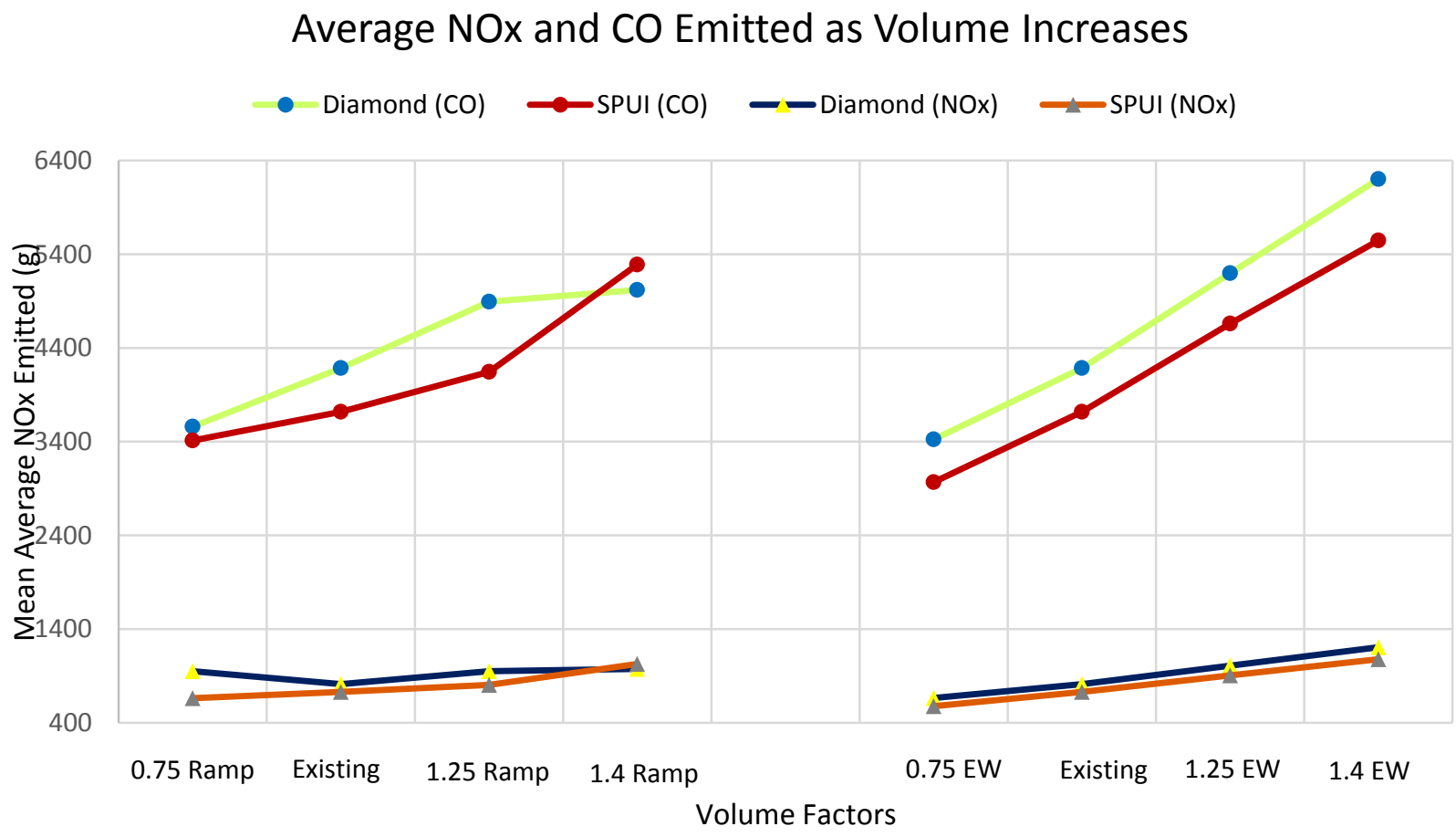

Figure 56: Average $\mathrm{CO}$ and NOx emitted for different volume conditions shown as a line graph

Form Figure 56 we can see that for the EW condition both CO and NOx emission are increasing linearly as the volume increases. The sensitivity for both the Diamond and SPUI are the same and that is why they have that offset. Therefore, the SPUI performs just a bit better with regards to NOx and CO for EW volume conditions. For the ramp conditions, the SPUI performs increasingly better with regards to CO up until it reaches the 1.25 Ramp condition. After that major congestion occurs and the Diamond interchange begins to emit fewer grams of CO. The Diamond interchange also starts to emit fewer grams of NOx when it reaches the 1.4 Ramp conditions.

\section{Statistics of the Performance Measures}

All the performance measures that has been discussed can be seen numerically in Tables 12-14. Along with the mean, the tables show the standard deviation, minimum, maximum, and median values. 
Table 12: Statistical values for average vehicle delay for all volume conditions

\begin{tabular}{|c|c|c|c|c|c|c|c|c|c|c|}
\hline \multirow{3}{*}{$\begin{array}{l}\text { Volume } \\
\text { Factors }\end{array}$} & \multicolumn{10}{|c|}{ Statistics for Vehicle Delay } \\
\hline & \multicolumn{2}{|c|}{ Mean } & \multicolumn{2}{|c|}{ STDEV } & \multicolumn{2}{|c|}{ Minimum } & \multicolumn{2}{|c|}{ Maximum } & \multicolumn{2}{|c|}{ Median } \\
\hline & Diamond & SPUI & Diamond & SPUI & Diamond & SPUI & Diamond & SPUI & Diamond & SPUI \\
\hline 0.75 Ramp & 58.93 & 60.37 & 0.51 & 0.78 & 58.41 & 59.24 & 59.52 & 60.98 & 58.89 & 60.64 \\
\hline Existing & 64.21 & 62.30 & 0.91 & 0.70 & 63.26 & 61.14 & 65.21 & 63.32 & 63.96 & 62.27 \\
\hline 1.25 Ramp & 66.63 & 67.91 & 0.47 & 2.83 & 66.32 & 63.36 & 67.16 & 70.94 & 66.40 & 68.52 \\
\hline 1.4 Ramp & 67.76 & 98.91 & 0.58 & 3.08 & 66.99 & 97.13 & 68.36 & 102.46 & 67.84 & 97.14 \\
\hline $0.75 \mathrm{EW}$ & 60.98 & 58.07 & 0.42 & 1.21 & 60.64 & 56.87 & 61.59 & 59.48 & 60.83 & 57.38 \\
\hline Existing & 64.21 & 62.30 & 0.91 & 0.70 & 63.26 & 61.14 & 65.21 & 63.32 & 63.96 & 62.27 \\
\hline $1.25 \mathrm{EW}$ & 70.00 & 70.97 & 0.94 & 2.29 & 68.65 & 68.57 & 70.66 & 73.30 & 70.65 & 71.50 \\
\hline 1.4 EW & 76.10 & 86.18 & 1.09 & 8.02 & 75.22 & 77.32 & 77.49 & 92.96 & 75.59 & 88.26 \\
\hline
\end{tabular}

Table 13: Statistical values for average vehicle stop delay for all volume conditions

\begin{tabular}{|c|c|c|c|c|c|c|c|c|c|c|}
\hline \multirow{3}{*}{$\begin{array}{l}\text { Volume } \\
\text { Factors }\end{array}$} & \multicolumn{10}{|c|}{ Statistics for Vehicle Stop Delay } \\
\hline & \multicolumn{2}{|c|}{ Mean } & \multicolumn{2}{|c|}{ STDEV } & \multicolumn{2}{|c|}{ Minimum } & \multicolumn{2}{|c|}{ Maximum } & \multicolumn{2}{|c|}{ Median } \\
\hline & Diamond & SPUI & Diamond & SPUI & Diamond & SPUI & Diamond & SPUI & Diamond & SPUI \\
\hline 0.75 Ramp & 43.69 & 44.64 & 0.63 & 0.62 & 42.84 & 43.92 & 44.17 & 45.44 & 43.69 & 44.60 \\
\hline Existing & 46.82 & 45.92 & 0.64 & 0.60 & 45.99 & 44.96 & 47.48 & 46.86 & 46.86 & 45.93 \\
\hline 1.25 Ramp & 48.04 & 49.53 & 0.38 & 2.11 & 47.69 & 46.06 & 48.44 & 51.62 & 47.98 & 50.24 \\
\hline 1.4 Ramp & 48.64 & 70.95 & 0.55 & 2.31 & 47.91 & 69.62 & 49.12 & 73.62 & 48.78 & 71.01 \\
\hline $0.75 \mathrm{EW}$ & 45.53 & 43.79 & 0.41 & 0.89 & 40.10 & 42.85 & 40.10 & 44.91 & 45.43 & 43.38 \\
\hline Existing & 46.82 & 45.92 & 0.64 & 0.60 & 45.99 & 44.96 & 47.48 & 46.86 & 46.86 & 45.93 \\
\hline 1.25 EW & 49.27 & 50.66 & 0.48 & 1.61 & 48.68 & 48.94 & 49.80 & 52.25 & 49.29 & 51.22 \\
\hline $1.4 \mathrm{EW}$ & 52.31 & 60.65 & 0.53 & 5.41 & 51.74 & 54.68 & 52.93 & 65.22 & 52.27 & 54.68 \\
\hline
\end{tabular}


Table 14: Statistical values for average vehicle speed for all volume conditions

\begin{tabular}{|c|c|c|c|c|c|c|c|c|c|c|}
\hline \multirow{3}{*}{$\begin{array}{c}\text { Volume } \\
\text { Factors }\end{array}$} & \multicolumn{10}{|c|}{ Statistics for Vehicle Speed } \\
\hline & \multicolumn{2}{|c|}{ Mean } & \multicolumn{2}{|c|}{ STDEV } & \multicolumn{2}{|c|}{ Minimum } & \multicolumn{2}{|c|}{ Maximum } & \multicolumn{2}{|c|}{ Median } \\
\hline & Diamond & SPUI & Diamond & SPUI & Diamond & SPUI & Diamond & SPUI & Diamond & SPUI \\
\hline 0.75 Ramp & 12.22 & 12.52 & 0.06 & 0.09 & 12.16 & 12.41 & 12.30 & 12.63 & 12.21 & 12.51 \\
\hline Existing & 11.60 & 12.28 & 0.08 & 0.09 & 11.52 & 12.14 & 11.70 & 12.39 & 11.60 & 12.28 \\
\hline 1.25 Ramp & 11.38 & 11.68 & 0.08 & 0.29 & 11.29 & 11.40 & 11.46 & 12.15 & 11.39 & 11.65 \\
\hline 1.4 Ramp & 11.24 & 9.16 & 0.08 & 0.21 & 11.16 & 8.92 & 11.31 & 9.28 & 11.25 & 9.21 \\
\hline $0.15 \mathrm{LVV}$ & 11.97 & 12.81 & 0.05 & 0.12 & 11.89 & 12.64 & 12.01 & 12.92 & 11.98 & 12.85 \\
\hline Existing & 11.60 & 12.28 & 0.08 & 0.09 & 11.52 & 12.14 & 11.70 & 12.39 & 11.60 & 12.28 \\
\hline $1.25 \mathrm{EW}$ & 11.02 & 11.37 & 0.09 & 0.25 & 10.94 & 11.13 & 11.15 & 11.64 & 10.99 & 11.27 \\
\hline $1.4 \mathrm{EW}$ & 10.44 & 10.07 & 0.10 & 0.61 & 10.32 & 9.54 & 10.52 & 10.74 & 10.48 & 9.91 \\
\hline
\end{tabular}

\subsection{Alternative Analysis}

From our analysis and results it was concluded that a SPUI is not the best choice of interchange for this specific location. However, this current interchange does experience high delays and congestions. What other alternatives can be looked at? One type of interchange that is neglected within the United States is the double roundabout interchange. These interchanges are utilized heavily in European countries. Therefore, it was decided to run this analysis and see how it would perform. The final design of the double round about interchange is shown in Figure 56. 


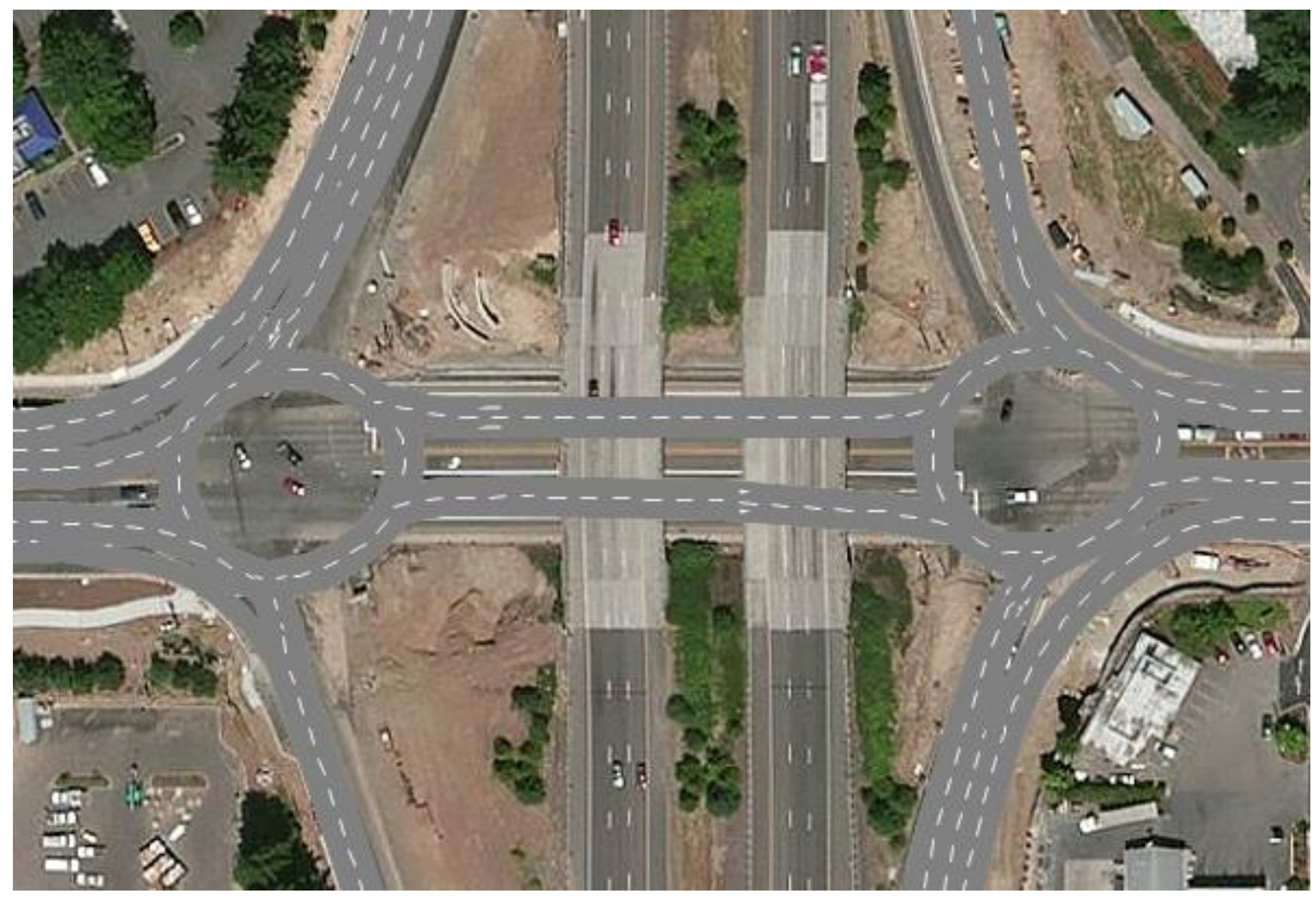

Figure 57: Double Roundabout interchange design for the Wilsonville interchange.

This interchange has a diameter of approximate 140 feet and consists of two lanes. It has a designated right turn coming off the freeway ramp and for going to the freeway. This design would actually reduce the number of lanes needed at the approaches and the segment between the two intersections of the interchange. The extra space can be used as medians, aesthetics, or bigger sidewalks. However, the roundabout might not be as friendly to the bicyclists and pedestrians.

We will once again perform the same analysis for the 7 different volume conditions for average vehicle delay, average vehicle stop delay, and average speed.

\section{Average Vehicle Delay:}


We will first perform the analysis for the average vehicle delay. Again, Figure 58 shows the average vehicle delay for all volume conditions in bar chart format and Figure 59 will show it as line graph format.

\section{Average Vehicle Delay for Different Volume Conditions}

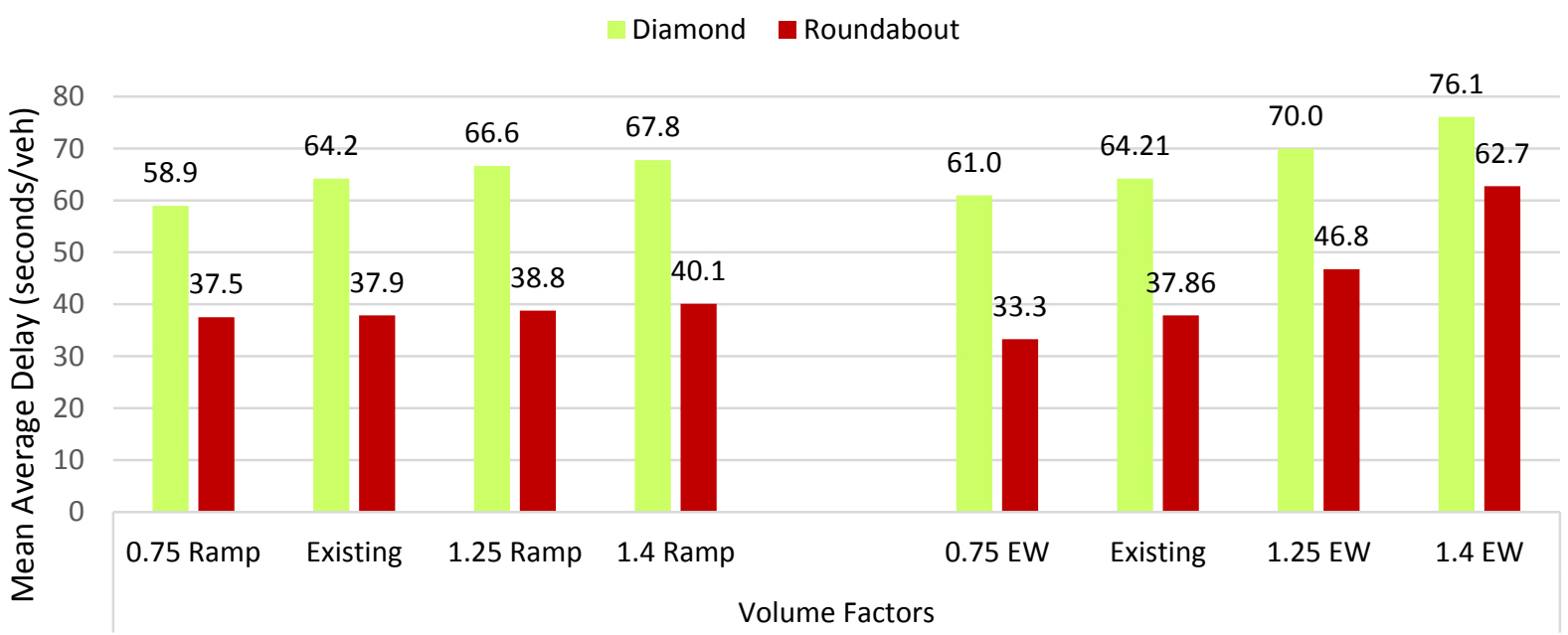

Figure 58: Average vehicle delay for different volume conditions shown as a bar graph

Average Vehicle Delay as Volume Increases

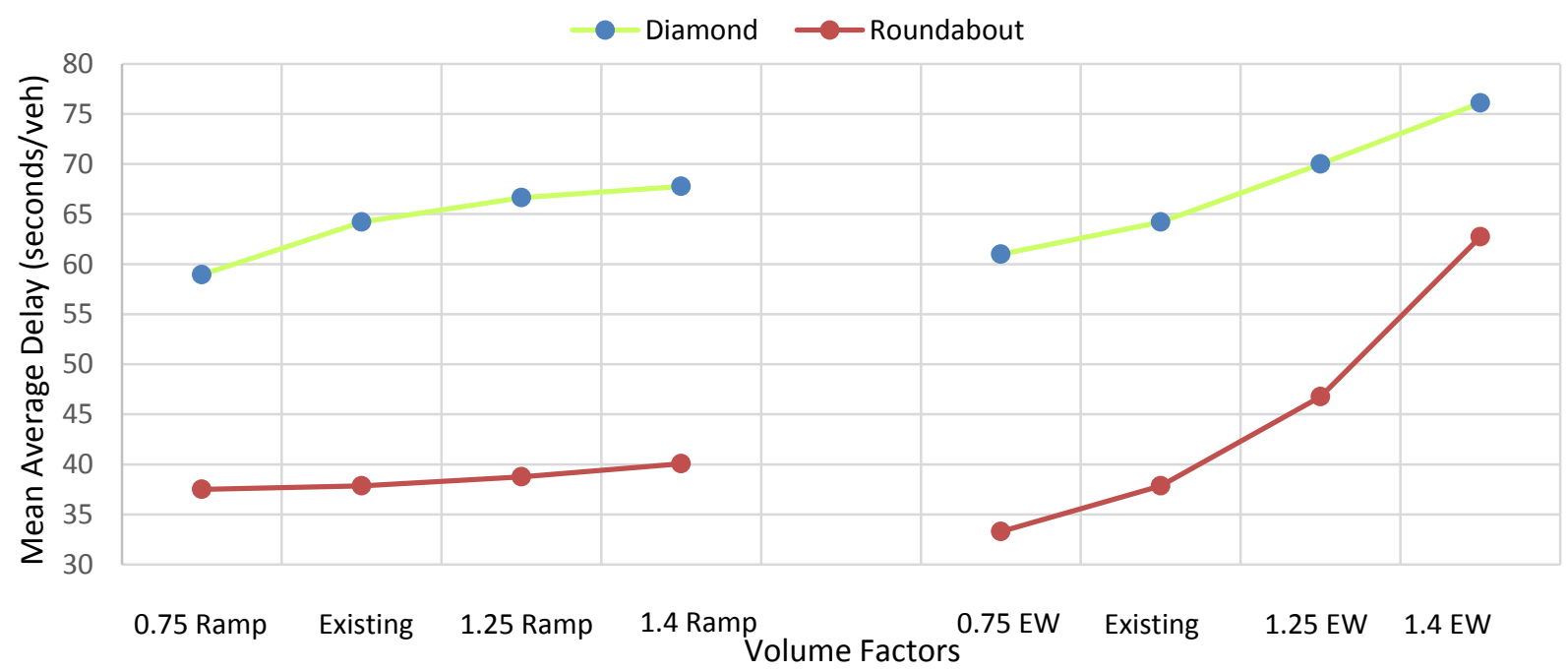

Figure 59: Average vehicle delay for different volume conditions shown as a line graph 
It is clear from Figure 58 and 59 that the double roundabout interchange is performing much better. It can be seen from Figure 58 that the roundabout is not very sensitive to ramp volume change. This might be due to the dedicated right turn movement. However, the roundabout is much more sensitive than the TDI for the EW volume conditions. The sensitivity of the interchanges can be seen more clearly in Figure 60. This figure shows the percent change in average vehicle delay from the interchange's existing condition. The higher percent change values can be seen for the EW volume conditions.

\section{Average Vehicle Delay Percent Change from Existing Interchange Condition to new Volume Condition}

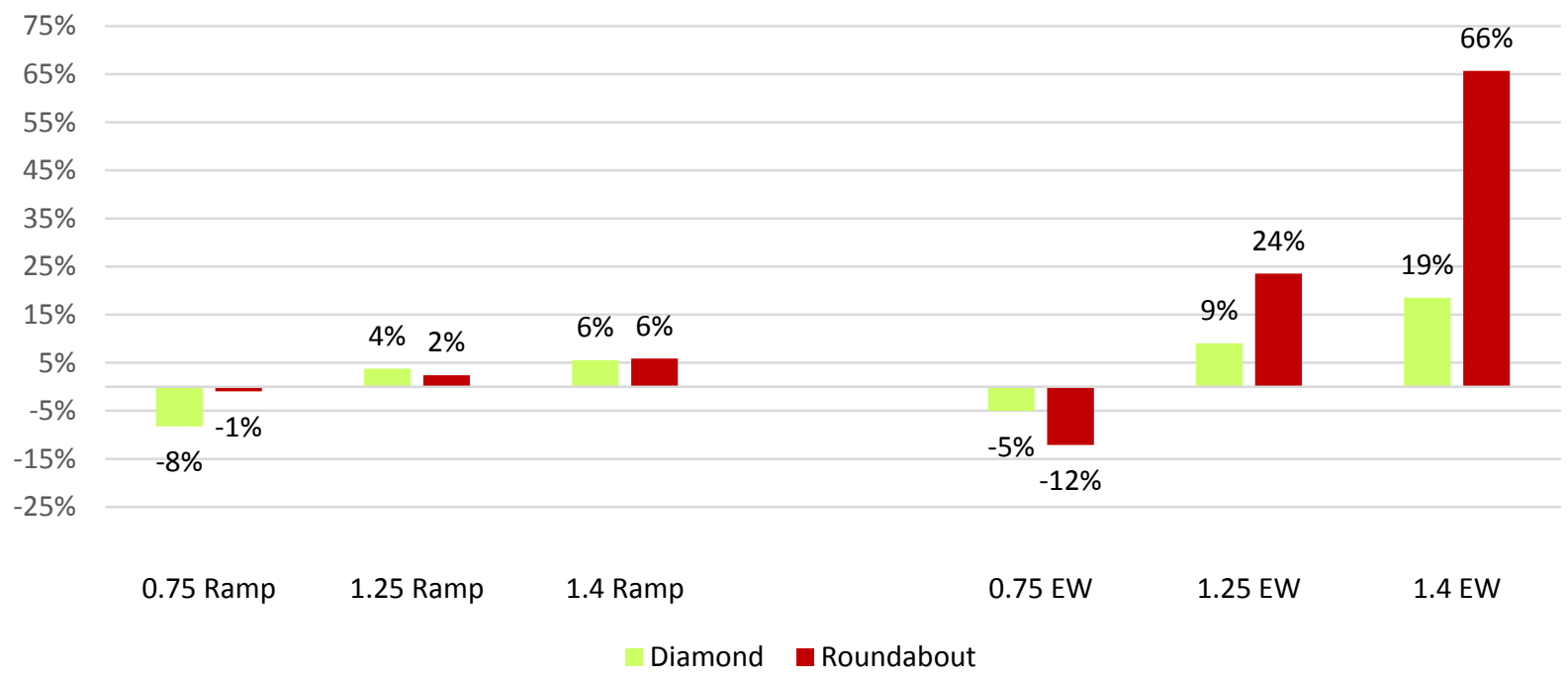

Figure 60: Percent change in average vehicle delay from the interchange's existing condition

\section{Average Vehicle Stop Delay:}

We will next perform the analysis for the average vehicle stop delay. Again, Figure 61 shows the average vehicle stop delay for all volume conditions in bar chart format and Figure 62 will show it as line graph format. 


\section{Average Vehicle Stop Delay for Different Volume Conditions}

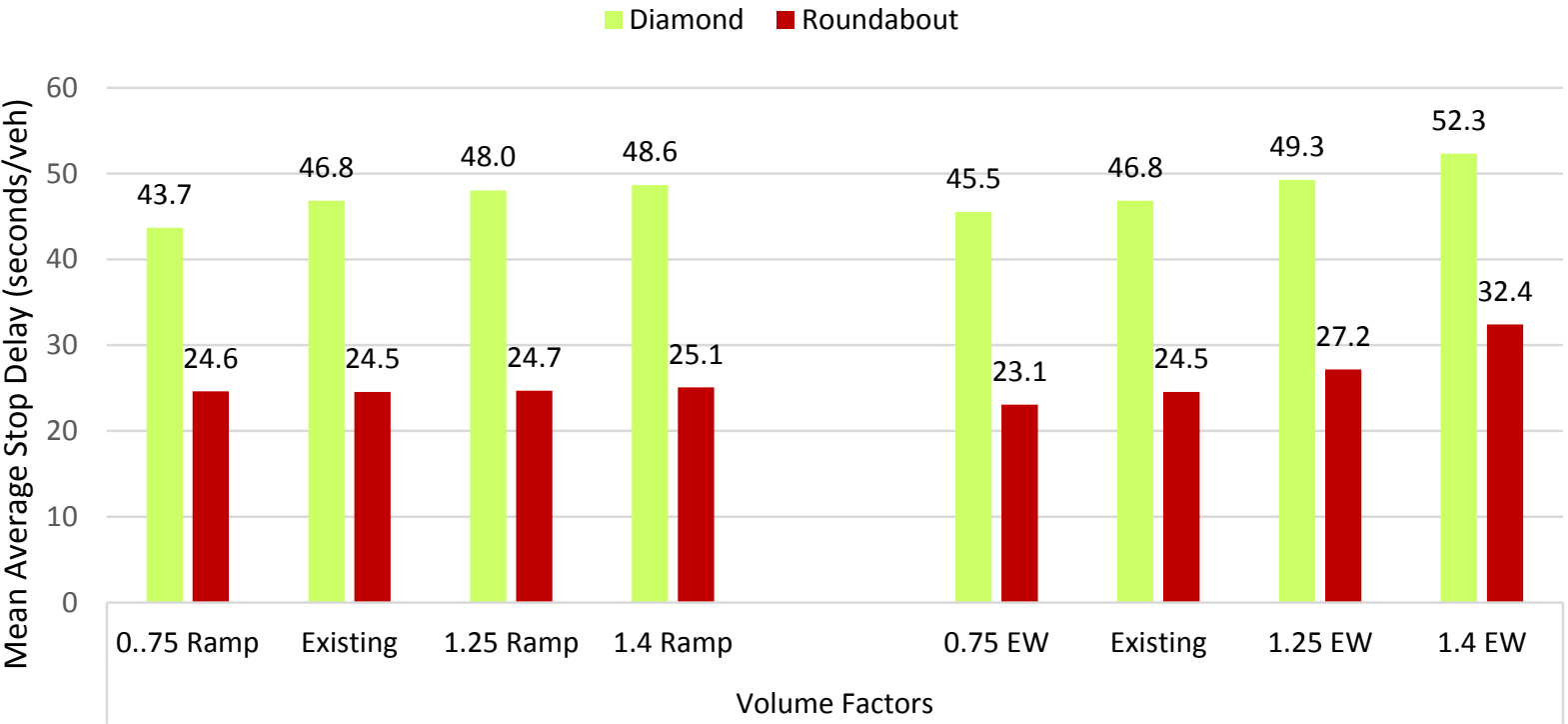

Figure 61: Average vehicle stop delay for different volume conditions shown as a bar graph

Average Vehicle Stop Delay as Volume Increases

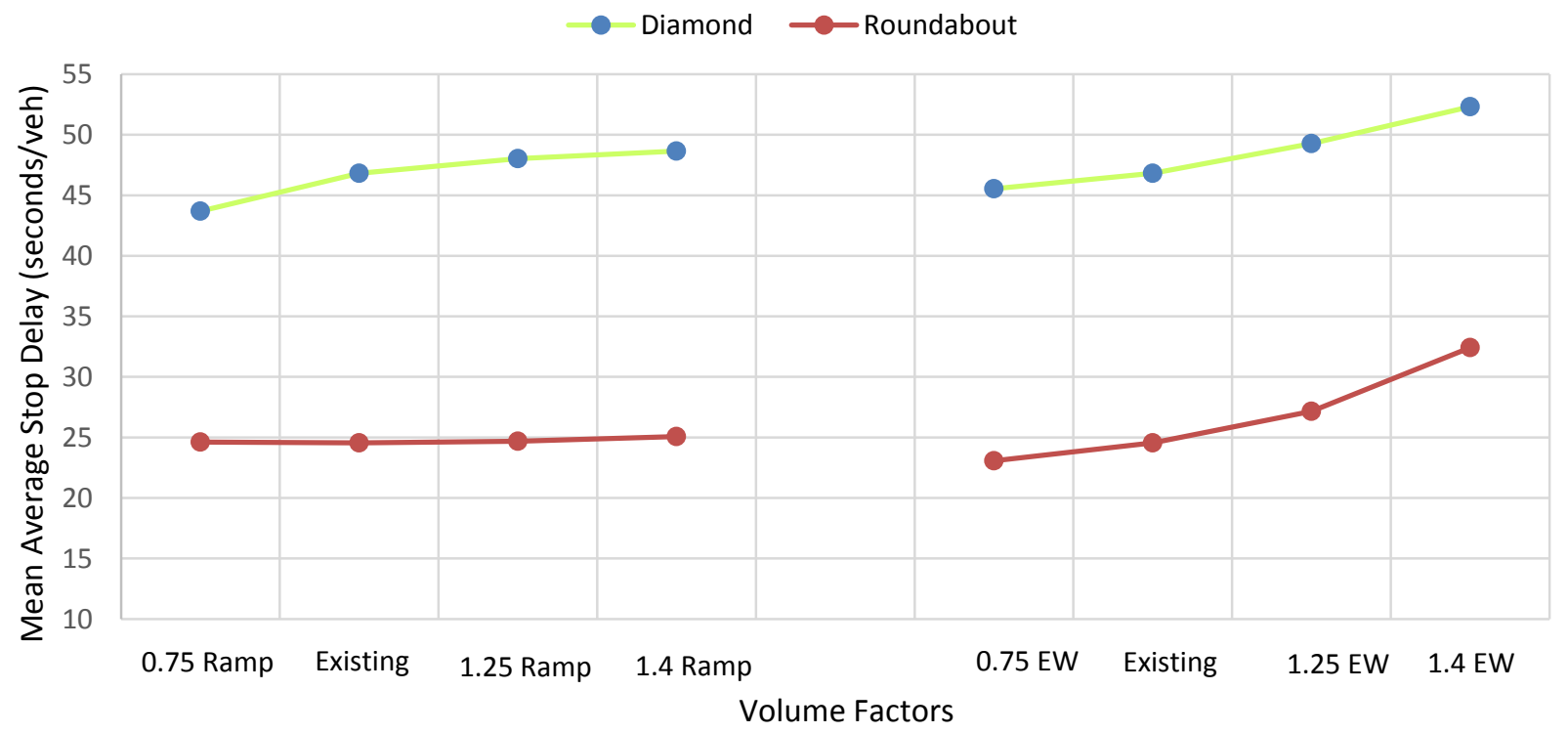

Figure 62: Average vehicle stop delay for different volume conditions shown as a line graph 
We can see similar trends as we saw for the average vehicle delay. The roundabout is again performing much better overall but with higher sensitivity to EW volume changes compared to the TDI. The sensitivity of the interchanges can be seen more clearly in Figure 63. This figure shows the percent change in average vehicle stop delay from the interchange's existing condition. The higher percent change values can be seen again for the EW volume conditions.

Average Stop Delay Percent Change from Existing Interchange Condition to new Volume Condition

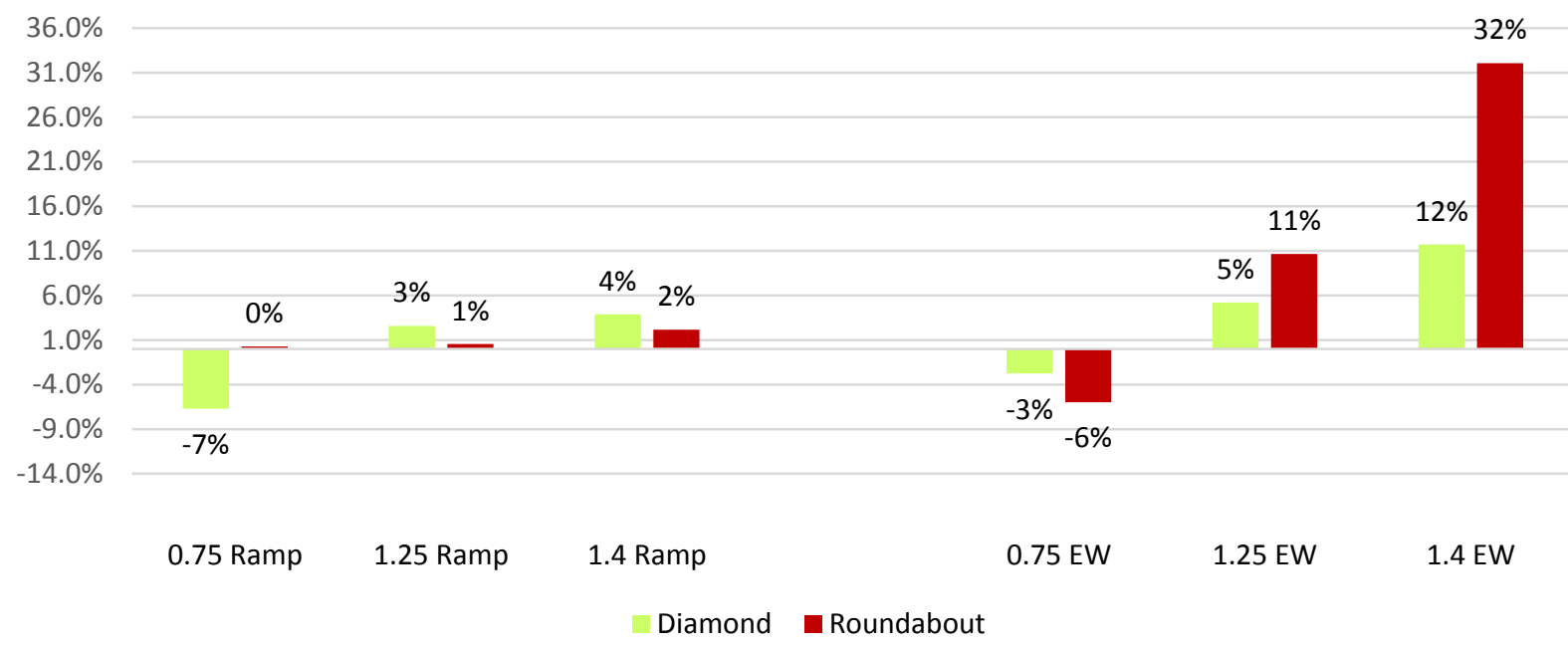

Figure 63: Percent change in average vehicle stop delay from the interchange's existing condition

\section{Average Vehicle Speed:}

Lastly we will perform the analysis for the average vehicle speed. Again, Figure 64 shows the average vehicle stop delay for all volume conditions in bar chart format and Figure 65 will show it as a line graph format. 


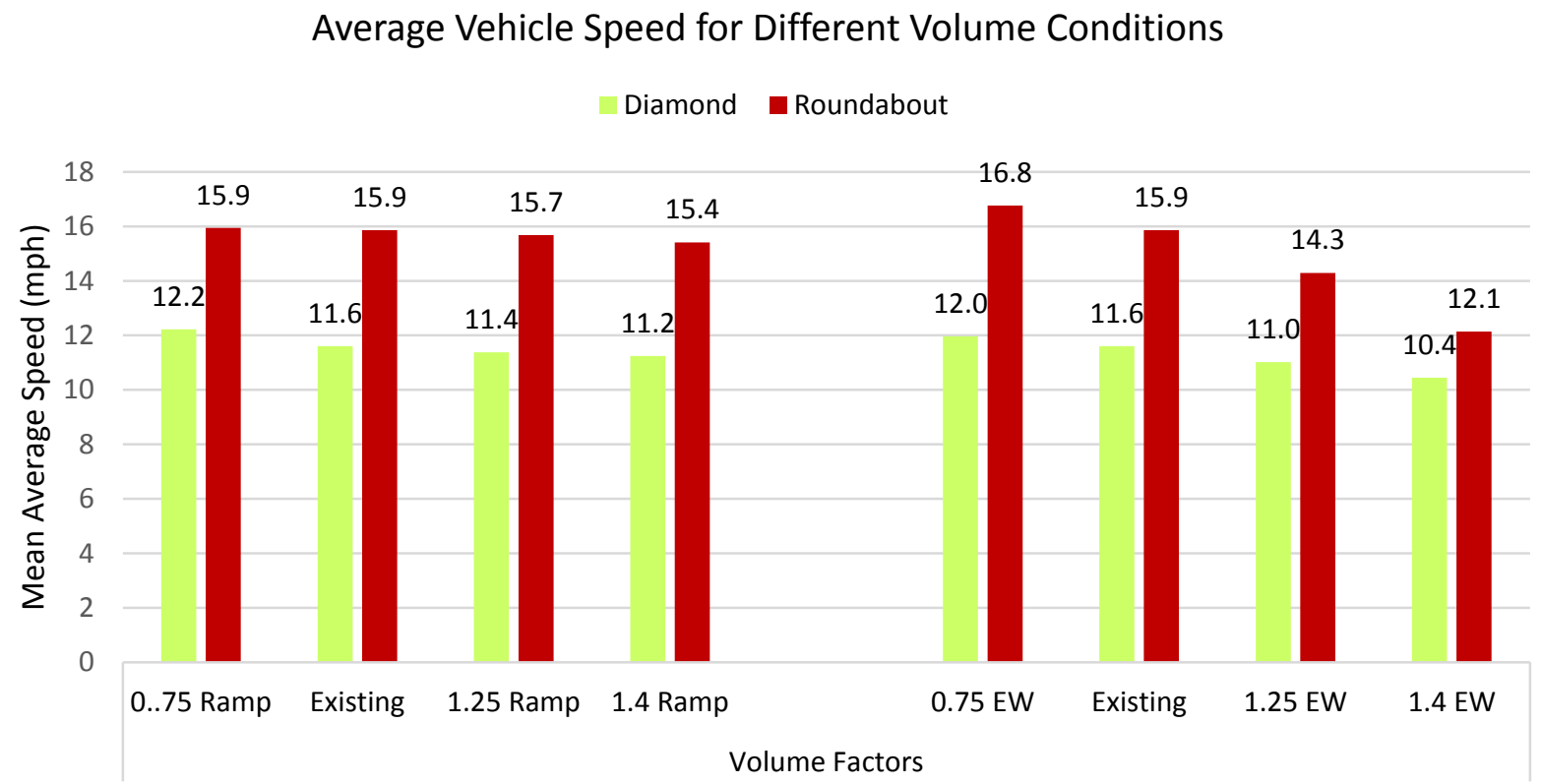

Figure 64: Average vehicle speed for different volume conditions shown as a bar graph

Average Vehicle Speed as Volume Increases

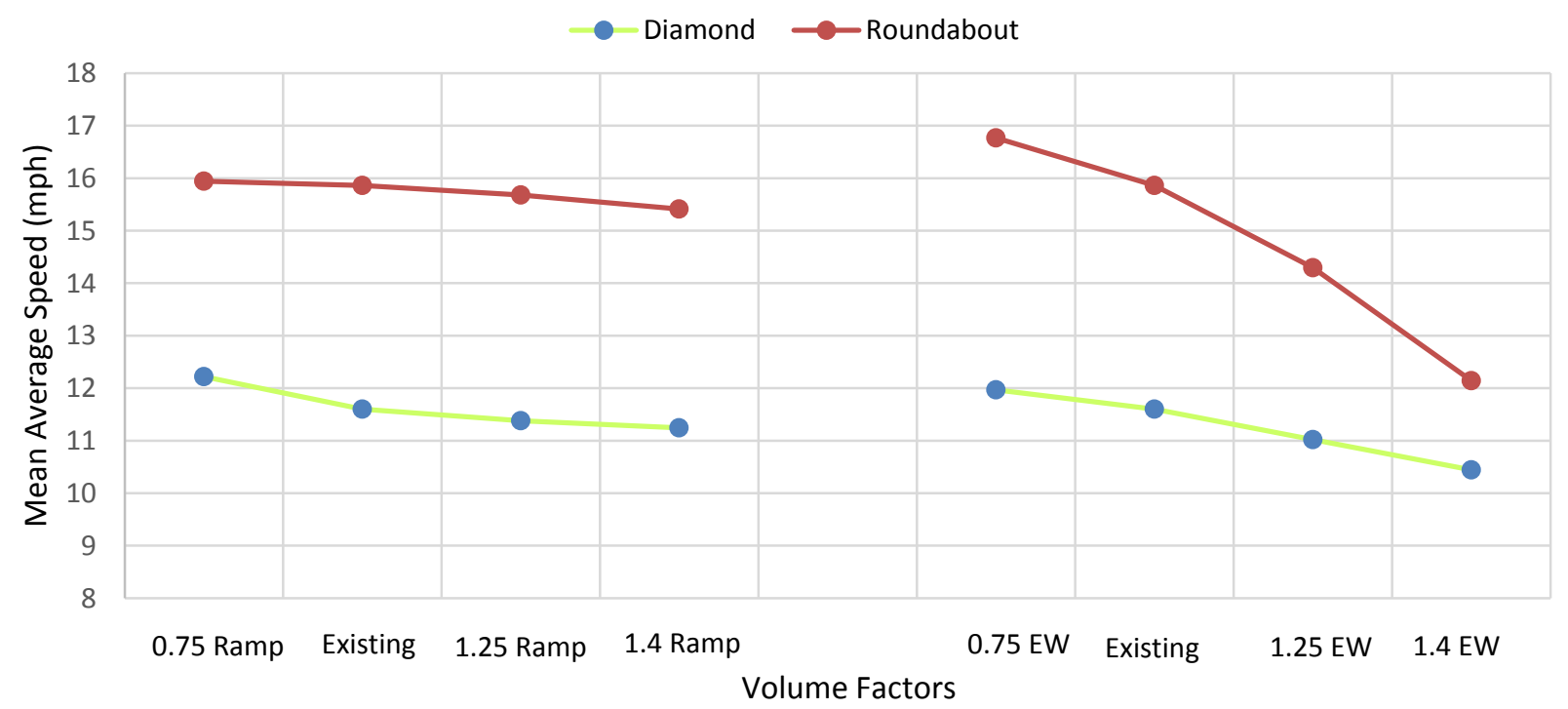

Figure 65: Average vehicle speed for different volume conditions shown as a line graph 
From Figures 64 and 65 we can see that vehicles in the roundabout network are traveling at a much faster pace than the TDI due to the fact that there is less congestion and delay. However, the roundabout is still much more sensitive to EW volume conditions than the TDI. The sensitivity of the interchanges can be seen more clearly in Figure 66. This figure shows the percent change in average vehicle speed from the interchange's existing condition. The higher percent change values can be seen for the EW volume conditions.

\section{Average Speed Percent Change from Existing Interchange Condition to new Volume Condition}

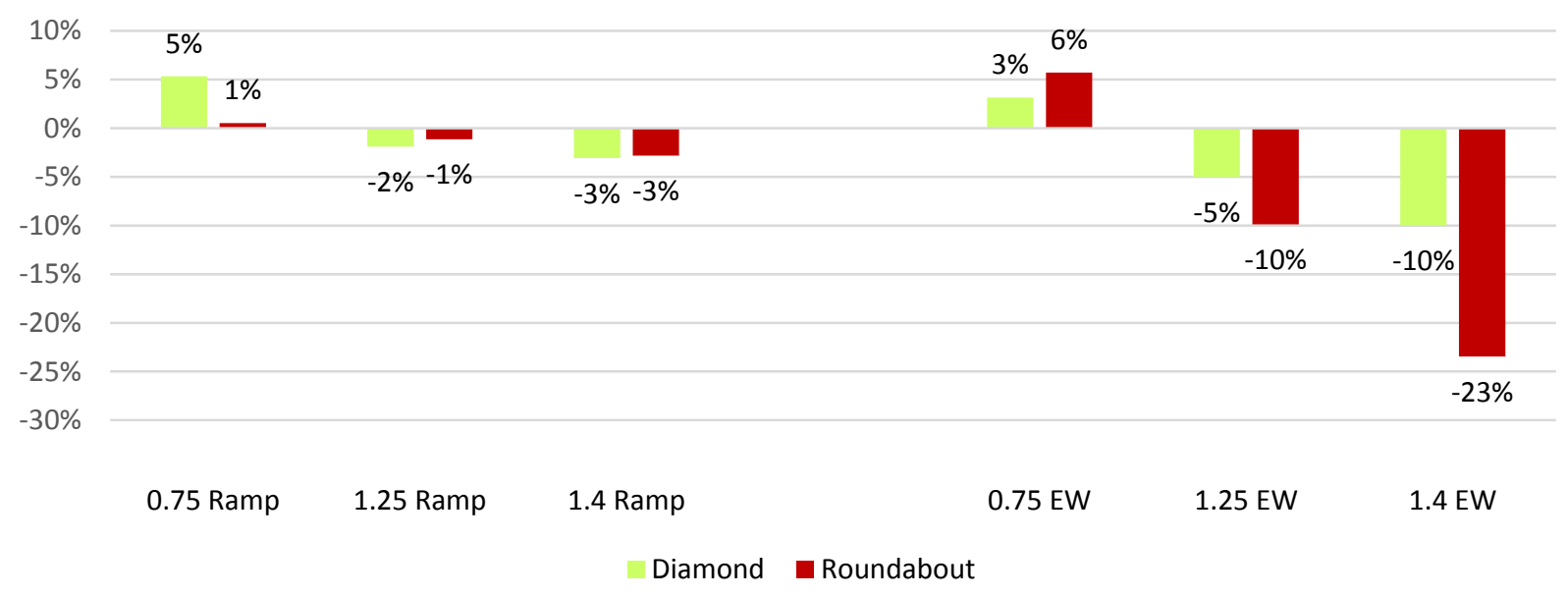

Figure 66: Percent change in average vehicle stop delay from the interchange's existing condition

To conclude, the roundabout did perform better in all the measures analyzed for all volume conditions. The roundabout interchange was more sensitive to EW volume changes but it is hard to believe the PM peak hour volumes would ever increase by more than $40 \%$ anytime soon. This type of interchange could be truly beneficial for improving performance and level of service. However, this type of interchange would take time for construction, it would impact pedestrian and bicyclists, and it could take time for motorists to get used to. More study should be done on this type of interchange to see what the negative aspects of this type of interchange could be in the United States. 


\subsection{DISCUSSION}

Four key findings were discovered after exploring the performance analyses of the two types of the interchanges. The findings are as follows:

- $\quad$ Finding \#1: The SPUI and the TDI perform similarly up to the point where we increase the volumes by $25 \%$.

- $\quad$ Finding \#2: There is a clear divergence in performance between the TDI and SPUI when the volume is increased by $40 \%$.

- $\quad$ Finding \#3: The SPUI does not react well when it reaches its capacity.

- Finding \#4: The SPUI is usually more sensitive to volume change than the TDI.

- Finding \#5: The nearby intersections cause the SPUI to be inefficient as they hold back traffic while the SPUI is flushing large volumes in.

Finding \#1:

Generally, when we do not increase the volume condition more than 25 percent, the SPUI and the TDI perform similarly. When the SPUI does perform better in these conditions it is only by a slight amount. This can yield to the fact that both types of interchanges still have a bit room left before they reach capacity. It can only be found out when they reach capacity only if we keep increasing the volumes. This is where the $40 \%$ increase in volume comes to play.

\section{Finding \#2:}

When we increase the volume by $40 \%$, this is where the performance in the interchanges departs. Somewhere between the 1.25 and 1.4 volume condition the SPUI reaches capacity and starts performing very poorly. The TDI stays at its steady increasing phase while SPUI's performance completely fails.

\section{Finding \#3:}


After observing multiple runs of the simulation and the analysis of the SPUI at high volume rates, it is clear that the SPUI does not function well when it reaches capacity. The entire network becomes very dense and slow moving. If the volumes are increased by more than $40 \%$, the network becomes fully congested. This is because the SPUI is flushing out a great amount of vehicles but the nearby intersections cannot handle it.

\section{Finding \#4:}

From the percent change graphs we noticed that in most cases, the SPUI reacts more dramatically to volume changes compared to the TDI. This is another proof that the SPUI has a bit less capacity than the TDI.

Finding \#5:

If we put all this together and think about why the SPUI is performing so poorly we can see that the two nearby intersections play a big role. The two nearby intersections are only 500 and 620 feet apart. The SPUI does a great job releasing a large amount of volume out per phase, but these volumes will meet another intersection that is also congested. The nearby intersections do not react well to these large volumes coming in so they back the queue up to the interchange in which will reduce its performance. This domino affect makes it hard to implement such interchange and so other options should be looked at as the SPUI is not the most efficient one for this location. To see whether this theory is true, the two nearby intersection were extended out to see if it would perform better or not.

The intersection west of the interchange was extended out 900 feet more while the intersection east of the interchange was extended out 920 feet more. This was done for both the TDI and the SPUI. The new average delay and the percent change in average vehicle delay from the interchange's existing condition were plotted in Figures 66 and 67. 
Average Vehicle Delay as Volume Increases When Nearby Intersections are Extended

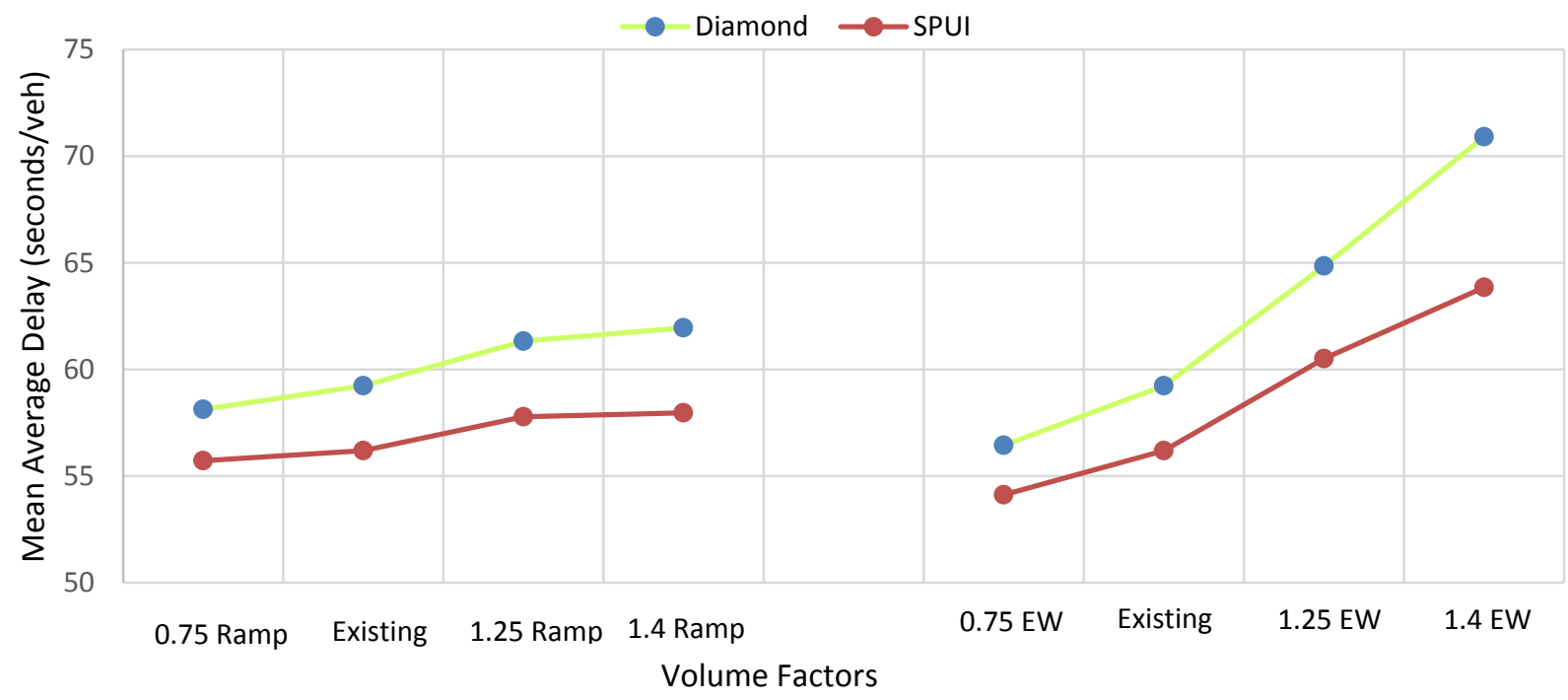

Figure 66: Average vehicle delay for different volume conditions when nearby intersections are extended out

Average Vehicle Delay Percent Change from Existing Interchange Condition to new Volume Condition when Nearby Intersections are Extended

Diamond $\square$ SPUI

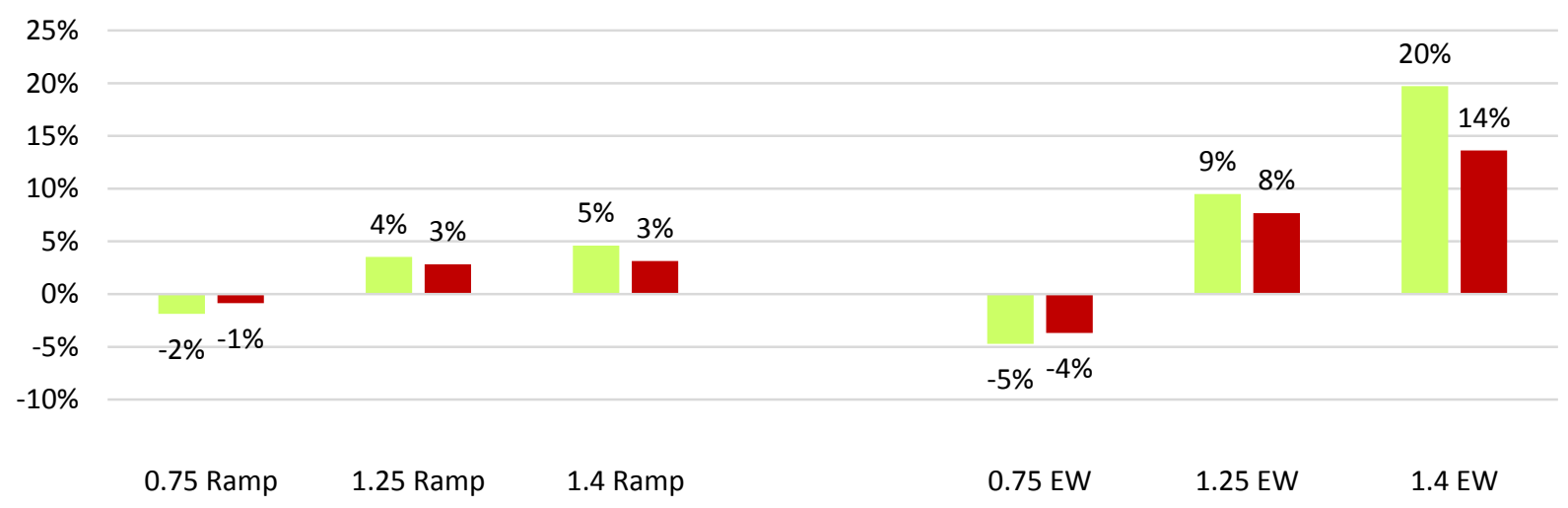

Figure 67: Percent change in average vehicle delay from the interchange's existing condition when nearby intersections are extended out

The first important information from Figure 56a and 56b that we can obtain is that the delay for both the TDI and SPUI has significantly improved. However, the SPUI has improved much more. Now we can 
see that the SPUI is performing progressively better as it is less sensitive to volume change compared to the TDI. This is because when the SPUI is flushing out large volumes, it does not have to worry about the queue from the next intersection. Therefore, having an intersection too close to a SPUI can significantly impact the SPUI's performance.

To continue, having intersections very close to the interchange could not be a problem if they performed at a decent level. After careful investigation of the nearby intersection's performance, it was clear that they were experiencing high delays. This is due to the fact that the minor roads of the nearby intersections have high volumes. If they did have lower volumes, longer green time could be dedicated to the EB and WB through movement and to coordinate with the SPUI. 


\subsection{FUTURE STEPS}

There is still plenty of work than can be done on this research. For starters, other current simulations software could be used to use further performance measures to analyze the impacts of the SPUI. A larger network could also be used to obtain a more accurate analysis. It would also be wise to experiment with different signal timing strategies and coordination to see how it would impact the analysis. Getting into signal timing can get complicated and can yield to a complete new research paper. Lastly, more data analysis, validation, and calibration would be beneficial for this type of project. 


\subsection{CONCLUSION}

After a thorough analysis of comparing a Tight Diamond interchange (TDI) and a SPUI at the Wilsonville interchange, it is clear that the TDI performs better on average than the SPUI. Therefore, it should not always be assumed that SPUIs will perform better than or equal to a TDI. In this study, the SPUI performed similarly for lower volume conditions with regards to delay. However, when volume conditions became higher, the SPUI started performing progressively worse than the Diamond interchange. This leads to the fact that the TDI allows higher capacity at this interchange compared to the SPUI.

The main reason for the failure of the SPUI at high volume conditions is due to the nearby intersections to the west and east of the interchange. These intersections are too close to the interchange. Not only this, but they are also performing quite poorly as is. The poor performance of the intersection does not blend well with large volumes of traffic coming from the interchange. The use of the TDI is actually perfect for this location, as it breaks up traffic and allows the queue to dissipate incrementally. The only way to fix this problem is by either improving the performance of the nearby intersections or by extending it outwards. Therefore, it is not recommended to reconstruct this interchange to a SPUI, as it will perform similarly anyways and would react more dramatically when volumes increase higher than the PM peak hour. However, reconstructing a tight diamond interchange to a SPUI is physically and geometrically possible and it could improve performance if there are not too many constraints. For this scenario, it would not be feasible or cost effective. 
10.0 APPENDIX A - STUDY AREA

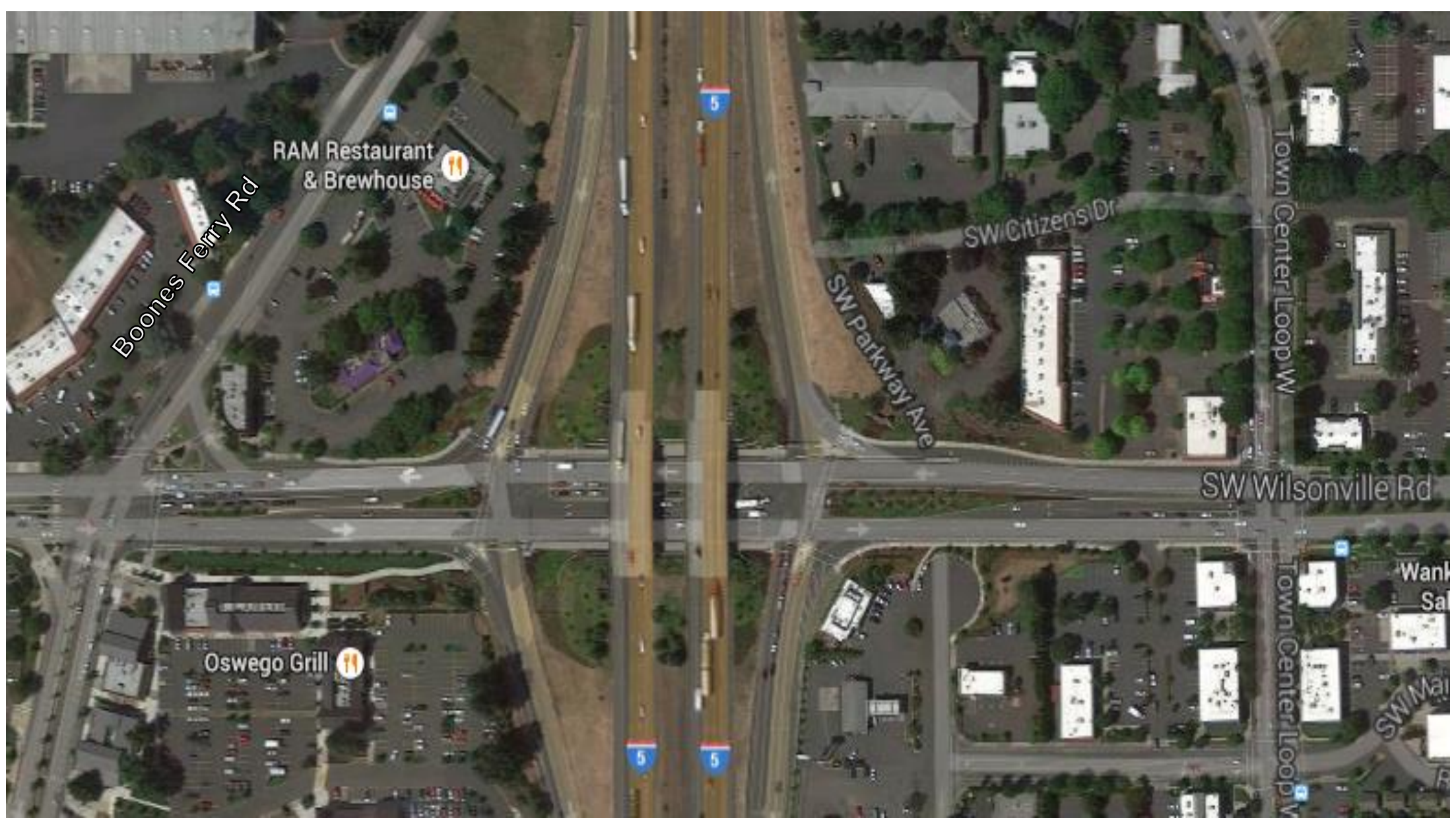

Figure A1: Research Project Study Area and the Location of the Diamond Interchange 


\subsection{REFERENCES}

1. Amer, Ahmed. "Tight Diamond Interchange versus Single Point Urban Interchange: Pedestrians Perspective." Center for Sustainable Mobility Virginia Tech Transportation Institute Virginia Tech, June 2009. Web.

2. "Carbon Monoxide Questions and Answers." U.S. Consumer Product Safety Commission, n.d. Web. 15 Feb. 2015.

3. Chaudhary, Nadeem A., and Chi-Leung Chu. Guidelines for Timing and Coordinating Diamond Interchanges with Adjacent Traffic Signals. College Station, TX: Texas Transportation Institute, Texas A \& M U System, 2000. Texas Department of Transportation, Nov. 2000. Web.

4. "Diamond Interchange." Expressways. Wikia, n.d. Web. 15 Feb. 2015. <http://expressways.wikia.com/wiki/Diamond_interchange>.

5. Garber, Nicholas J., and Michelle J. Smith. "Comparison of the Operations and Safety Characteristics of the Single Point Urban and Diamond Interchanges." VIRGINIA COUNCIL (n.d.): n. pag. Dec. 1996. Web.

6. Jangid, Anil. "Grade Seperation System and Road Junction System." Scribd. N.p., n.d. Web. 15 Feb. 2015.

7. Jones, Elizabeth, and Matthew Selinger. "Comparison of Operations of Single-Point and Tight Urban Diamond Interchanges." Transportation Research Record 1847.1 (2003): 29-35. 7 July 2002. Web.

8. Messer, Carroll J., American Association of State Highway and Transportation Officials, and FHWA. "Single Point Urban Interchange Design and Operations Analysis." Google Books. Washington, D.C. : Transportation Research Board, National Research Council, Dec. 1991. Web. 15 Feb. 2015. 
9. PTV Vissim. "PTV Vissim FAQs." PTV Vissim FAQs. N.p., n.d. Web. 15 Feb. 2015. <http://visiontraffic.ptvgroup.com/en-uk/training-support/support/ptv-vissim/faqs/>.

10. PTV Vissim. "VISSIM 5.30-05 User Manual." (n.d.): n. pag. 2011. Web. <http://www.et.byu.edu/ msaito/CE662MS/Labs/VISSIM_530_e.pdf>.

11. Qureshi, Mohammad, Navin Sugathan, Rohit Lasod, and Gary Spring. "Design of Single Point Urban Interchanges." Research, Development and Technology (2004): n. pag. MoDOT, Sept. 2004. Web.

12. "Single Point Urban Interchanges." Single Point Urban Interchanges. MoDOT, 2013. Web. <http://www.modot.org/stlouis/links/SinglePointUrbanInterchanges.htm>.

13. "SPUI Frequently Asked Questions." MoDOT, 2013. Web. <http://www.modot.org/stlouis/links/SPUIFrequentlyAskedQuestions.htm>.

14. "Studies : About Interchanges." Ohio Department of Transportation, n.d. Web. 15 Feb. 2015.

15. Typical SPUI Layout. Digital image. N.p., n.d. Web. 15 Feb. 2015. <http://upload.wikimedia.org/wikipedia/commons/thumb/b/b1/Spui-schematic.svg/2000pxSpui-schematic.svg.png>.

16. Typical Tight Diamond Interchange Layout. Digital image. FHWA, n.d. Web. <http://www.fhwa.dot.gov/publications/research/safety/04091/images/fig112.gif>.

17. Venkatachalam, Thamizh Arasan, and Dhivya Gnanavelu. "Concentration of Heterogeneous Road Traffic." Concentration of Heterogeneous Road Traffic. N.p., 1 Oct. 2009. Web.

18. "What Are the Trends in Outdoor Air Quality and Their Effects on Human Health and the Environment?" Nitrogen Oxides Emissions (n.d.): n. pag. Colorado.gov. Web. 15 Feb. 2015. 